\title{
INTEGRATED CERAMIC MEMBRANE SYSTEM FOR HYDROGEN PRODUCTION
}

Final Report for the Period February 2003 - June 2010

\author{
Joseph Schwartz, Hankwon Lim, and Raymond Drnevich \\ Praxair, Inc.
}

Date Published - July 2010

\author{
PREPARED FOR THE UNITED STATES \\ DEPARTMENT OF ENERGY \\ Under Cooperative Agreement \\ No. DE-FC36-00GO10534
}

\author{
Technical Point of Contact \\ Joseph Schwartz \\ Phone: 716-879-7455 \\ Fax: 716-879-7091 \\ joseph_schwartz@praxair.com \\ Praxair, Inc. \\ 175 East Park Drive \\ Tonawanda, NY 14150
}

Copyright (C) 2010 Praxair Technology, Inc.

This paper was written with support of the U.S. Department of Energy under Contract No. DE-FC3600GO10534. The Government reserves for itself and others acting on its behalf a royalty-free, nonexclusive, irrevocable, worldwide license for Governmental purposes to publish, distribute, translate, duplicate, exhibit and perform this copyrighted report. 


\section{Contents}

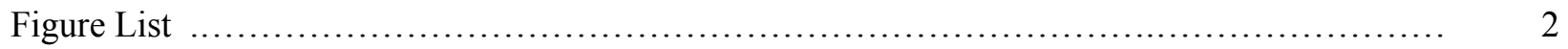

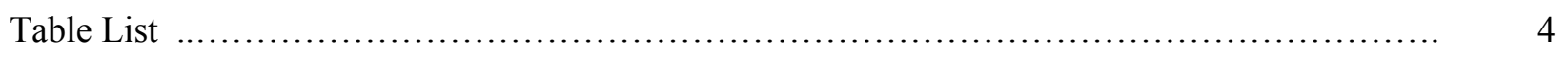

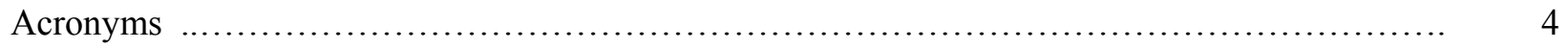

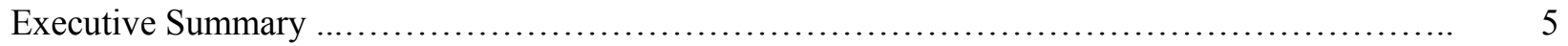

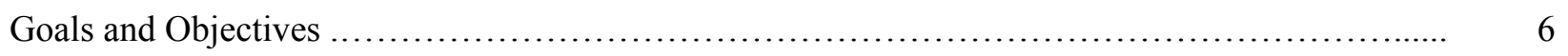

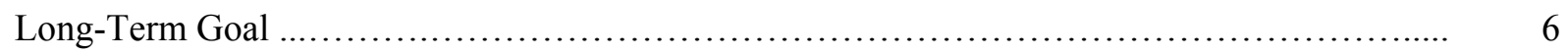

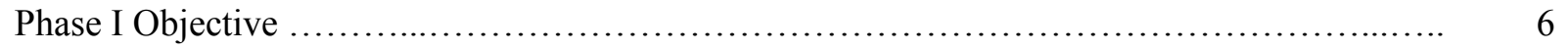

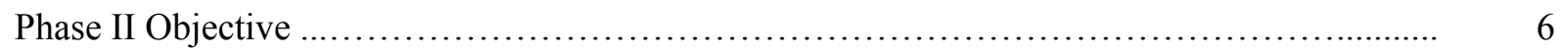

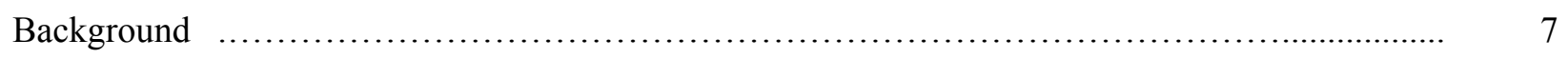

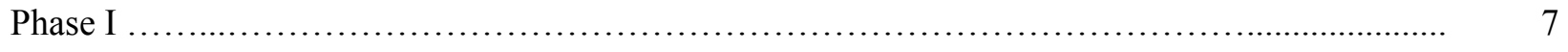

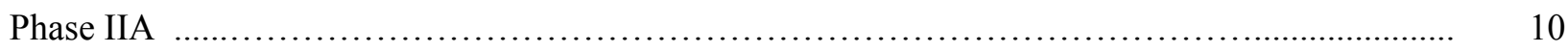

Approach............................................................... 10

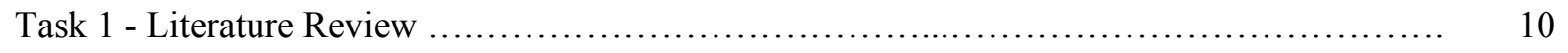

Task 2 - Define Substrate Material and Architecture .................................. 12

Task 3 - Define Optimum HTM Material ......................................... 14

Task 4 - Prepare Membrane Tubes and Verify Performance ............................ 16

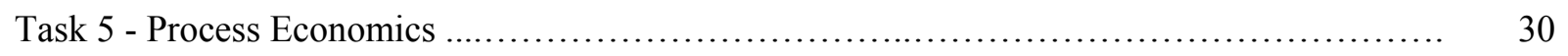

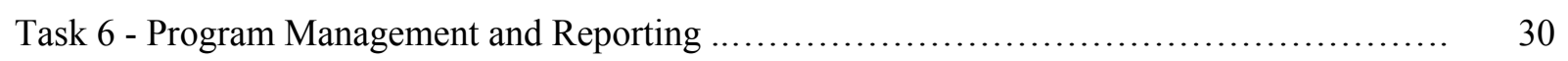

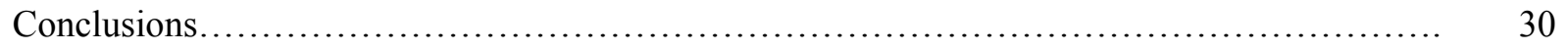

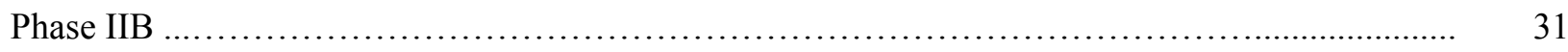

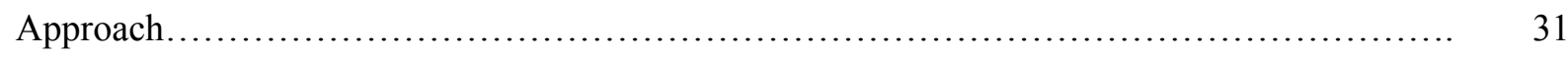

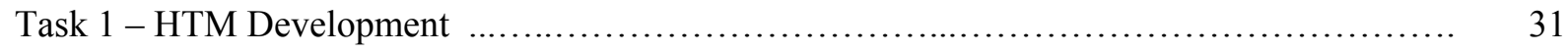

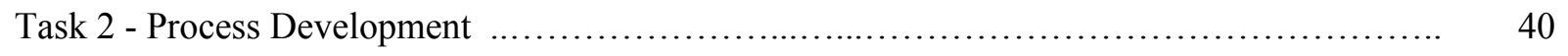

Task 3 - Develop Conceptual Design for the ICMS ................................. 48

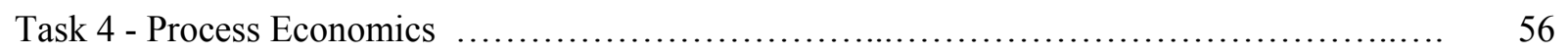

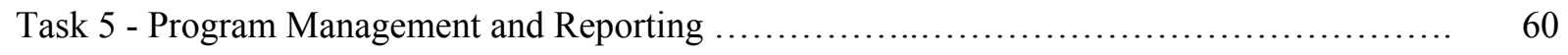

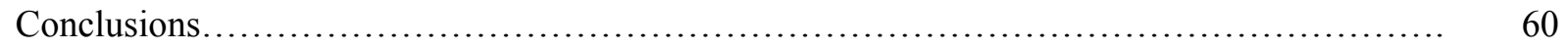

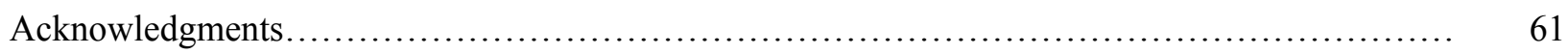

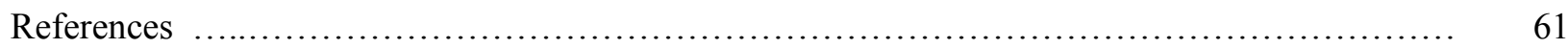




\section{Figure List}

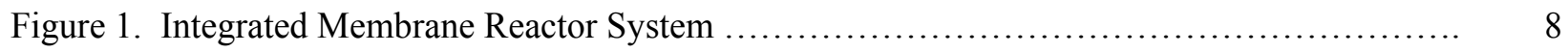

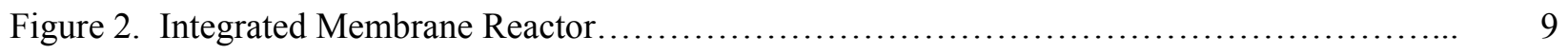

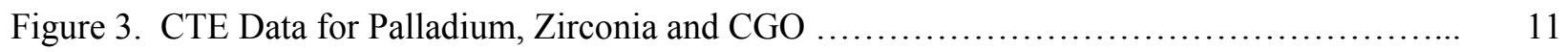

Figure 4. Isopressing Mold. Steel Mandrel with Polyurethane Bag and Cap ................... 15

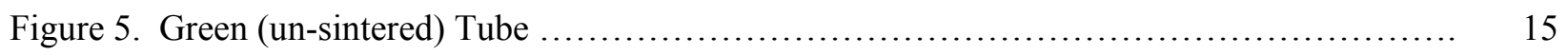

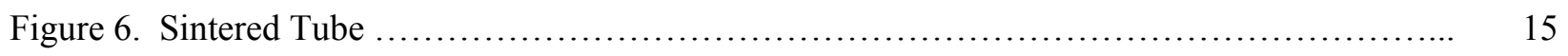

Figure 7. Schematic of Membrane Test Apparatus ....................................... 16

Figure 8. Top surface of Zirconia Substrate Before and After Plating ...................... 18

Figure 9. Cross-Section of the Plated Tube Shown in Figure 8 ............................. 19

Figure 10. Top Surface of an Unplated Substrate ..................................... 20

Figure 11. Top Surface and Cross-Section of a Plated Tube .............................. 21

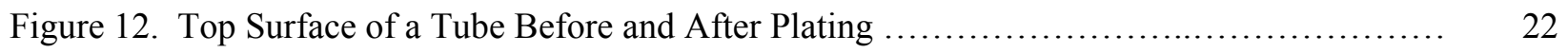

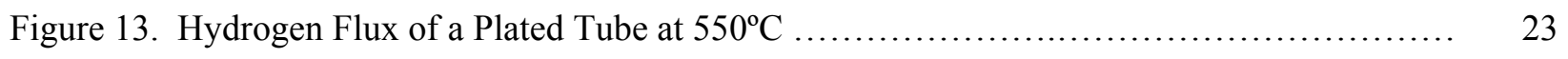

Figure 14. Cross-Section and Top Surface of a Plated Tube .............................. 23

Figure 15. Hydrogen Flux for a Pd-Ag Membrane with a 5 - $\mu \mathrm{m}$ Film........................ 24

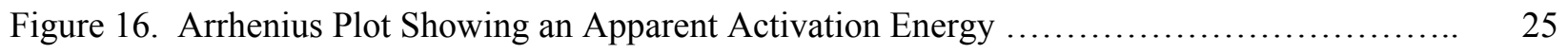

Figure 17. Hydrogen Flux Increased as Membrane Thickness Decreased ...................... 26

Figure 18. Observed Hydrogen Flux Rates for Pd-Cu Alloy Composite Membrane ................. 27

Figure 19. Hydrogen Permeation with $\mathrm{H}_{2} \mathrm{~S}$ Exposure ( $\mathrm{Pd}-\mathrm{Cu}$ Composite Membrane) .............. 28

Figure 20. Hydrogen Flux for a Pd-Cu Alloy Composite Membrane ............................ 29

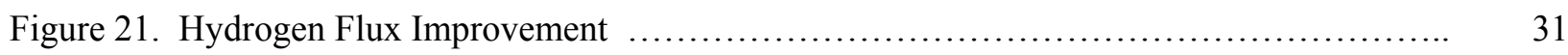

Figure 22. Cross-Section of Pd Alloy Membrane and Substrate ............................. 32

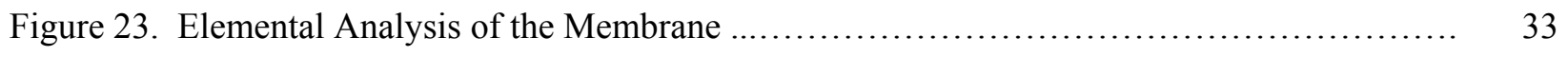

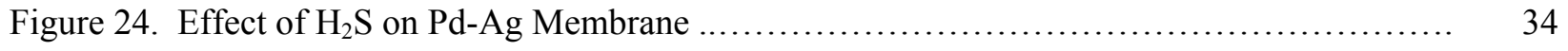

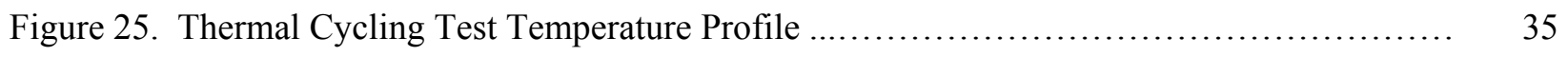

Figure 26. Thermal Cycling Test Flux for a Pd-Au Tube ................................. 36

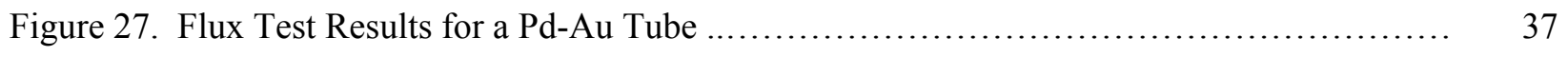

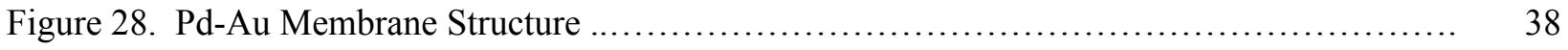


Figure 29. Surface Pore Size Data for Different Substrates ................................ 39

Figure 30. Mixed Gas Flux Results for Ternary Pd-Ru-Au Tube .......................... 40

Figure 31. Hydrogen Flux for Ternary Pd-Ru-Au Tube ................................... 41

Figure 32. The Effect of Pressure on Hydrogen Flux ...................................... 42

Figure 33. The Effect of Gas Hourly Space Velocity on Hydrogen Flux ........................ 43

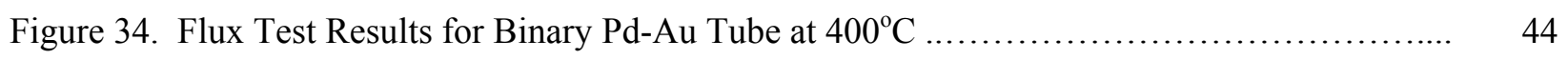

Figure 35. Hydrogen Generation with a Low $\mathrm{CO}_{2} / \mathrm{CO}$ Ratio of $0.5 \ldots \ldots \ldots \ldots \ldots \ldots \ldots \ldots \ldots \ldots \ldots \ldots$

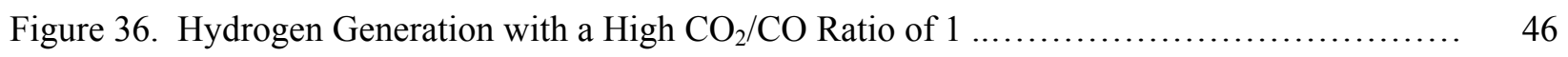

Figure 37. Flux Results for Pd-Au Membrane......................................... 47

Figure 38. Modeling Results for a Case Without Methanation ............................ 48

Figure 39. Modeling Results for a Case with 5\% Methane in the Retentate .................... 49

Figure 40. Modeling Results Showing the Effect of Temperature ......................... 50

Figure 41. Modeling Results Showing the Effect of Feed Pressure ........................... 51

Figure 42. Modeling Results Showing the Effect of Permeate Pressure....................... 52

Figure 43. Modeling Results Showing the Effect of Incremental Increase in Membrane Area........ 53

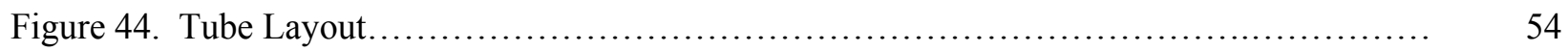

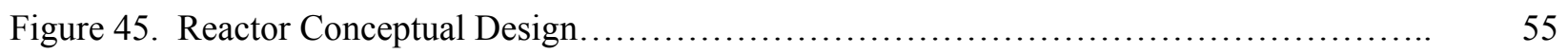

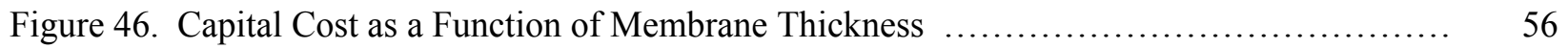

Figure 47. Conventional SMR process........................................... 57

Figure 48. Integrated Membrane Reactor System Process.............................. 58

Figure 49. Cost Comparison Between HTM and PSA Processes......................... 60 


\section{Table List}

Praxair, Inc.

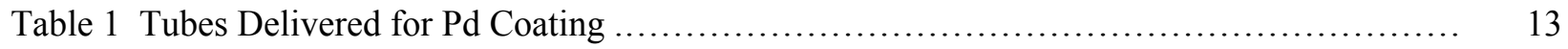

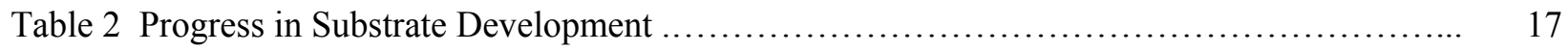

Table 3. Parameters for Economic Cost Comparison of Incremental Hydrogen .................... 59

\section{Acronyms}

CSM Colorado School of Mines

CTE Coefficient of Thermal Expansion

HTM Hydrogen Transport Membrane

ICMS Integrated Ceramic Membrane System

OTM Oxygen Transport Membrane

PSA Pressure Swing Adsorption

RTI Research Triangle Institute

SCFH Standard Cubic Feet per Hour

SMR Steam Methane Reformer or Steam Methane Reforming

WGS Water Gas Shift 


\section{Executive Summary}

Praxair, Inc.

Phase I was a technoeconomic feasibility study that defined the process scheme for the integrated ceramic membrane system for hydrogen production and determined the plan for Phase II. The hydrogen production system is comprised of an oxygen transport membrane (OTM) and a hydrogen transport membrane (HTM).

Two process options were evaluated: 1) Integrated OTM-HTM reactor - in this configuration, the HTM was a ceramic proton conductor operating at temperatures up to $900^{\circ} \mathrm{C}$, and 2) Sequential OTM and HTM reactors - in this configuration, the HTM was assumed to be a Pd alloy operating at less than $600^{\circ} \mathrm{C}$. The analysis suggested that there are no technical issues related to either system that cannot be managed. The process with the sequential reactors was found to be more efficient, less expensive, and more likely to be commercialized in a shorter time than the single reactor. Therefore, Phase II focused on the sequential reactor system, specifically, the second stage, or the HTM portion. Work on the OTM portion was conducted in a separate program.

Phase IIA began in February 2003. Candidate substrate materials and alloys were identified and porous ceramic tubes were produced and coated with Pd. Much effort was made to develop porous substrates with reasonable pore sizes suitable for Pd alloy coating. The second generation of tubes showed some improvement in pore size control, but this was not enough to get a viable membrane. Further improvements were made to the porous ceramic tube manufacturing process. When a support tube was successfully coated, the membrane was tested to determine the hydrogen flux. The results from all these tests were used to update the technoeconomic analysis from Phase I to confirm that the sequential membrane reactor system can potentially be a low-cost hydrogen supply option when using an existing membrane on a larger scale.

Phase IIB began in October 2004 and focused on demonstrating an integrated HTM/water gas shift (WGS) reactor to increase $\mathrm{CO}$ conversion and produce more hydrogen than a standard water gas shift reactor would. Substantial improvements in substrate and membrane performance were achieved in another DOE project (DE-FC26-07NT43054). These improved membranes were used for testing in a water gas shift environment in this program. The amount of net $\mathrm{H}_{2}$ generated (defined as the difference of hydrogen produced and fed) was greater than would be produced at equilibrium using conventional water gas shift reactors up to 75 psig because of the shift in equilibrium caused by continuous hydrogen removal. However, methanation happened at higher pressures, 100 and $125 \mathrm{psig}$, and resulted in less net $\mathrm{H}_{2}$ generated than would be expected by equilibrium conversion alone. An effort to avoid methanation by testing in more oxidizing conditions (by increasing $\mathrm{CO}_{2} / \mathrm{CO}$ ratio in a feed gas) was successful and net $\mathrm{H}_{2}$ generated was higher (40-60\%) than a conventional reactor at equilibrium at all pressures tested (up to $125 \mathrm{psig}$ ). A model was developed to predict reactor performance in both cases with and without methanation. The required membrane area depends on conditions, but the required membrane area is about $10 \mathrm{ft}^{2}$ to produce about $2000 \mathrm{scfh}$ of hydrogen. The maximum amount of hydrogen that can be produced in a membrane reactor decreased significantly due to methanation from about $2600 \mathrm{scfh}$ to about $2400 \mathrm{scfh}$. Therefore, it is critical to eliminate methanation to fully benefit from the use of a membrane in the reaction. Other modeling work showed that operating a membrane reactor at higher temperature provides an opportunity to make the reactor smaller and potentially provides a significant capital cost savings compared to a shift reactor/PSA combination. 


\section{Goals and Objectives}

Praxair, Inc.

\section{Long-Term Goal}

The long-term goal of the program is to commercialize a cost-effective small-scale hydrogen plant based on the integration of hydrogen transport membranes (HTM) and syngas generation technology. The main thrust is to reduce capital cost through process intensification by minimizing the number of unit operations and processing steps required to make hydrogen. Reducing capital cost is particularly important for smaller reactors $(2.4-12.5 \mathrm{~kg} / \mathrm{h})$, such as those currently under consideration for hydrogen fueling stations. In this scenario, natural gas from existing pipelines would be provided to fueling stations where hydrogen would be produced onsite. Operating costs become more important as systems become larger and membranes scale up almost linearly. These costs become dominant issues when one considers making large reactors using this process, but linear scaling is an advantage when one wants to make a small onsite reactor producing $300 \mathrm{~kg} /$ day of hydrogen or less. Although this will not be sufficient to provide enough hydrogen in a "Hydrogen Economy" where all vehicles use hydrogen fuel, it will be sufficient to provide enough hydrogen for a significant part of the transition period.

\section{Phase I Objective}

The Phase I objective was to carry out technical and economic feasibility studies to validate the concept and screen process schemes, obtain basic information on HTM performance for technoeconomic evaluation, and define a development program that will lead to commercialization. Phase I led to the conclusion that a sequential reactor scheme in which an oxygen transport membrane (OTM) reactor was used to produce syngas from natural gas followed by a palladium-based HTM integrated water-gas-shift reactor was a better option than a single OTM/HTM reactor using a ceramic HTM. Advantages of the two-stage reactor system included:

- Palladium membranes have a higher flux than ceramic proton conducting membranes

- Palladium membranes have a lower expected capital cost (because of the higher flux and very thin Pd layer) than ceramic membranes

- Palladium membranes are closer to commercialization, so development time will be shorter

- The independent HTM stage can be used with any syngas reactor and does not depend on OTM development for commercialization

- Higher reliability

- The high-temperature OTM reactor will be much smaller than a high-temperature OTM/HTM reactor, and consequently, less expensive

- The overall thermal efficiency of the process is higher

- Lower technical risk

Phase I also concluded that the dual reactor system could produce hydrogen at a competitive price when compared to other small-scale production methods or delivered liquid hydrogen.

\section{Phase II Objective}

The Phase II objective was to develop a palladium-based HTM that meets performance goals for flux, selectivity, life, and cycling on a bench scale and to confirm the HTM performance experimentally in an integrated single-tube reactor. The initial part of Phase II, Phase IIA, concentrated on developing the substrate, membrane, and coating technology and testing the membrane under simulated reactor conditions. Phase IIB concentrated on proving HTM performance in a single-tube water-gas-shift reactor.

The goal of Phase IIA was to develop a composite membrane comprising a ceramic substrate and a thin film membrane made of Pd alloy. Initial efforts were directed at developing a suitable substrate with a 
pore structure that offers minimum resistance to hydrogen permeation, yet is also mechanically strong enough for use in the high-temperature and high-pressure membrane shift reactor. This requires a substrate with surface pores that are large enough to allow sufficient hydrogen flow and small enough to enable a thin, continuous, leak-free Pd alloy film to be deposited. Several significant improvements in substrate preparation were made so that tubes could be coated with Pd alloys and tested.

The goal of Phase IIB was to improve the existing composite membrane and to demonstrate performance under water gas shift conditions. Stable Pd alloy membranes were successfully prepared and integrated with a water gas shift reactor. The net $\mathrm{H}_{2}$ produced by the integrated HTM/WGS reactor was higher in several tests than would be produced using a conventional water gas shift reactor at equilibrium followed by pressure swing adsorption (PSA) for hydrogen purification.

\section{Background}

Steam methane reformer (SMR) based hydrogen production facilities are highly capital intensive because they are custom designed and are built using one-at-a-time design and fabrication techniques. Capital costs account for $70-85 \%$ of the total hydrogen cost for on site systems that produce less than about 20 $\mathrm{kg} / \mathrm{h}$. As a result, the opportunity exists to substantially reduce product hydrogen costs by introducing advanced technology that can reduce the number of unit operations and capital cost. The focus of this program is to develop an integrated system for the production of hydrogen at $2.4-12.5 \mathrm{~kg} / \mathrm{h}$. The design is based on replacing the water gas shift (WGS) reactor(s) and pressure swing adsorption (PSA) unit with a single integrated shift reactor/membrane system. This will reduce the number of unit operations and vessels in the system, and consequently, could reduce the capital cost. Another potential advantage is that the membrane will remove hydrogen in the shift reactor, which will shift the equilibrium toward increased hydrogen production. Therefore, this system also offers the added benefit of increased hydrogen production efficiency when compared to conventional technology. This program emphasized the development of membrane technology and the development of a reactor design to use the membranes.

\section{Phase I}

Phase I of the program determined that sequential reactors are preferable to a single integrated OTM/HTM reactor. A schematic diagram of the membrane reactor system is shown in Figure 1. The system comprises two reactors, one containing an OTM and the other containing an HTM. This program focused exclusively on developing the HTM reactor. The OTM reactor was pursued in other programs with the help of DOE funding. Successful development of the HTM reactor is not dependent on developing the OTM reactor. Therefore, it can be used with other syngas generators, so it can be commercialized independently. This includes the possibility that the HTM reactor could be commercialized before development of the OTM reactor is complete. Because of its higher operating temperature, the OTM reactor is expected to be significantly more expensive, ignoring the cost of the membranes. The higher operating temperature also makes development of the reactor more challenging. Allowing for lower operating temperature is expected to make developing the HTM more likely, especially in the near term. 


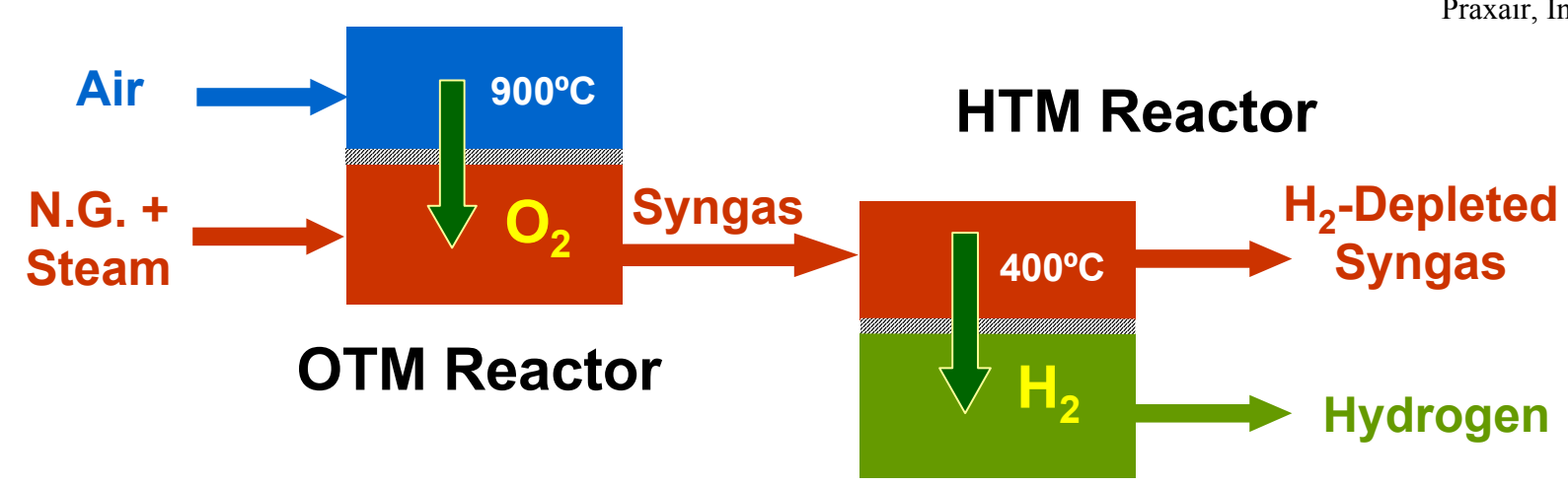

Figure 1. Integrated Membrane Reactor System

Air at low pressure (a few psig) is fed to the retentate side of the OTM and compressed natural gas (200-400 psig) and steam are fed to the permeate side of the OTM. Oxygen is transported across the OTM to the permeate side, where it reacts with natural gas to form syngas (eq. 1). A portion of natural gas also reacts with steam to form syngas. Catalyst is incorporated in the reactor to promote steam reforming (eq. 2) on the permeate side.

$$
\begin{array}{ll}
\text { Partial Oxidation } & \mathrm{CH}_{4}+1 / 2 \mathrm{O}_{2} \rightarrow \mathrm{CO}+2 \mathrm{H}_{2} \\
\text { Steam Reforming } & \mathrm{CH}_{4}+\mathrm{H}_{2} \mathrm{O} \rightarrow \mathrm{CO}+3 \mathrm{H}_{2}
\end{array}
$$

Alternatively, other conventional syngas production methods including steam reforming, autothermal reforming, and partial oxidation could be used instead of the OTM reactor.

The syngas product is cooled and fed to the retentate side of the HTM, where catalyst is used to promote the WGS reaction (eq. 3). Hydrogen product is transported through the HTM to the permeate side driven by a hydrogen partial pressure difference. Additional hydrogen is formed by the WGS reaction because hydrogen removal by the HTM shifts the equilibrium toward greater hydrogen production.

$$
\text { Water Gas Shift } \quad \mathrm{H}_{2} \mathrm{O}+\mathrm{CO} \leftrightarrow \mathrm{H}_{2}+\mathrm{CO}_{2}
$$

As much hydrogen as possible is recovered from the reactor by the HTM. Eventually, a pinch partial pressure difference between the reaction zone and the permeate side is reached and no more hydrogen can be recovered. The retentate, which includes a significant amount of hydrogen, is recycled or used in another process. 
A schematic diagram of the alternative single reactor design is shown in Figure 2[1]. The system comprises one reactor containing both OTM and HTM. This configuration maximizes the amount of process intensification by combining all unit operations into a single vessel. Fuel and excess air are fed to the combustion zone to produce hot air, which is fed to the OTM tubes. Oxygen selectively permeates the OTM and enters the reaction zone, where it reacts with natural gas and steam to form syngas. At the same time, hydrogen is removed from the syngas by HTM tubes. The permeate hydrogen partial pressure is maintained at a low pressure using steam to sweep the permeate side of the HTM. The resulting hydrogen/steam mixture exits the reactor, where hydrogen can be recovered by condensing steam.

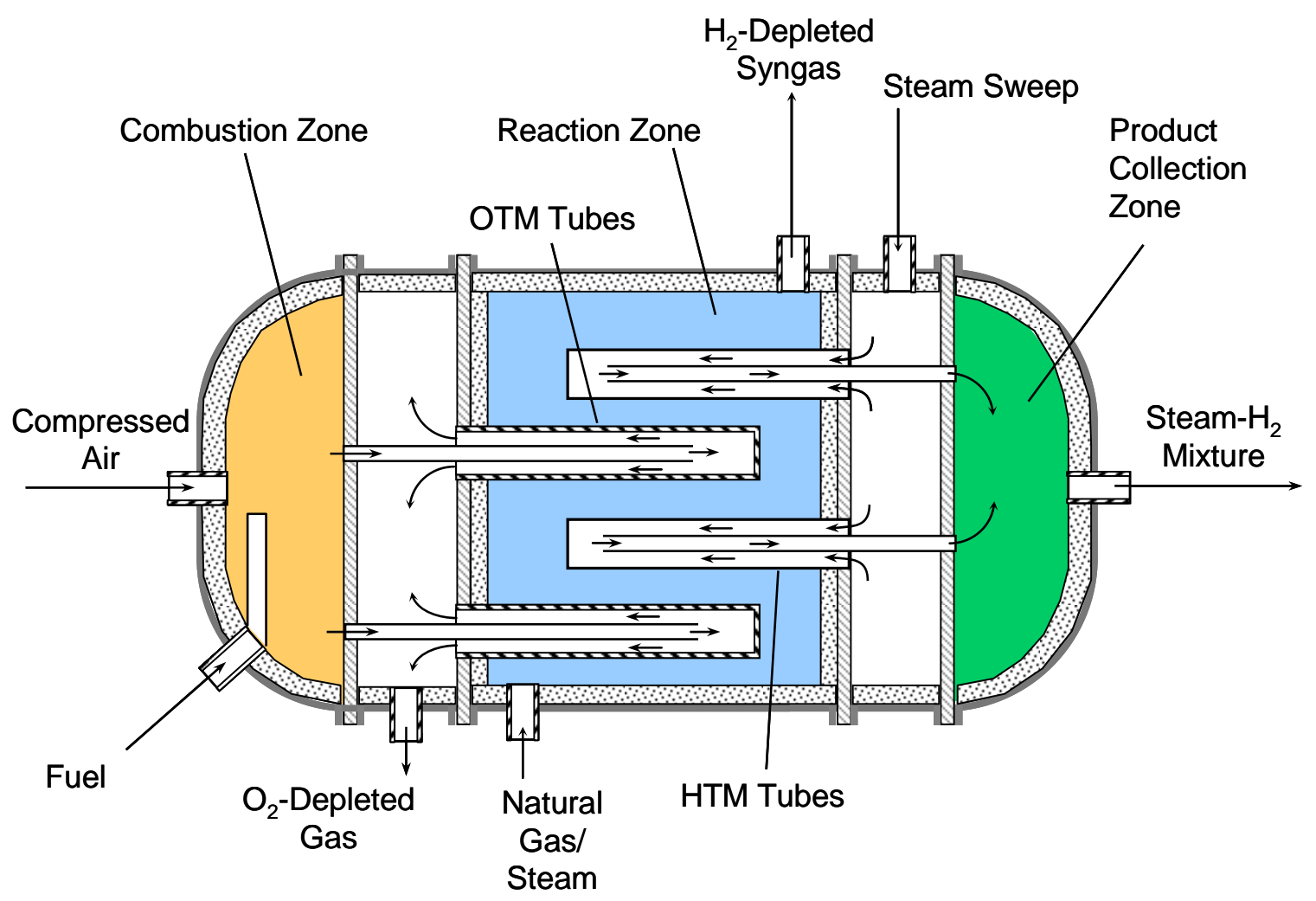

Figure 2. Integrated Membrane Reactor

The system shown in Figure 2 suffers from several disadvantages. Palladium membranes cannot operate at the high temperatures required by OTM, over $850^{\circ} \mathrm{C}$. Therefore, ceramic proton conducting membranes were considered. These membranes have lower flux, lower reliability, and higher cost than composite palladium membranes. The low flux requires the entire reactor to be larger and operate at very high temperature, leading to higher overall capital cost even though one vessel is required instead of two. This system is an example of process intensification that does not provide a capital cost advantage. 


\section{Phase IIA}

Praxair, Inc.

\section{Approach}

Phase IIA focused on developing a composite Pd membrane that could be tested. The first task was to review work that had been done to provide guidance on material selection and fabrication methods. The results of the literature review would be combined with Praxair's expertise in ceramic substrate manufacturing developed for OTM to produce membrane substrates for HTM. Once the candidate material was defined, tubes would be prepared and tested. Meanwhile, in a parallel effort, the cost of the HTM system would be compared to competitive processes and systems to ensure that it had the potential to be cost effective if performance targets were met.

\section{Task 1 - Literature Review}

Substantial work has already been done on Pd membranes for hydrogen separation. The literature review focused on two specific problems, finding a compatible ceramic substrate and finding an alloy composition that would be resistant to contamination.

\section{Ceramic Substrate}

The literature search was aimed at finding suitable ceramic substrate candidates for the palladium separation layer. The criteria for selection of the substrates were as follows:

1. Good match in the coefficient of thermal expansion (CTE) with the palladium alloy

2. Inertness to the palladium layer

3. Stability of the substrate in hydrogen-rich atmospheres at operating temperatures

4. Availability

5. Ease of fabrication in the desired form

6. Cost

The main candidates for the substrate material were aluminum oxide (alumina) and zirconium oxide (zirconia). Because both materials met the requirements defined in items 2 through 6 , the literature review focused on item 1, the coefficient of thermal expansion. The CTE of zirconia is about $10 \times 10^{-6}$ $\mathrm{cm} / \mathrm{cm} \bullet{ }^{\circ} \mathrm{C}$ and that of alumina is about $8.8 \times 10^{-6} \mathrm{~cm} / \mathrm{cm} \bullet{ }^{\circ} \mathrm{C}$ in the temperature range from 0 to $1000^{\circ} \mathrm{C}$ [2]. The CTE of alumina increases with increasing temperature, especially from 0 to $400^{\circ} \mathrm{C}$. This temperature dependence of thermal expansion could become a significant problem. The CTE of palladium in the same range is about $11.8 \times 10^{-6} \mathrm{~cm} / \mathrm{cm} \bullet{ }^{\circ} \mathrm{C}$ [3]. Metal alloys generally have a CTE between the CTE's of the pure components. Recent data on gadolinia doped cerium oxide (CGO) show its CTE is about $12.5 \times 10^{-6} \mathrm{~cm} / \mathrm{cm} \bullet{ }^{\circ} \mathrm{C}$. Hence, zirconia and cerium oxide were considered as the lead candidates for the substrate. The thermal expansions of these materials are shown in Figure 3 [4]. Later testing showed that zirconia performed sufficiently well, including multiple thermal cycles. Zirconia was selected as the substrate material because of its availability, ease of manufacturing, and high strength. 


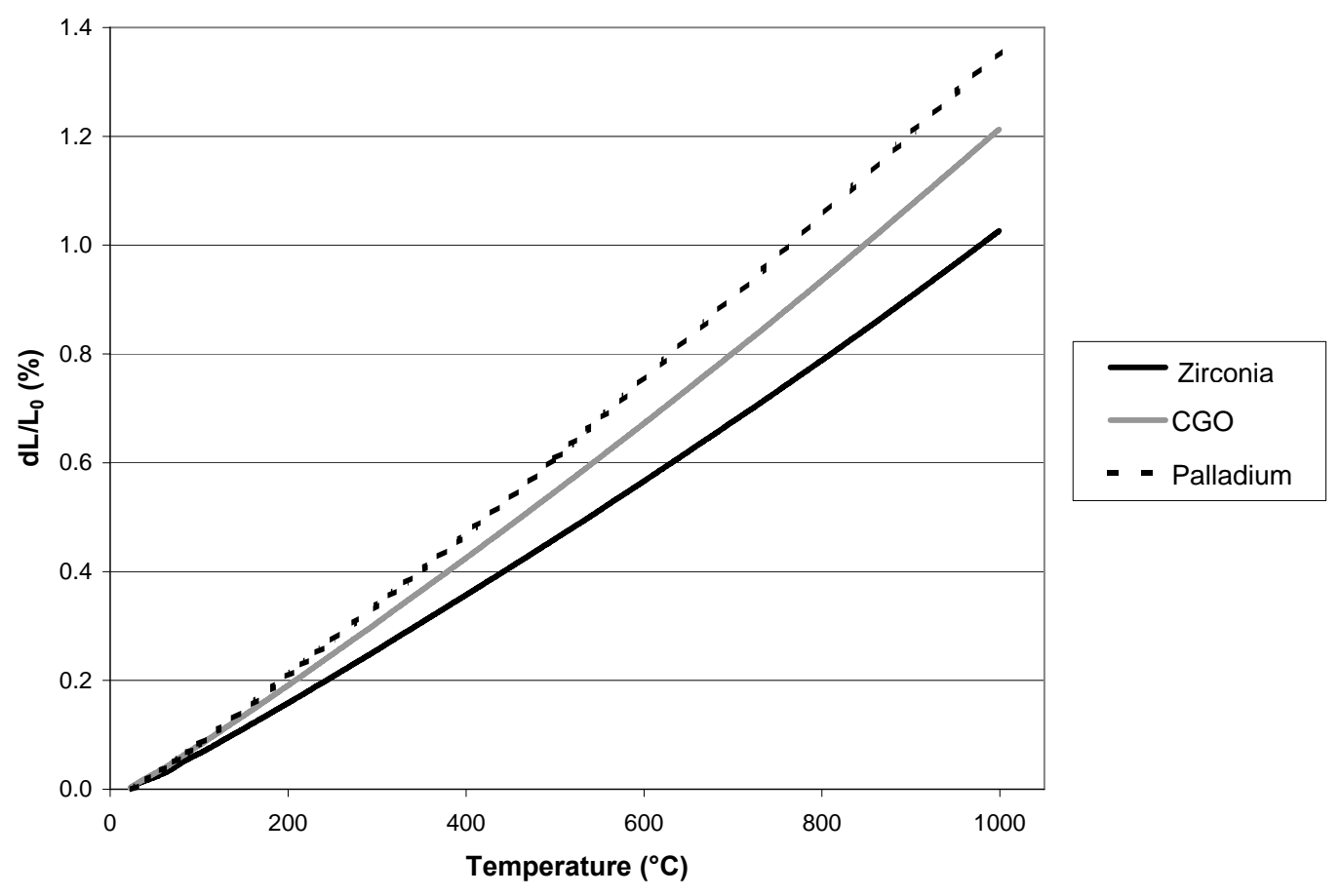

Figure 3. CTE Data for Palladium, Zirconia and CGO

\section{Contamination}

The contaminants and major gas species of interest in synthesis gas reforming are hydrogen sulfide, carbon monoxide, carbon dioxide, steam, carbon, methane, and heavier hydrocarbons. In some cases, hydrochloric acid and ammonia may also be present. Of all contaminants, hydrogen sulfide and hydrochloric acid cause severe poisoning of palladium and palladium alloys and must be removed upstream of the membrane. Selection of an appropriate palladium alloy may primarily be influenced by its resistance towards hydrogen sulfide as discussed below. Significant reduction in hydrogen permeation has been reported due to carbon monoxide and steam, especially at low temperatures (below $300^{\circ} \mathrm{C}$ ) due to competitive adsorption and interference at hydrogen dissociation sites. The effect is small at higher temperatures (above $450^{\circ} \mathrm{C}$ ). Saturated hydrocarbons, including methane, have a relatively minor effect, which also diminishes with increasing temperature. Carbon formation on the palladium surface and cracking of hydrocarbons (especially unsaturated hydrocarbons) reduce hydrogen permeability significantly. Fortunately, adequate steam (greater than stoichiometric proportion) can eliminate carbon formation, minimizing the effect on hydrogen permeation.

Among all species, $\mathrm{H}_{2} \mathrm{~S}$ appears to affect different palladium alloys differently as described in a detailed study with 1-mil membrane foils at $350^{\circ} \mathrm{C}$ [5]. Pure palladium was actually found to be more resistant to $\mathrm{H}_{2} \mathrm{~S}$ than both $73 \mathrm{Pd}-27 \mathrm{Ag}$ and $60 \mathrm{Pd}-40 \mathrm{Cu}$ alloys. Hydrogen permeation was reduced by about a factor of 3 in the presence of $4-5 \mathrm{ppm} \mathrm{H}_{2} \mathrm{~S}$ at $350^{\circ} \mathrm{C}$. The hydrogen permeability of Pd-Ag alloy reduced rapidly over a period of 6 hours to almost zero, whereas, $\mathrm{Pd}-\mathrm{Cu}$ alloy exhibited an order of magnitude reduction in hydrogen permeability under the same conditions. 60Pd-40Au alloy was found to be the most resistant to sulfur with only $10 \%$ reduction in hydrogen permeability with $4 \mathrm{ppm}_{2} \mathrm{~S}$ and about $50 \%$ reduction at $20 \mathrm{ppm} \mathrm{H}_{2} \mathrm{~S}$. It is clear from this study that $\mathrm{H}_{2} \mathrm{~S}$ concentrations in the feed gas must be reduced to ppm levels or lower regardless of the alloy used and among the three alloys, $\mathrm{Pd}$-Au could be the most preferable based on sulfur tolerance. 
Most of the research to-date, however, has focused on Pd-Ag alloy because it has the highest hydrogen permeability. Recently, studies have been conducted with Pd-Cu alloy for its resistance to sulfur. Unlike previous tests [5], these tests showed almost no reduction in hydrogen permeability for a 50 micron thick $60 \mathrm{Pd}-40 \mathrm{Cu}$ alloy foil over a 300 hour period at $500^{\circ} \mathrm{C}$ in presence of $1000 \mathrm{ppm} \mathrm{H}_{2} \mathrm{~S}$ in hydrogen [6]. The reasons for this difference are not well understood. Pd-Cu alloy 1-mil foils were found to exhibit a maximum in hydrogen permeability at $400^{\circ} \mathrm{C}$ that decreased significantly with a further increase in temperature because of a phase change [7]. Recent studies with $\mathrm{Pd}-\mathrm{Cu}$ alloy/ceramic composite membranes with 10-12 micron thick metal films, however, indicated increasing hydrogen flux with temperature up to the highest temperature tested, $500^{\circ} \mathrm{C}$. When exposed to sulfur, $\mathrm{Pd}$ can form palladium sulfide, which has a much higher lattice constant than Pd. The resulting stress can cause the membrane to crack [8]. This does not happen to platinum because the lattice constants are very similar and up to 50\% of the original flux was recovered.

Platinum metal is highly resistant to $\mathrm{H}_{2} \mathrm{~S}$ with less than $5 \mathrm{~nm}$ depth penetration by sulfur when exposed to $6000 \mathrm{ppm} \mathrm{H}_{2} \mathrm{~S}$ at $650^{\circ} \mathrm{C}$ for 113 hours [9]. Platinum however is almost three orders of magnitude less permeable than palladium. One possible approach to provide sulfur resistance in a composite membrane would be to deposit an ultra-thin platinum layer (about $5 \mathrm{~nm}$ ) on top of the $2-5 \mu \mathrm{m}$ palladium alloy layer. This could provide sufficient sulfur resistance without significantly affecting the hydrogen permeation.

\section{Compatibility of Catalyst with HTM}

Catalyst and its support may interact with OTM and HTM materials. The way catalyst is employed in the HTM reactor has a big impact on determining if catalyst compatibility could be an issue. Porous shroud tubes can be used to separate catalyst from the membrane if necessary. Catalyst activity is also an important factor in determining the performance of the membrane reactor, possibly even more important than the performance of the membrane [10]. This is particularly true when the reduction potential of the syngas changes due to hydrogen removal.

This literature review led to the following conclusions:

- Zirconia, which had been developed as a substrate for OTM, could be used for HTM

- Pd-Ag and Pd-Cu would be the primary alloys considered in Phase IIA

- Electroless plating would be used as the primary palladium alloy deposition method

\section{Task 2 -Define Substrate Material and Architecture}

Porous substrates are necessary to provide sufficient strength for the thin palladium alloy membrane separation layer. Praxair is using its experience in manufacturing porous ceramic tubes to develop scalable techniques that can directly lead to a process to manufacture substrate tubes on a commercial scale that meets the required cost target.

Ceramic substrate tubes were made using isostatic pressing. In isostatic pressing [2], ceramic powder, and usually organic binder, is compacted inside a mold to produce a strong dense piece. The compaction pressure is generally between about 3000 and about 30,000 psi. Once the piece is formed, it is fired to temperatures typically between about $700^{\circ} \mathrm{C}$ and about $1800^{\circ} \mathrm{C}$, depending on the material, to sinter it and burn out the binder.

Porous substrates are made using fugitive pore formers. The pore formers are added to the ceramic powder before pressing and are burned out during sintering. Several powder/pore former combinations were tested. The target was to produce substrates with very small pores and high porosity. A smooth, flat surface is also essential to allow for elecroless plating to produce a continuous layer of Pd alloy that does not leak and is also sufficiently thin to allow sufficient hydrogen permeation. 
Starting powders used were zirconia with no binder spray granulated zirconia with binder. The pore formers Types A, B, C, D, and E. Pore formers were added in varying weight ratios based upon their densities. The mixing of pore former and powder sometimes necessitated the addition of a binder to allow for further processing. While not affecting primary particle size, this sometimes produced large agglomerates, which are undesirable because they increase pore size. Consequently, powders were screened prior to use in order to help control the pore size.

After compaction in the isostatic press, the tubes were sintered. The tubes were heated at a controlled rate to burn out the pore formers. The heating rate and the atmosphere around the tubes during heating were selected based on experience from other work done at Praxair. The total time at maximum temperature was varied.

The best results were achieved with a powder/pore former mixture zirconia with Type E and sintered. The use of these two materials requires no additional binder and minimal, if any, screening. The tubes were formed by cold isostatic compaction of the powder/pore former mixture. These powder and processing conditions yielded tubes with pore sizes in the desired range. However, the surface porosity was larger than desired in a few localized areas. Consequently, the process was modified to produce improved substrate tubes.

A list of the different tubes produced and some of their properties is given in Table 1. The development process required several attempts, but the result is a scalable process to make substrates reproducibly and at low cost.

Table 1 Tubes Delivered for Pd Coating

\begin{tabular}{|c|c|c|c|c|l|}
\hline Tube ID & Group & Sint. Temp. & Pore Former & Type & Other \\
\hline $030214-1$ & 1 & Temp 1 & Type A & Zirconia & \\
\hline $030214-2$ & 1 & Temp 1 & Type A & Zirconia & \\
\hline $030221-0$ & 1 & Temp 2 & Type A & Zirconia & \\
\hline $030221-1$ & 1 & Temp 2 & Type A & Zirconia & \\
\hline $030228-1$ & 1 & Temp 2 & Type A & Zirconia & \\
\hline $030324-0$ & 2 & Temp 2 & Type A & Zirconia & Change mold size \\
\hline $030327-0$ & 2 & Temp 2 & Type A & Zirconia & \\
\hline $030408-0$ & 2 & Temp 2 & Type A & Zirconia & \\
\hline $030417-2$ & 3 & Temp 1 & Type A & Zirconia & Screened \\
\hline $030422-0$ & 3 & Temp 1 & Type A & Zirconia & Screened \\
\hline $030617-0$ & 3 & Temp 1 & Type A & Zirconia & Screened, Increase pore former \\
\hline $030624-0$ & 4 & Temp 1 & Type C & Zirconia & \\
\hline $030627-0$ & 4 & Temp 1 & Type B & Zirconia & \\
\hline $030710-0$ & 4 & Temp 2 & Type D & Zirconia & \\
\hline $030725-1$ & 4 & Temp 3 & Type D & Zirconia & \\
\hline $030730-0$ & 4 & Temp 1 & Type D & Zirconia & \\
\hline $030812-0$ & 4 & Temp 1 & Type D & Zirconia & \\
\hline
\end{tabular}




\begin{tabular}{|l|l|l|l|l|l|}
\hline $030912-0$ & 5 & Temp 1 & Type E & Zirconia & \\
\hline $030917-0$ & 5 & Temp 1 & Type E & Zirconia & \\
\hline $030922-0$ & 5 & Temp 1 & Type E & Zirconia & \\
\hline $030926-2$ & 5 & Temp 1 & Type E & Zirconia & \\
\hline $030929-0$ & 5 & Temp 1 & Type E & Zirconia & \\
\hline
\end{tabular}

\section{Task 3 - Define Optimum HTM Material}

Porous substrates made of zirconia and alumina were prepared by isostatic pressing.

\section{Substrate Preparation}

Ceramic powders were purchased from a commercial supplier. These powders were mixed with two different sizes of a pore former and a binder. The three constituents were rapidly wet-mixed and dried prior to isostatic compaction.

The powders were filled in a polyurethane mold around a steel mandrel and compacted at a pressure of 30,000 PSI (205Mpa). The molded tubes, which are open at one end, were stripped from the mold and sintered horizontally in an electric furnace. The sintering temperature was varied with the intent to obtain different pore sizes. The tubes typically showed a shrinkage of about $20 \%$ in the sintering process. This is because the green tube contains a significant amount of binder and pore former that is eliminated in the sintering step. The shrinkage makes it difficult to precisely control the final dimensions of the sintered tube. However, precise control of the size of the sintered tube is necessary to ensure a proper fit and good sealing in the reactor.

After the tubes were sintered, they were shipped to Research Triangle Institute (RTI) for plating trials. These initial tests were intended to determine the effectiveness of the process developed at Praxair in making tubes of the type needed by RTI. After these tubes were evaluated at RTI, the process was modified to attempt to meet the desired pore size distribution. The mold used for making the tubes, a green, unsintered, tube, and a sintered tube are shown in Figures 4-6. Figures 5 and 6, which are shown on the same scale, clearly show the shrinkage that occurs in the porous tube due to sintering. 


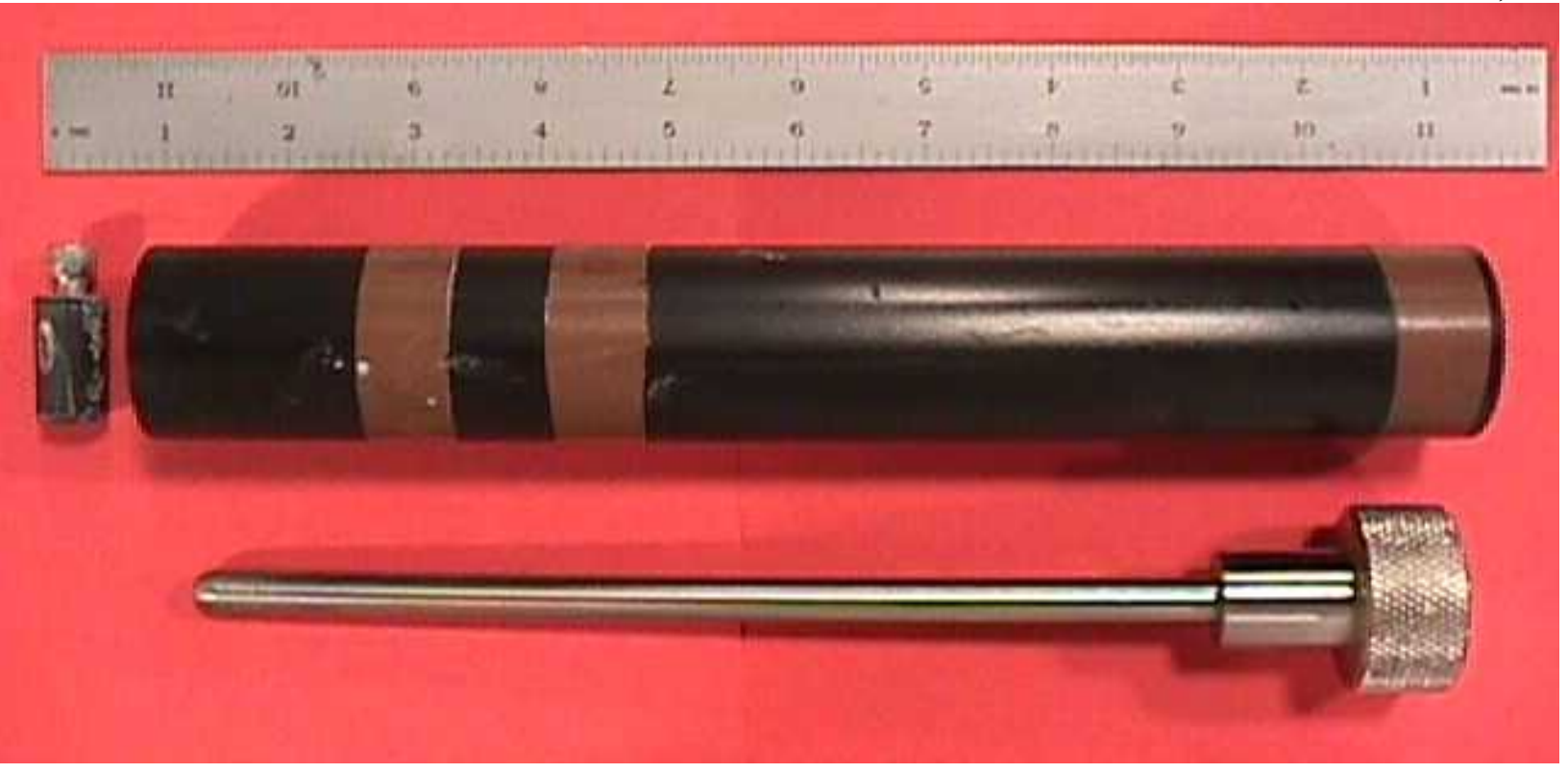

Figure 4. Isopressing Mold. Steel Mandrel with Polyurethane Bag and Cap

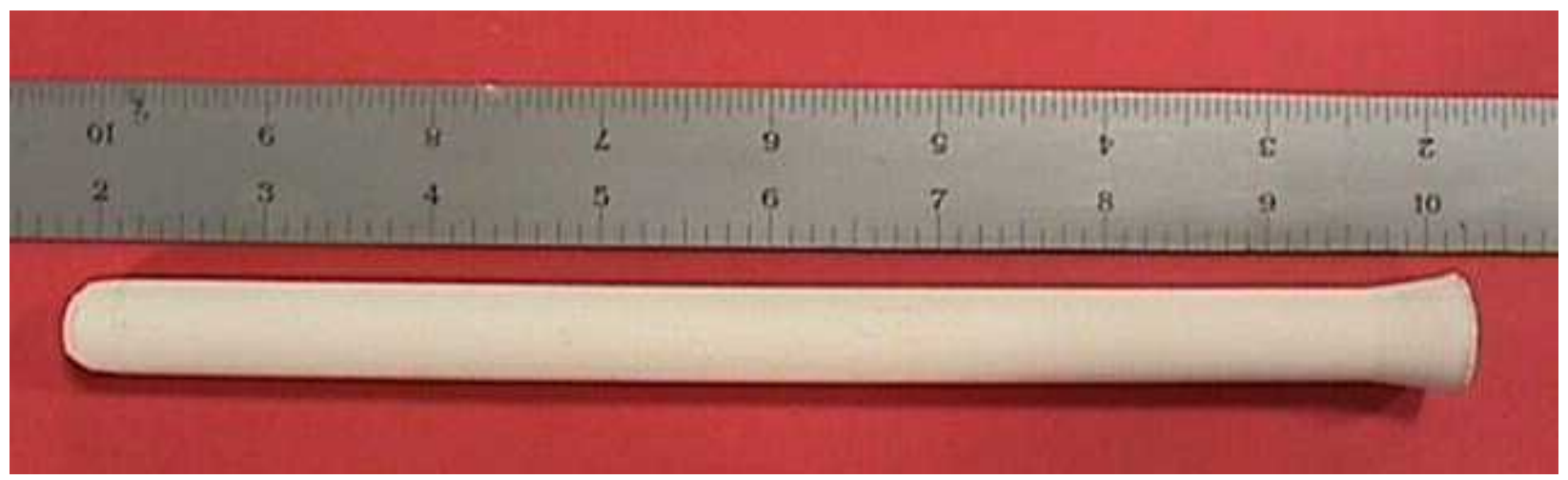

Figure 5. Green (un-sintered) Tube

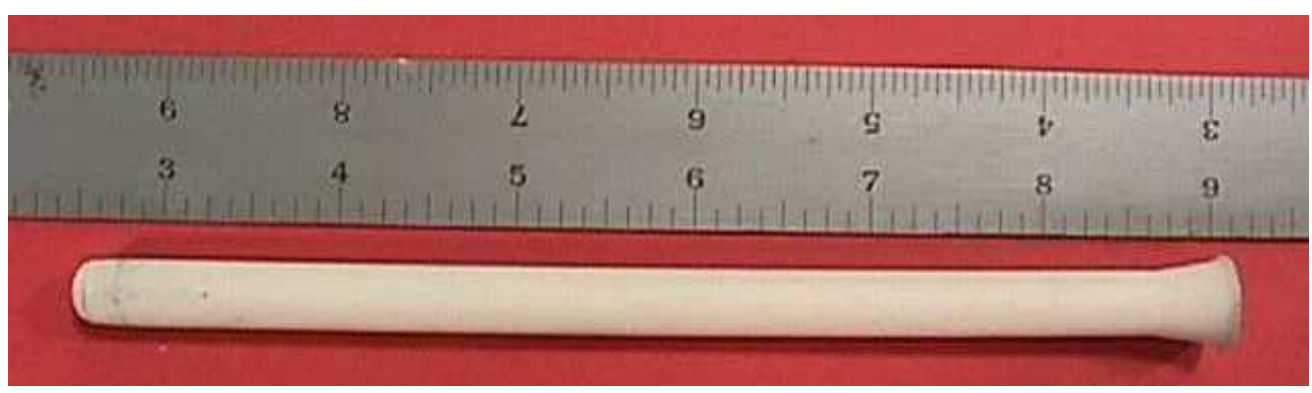

Figure 6. Sintered Tube 


\section{Task 4 - Prepare Membrane Tubes and Verify Performance}

The membrane test apparatus is shown schematically in Figure 7. The membranes are evaluated by conducting permeation tests with pure and mixed gases, including steam. Short-term measurements include membrane performance (flux and selectivity) and seal performance (leak rate). Long-term durability and thermal cycling $\left(20-600^{\circ} \mathrm{C}\right)$ stability of the selected composite membranes can also be verified. Membranes are analyzed by SEM/EDAX to determine the homogeneity, composition, structure, and integrity of the films deposited.

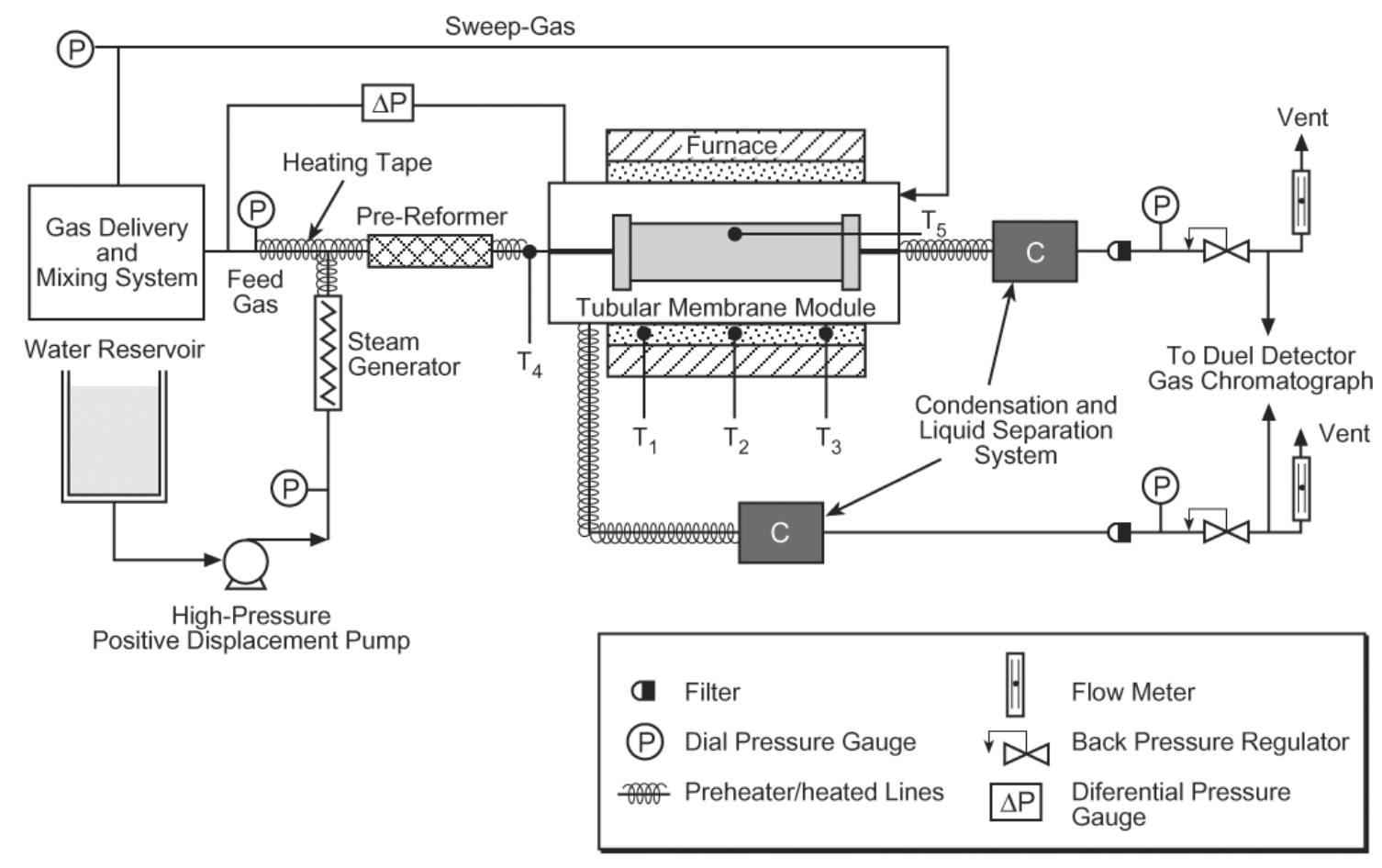

Figure 7. Schematic of Membrane Test Apparatus

Preparation of disk shaped membranes was eliminated and all effort was focused on fabricating tubular membranes. Initially, more than 20 substrate tubes were prepared and evaluated. The tubes can be broken down into six groups with progressive reduction in pore size and/or improved surface characteristics. Each group represents a significant step-change improvement in substrate properties. The combination of all of these improvements led to the production of suitable substrates (Group 6) starting from substrates with pores that were about 100x too large (Group 1). A total of 13 palladium-alloy composite membranes were prepared from this group and evaluated for nitrogen permeation. Composite membrane tubes prepared with two last groups (\#5 and \#6) of substrate tubes, with the finest pore size, had low-enough nitrogen permeation to allow high temperature testing for hydrogen permeation.

Table 2 shows the significant progress made in substrate tube production during this portion of the program. The pore size was not measured for Group 4 tubes because of the high leak rate and because Group 5 tubes were available for coating and testing. 
Table 2 Progress in Substrate Development

\begin{tabular}{|c|c|c|c|}
\hline Substrate Fabrication Date & $\begin{array}{l}\text { Pore Size } \\
\qquad(\mu \mathrm{m})\end{array}$ & $\begin{array}{l}\text { Nitrogen Leak Rate } \\
25^{\circ} \mathrm{C}\left(\mathrm{ccm} / \mathrm{cm}^{2}\right)\end{array}$ & $\begin{array}{c}\text { Hydrogen Flux } \\
40 \mathrm{psi}, 550^{\circ} \mathrm{C} \\
\left(\mathrm{ccm} / \mathrm{cm}^{2}\right)\end{array}$ \\
\hline February 2003 (Group 1) & $>50$ & & $\mathrm{~N} / \mathrm{A}$ \\
\hline March-April (Group 2) & 50 & & $\mathrm{~N} / \mathrm{A}$ \\
\hline April - June (Group 3) & 20 & 20 at 10 psid & $\mathrm{N} / \mathrm{A}$ \\
\hline June - August (Group 4) & & 3 at 5 psid & $\mathrm{N} / \mathrm{A}$ \\
\hline $\begin{array}{c}\text { September - November } \\
\text { (Group 5) }\end{array}$ & $5-10$ & 1 at 30 psid & 18.8 \\
\hline $\begin{array}{c}\text { December - March } 2004 \\
\text { (Group 6) }\end{array}$ & $<5$ & $<1$ at 30 psid & 33 \\
\hline
\end{tabular}

\section{Group 1 Substrates}

One of tubes from Group 1 was activated and plated with Pd-Pd-Ag-Pd layers. The tube was then thermally annealed in argon. Although the plating appeared to go on well and seemed to follow contours into the large holes, it did not bridge the gaps at all of the large openings on the surface. A nitrogen leak test confirmed the presence of large holes throughout the surface after plating.

\section{Group 2 Substrates}

Because of the problems with tubes from Group 1, tubes from Group 2 were made with smaller pores and thicker plating was used. Each of these steps was expected to improve the tube and make it less likely to leak. Tube \# 030327-0 was activated and plated with Pd-Pd-Ag-Pd layers. However, permeation analysis indicated a substantial leak of nitrogen through pinholes throughout the surface even at low pressures $(\sim 5$ psig). 


\section{Group 3 Substrates}

Praxair, Inc.

Compared to substrates from Groups 1 and 2, these tubes had fewer large pore openings on the surface. However, pores in the bulk of the substrate were still about 30-50 $\mu \mathrm{m}$ resulting in incomplete closing of pores upon plating and large nitrogen permeation rates even at low pressure drops.

Tube \#030422-0 from Group 3 was activated and plated with Pd-Ag-Pd layers. Permeation analysis indicated a substantial leak of nitrogen through pinholes throughout the surface even at low pressure $(\sim 5$ psi). This substrate tube was prepared with improved surface characteristics with smaller pores. The average pore size of the openings on the surface of this tube does appear to be smaller compared to the earlier tubes as seen in Figure 8. However, pores of 20-30 $\mu \mathrm{m}$ are still present, which are too large to obtain a thin leak-tight palladium alloy plating.

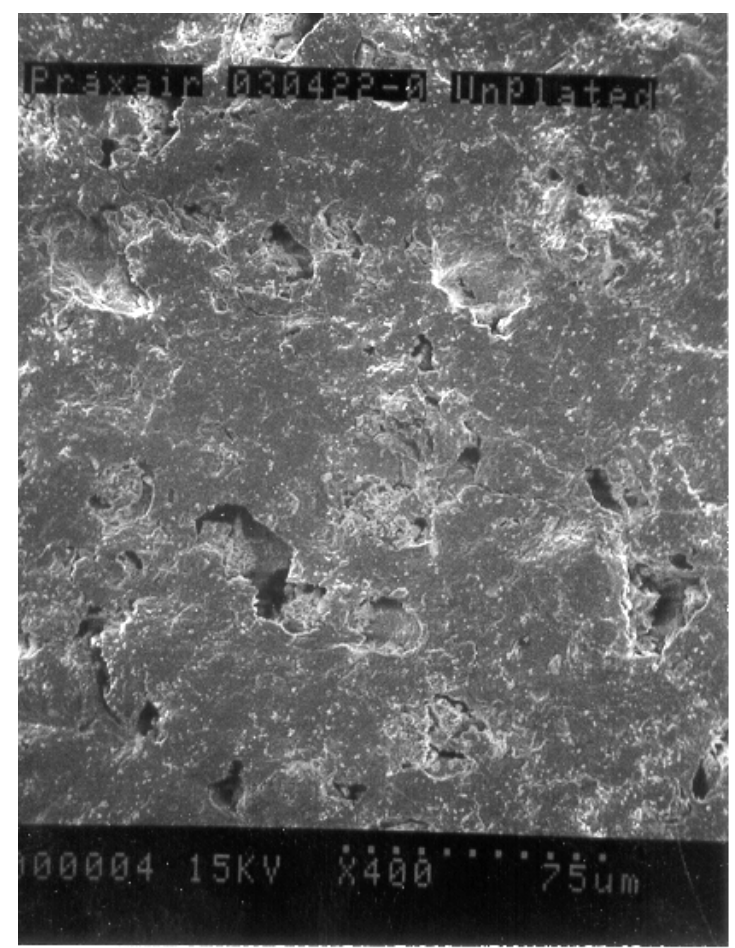

Unplated

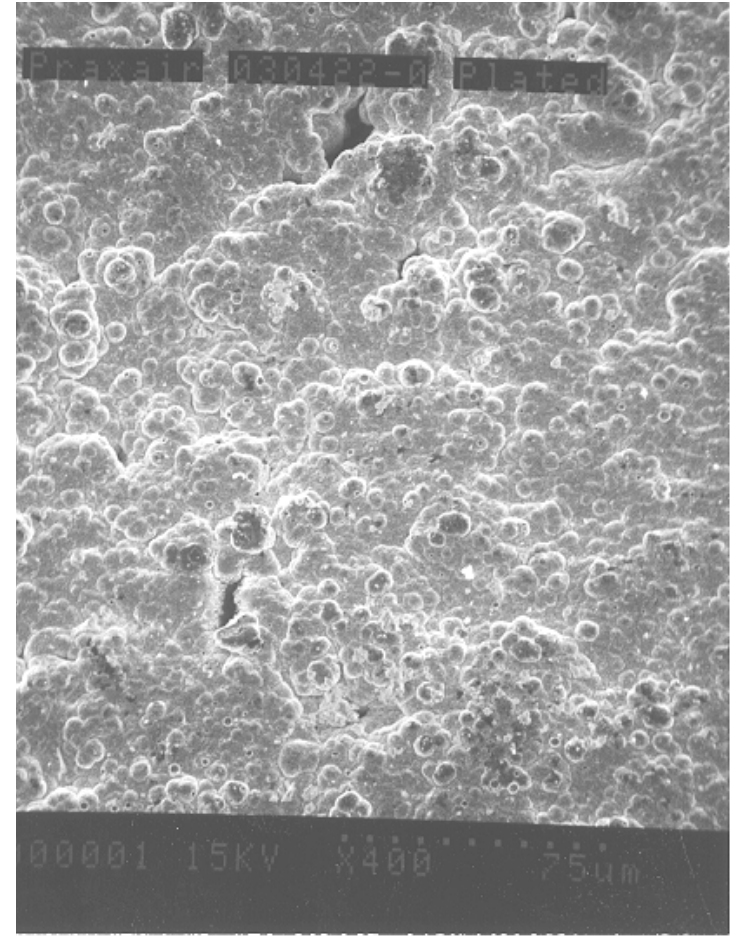

Plated

Figure 8. Top Surface of Zirconia Substrate Before and After Plating (Group 3 Tube \#030422-0)

Compared to earlier substrate tubes, both the average pore size and the surface porosity of tube 030422-0 are lower. Smaller pore size and greater porosity are desirable for improving hydrogen flux. Figure 8 shows the top surface of the plated film. Large openings of 15-20 $\mu \mathrm{m}$ (longer dimension) are still present on the plated surface. 


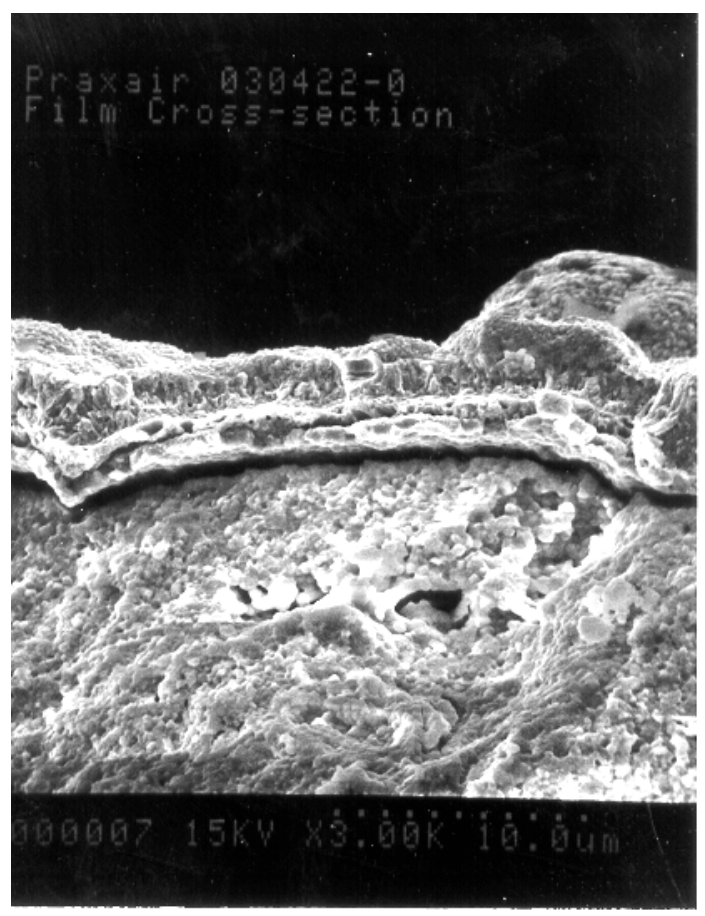

Praxair, Inc.

Figure 9. Cross-Section of the Plated Tube Shown in Figure 8

The film cross-section is shown in Figure 9 and indicates that the film was about 4-5 $\mu \mathrm{m}$ thick. The electroless plating process involves reduction of the metal complex to elemental metal using a reducing agent. The reducing agent (hydrazine) is usually mixed with the metal complex solution just before commencing the plating process. The reaction occurs primarily on active sites of previously deposited metal nuclei. Because plating of the tubes in Group 3 indicated pinholes throughout the tube due to incomplete closing of the surface pores, an attempt was made to promote plating within the pores. This was done by separating the reducing agent from the plating solution and supplying it to the opposite side of the tube surface being plated. This approach reduced the nitrogen leak by a factor of 10 from 700 $\mathrm{cc} / \mathrm{min}$ at $10 \mathrm{psi}$ to $70 \mathrm{cc} / \mathrm{min}$ at $10 \mathrm{psi}$. However, further reduction was not observed by repeating the plating or by using different variations such as applying vacuum or pressure on the opposite sides of the tube to promote mixing of the plating solution and the reducing agent within the pores.

\section{Group 4 Substrates}

Metal plating on these substrate tubes visually indicated good plating and texture indicating improved surface smoothness. However, large pores were still visible on the plated surface indicating incomplete closing of pores that resulted in nitrogen breakthrough. Separation of the reducing agent and application of vacuum were attempted for some of the sequential plating cycles. The observed nitrogen leak rates, although lower than those observed earlier, were still substantial, about $100-300 \mathrm{cc} / \mathrm{min}$ at 5 psi pressure differential. Hydrogen permeation tests were therefore not attempted with these tubes. 


\section{Group 5 Substrates}

Praxair, Inc.

This group of substrate tubes had a smaller pore size and the metal plating on these tubes visually indicated good texture. Initially, the metal plating was still not leak tight indicating presence of large pores not completely closed by plating. The observed nitrogen permeation rate was lower than those for the earlier tubes. Figure 10 shows the top surface of the substrate tube indicating significantly smaller pores than those observed earlier. Large openings of the order of 5-10 $\mu \mathrm{m}$, such as the circled area, are still visible on the surface of these substrate tubes. These openings cannot be sealed by electroless plating using a 5-10 $\mu \mathrm{m}$ film of deposited palladium.

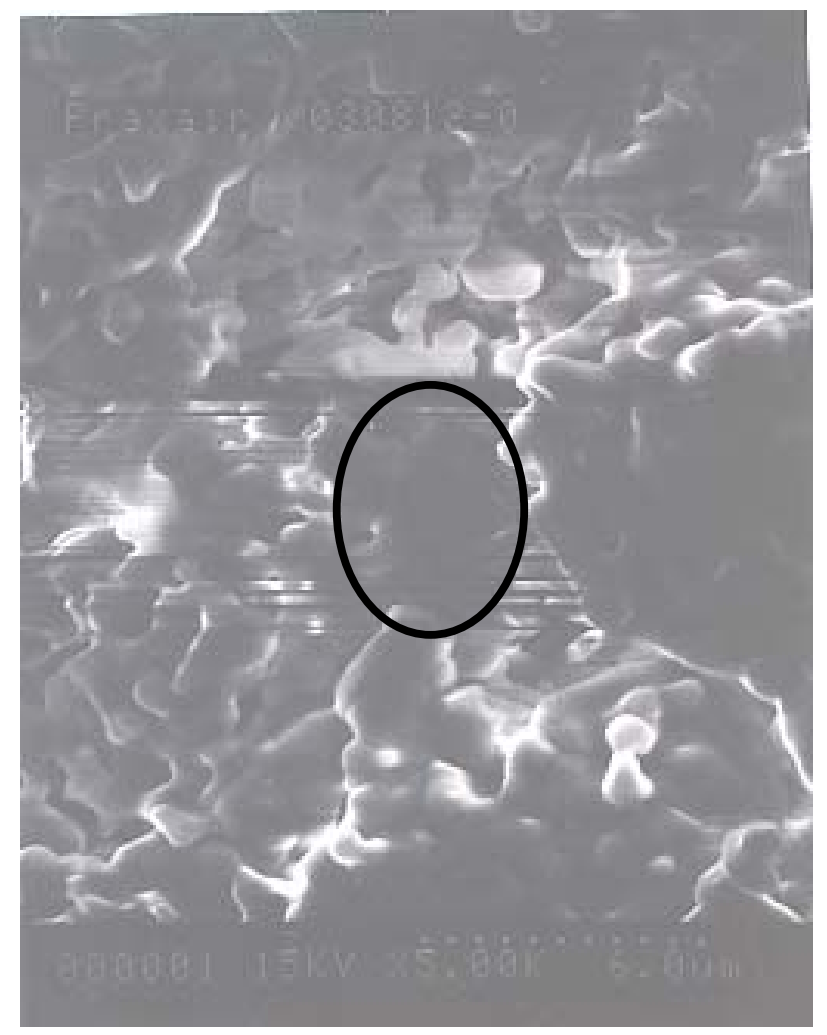

Figure 10. Top Surface of an Unplated Substrate 
Figure 11 shows the plated surface that indicates good metal coverage yet still has large gaps and openings that were not filled by the palladium plating. Figure 11 also shows the cross-section of the membrane that indicates about 10-15 $\mu \mathrm{m}$ film. The composite membrane still had a large nitrogen leak rate of about $180 \mathrm{cc} / \mathrm{min}$ at $5 \mathrm{psi}$ pressure differential.
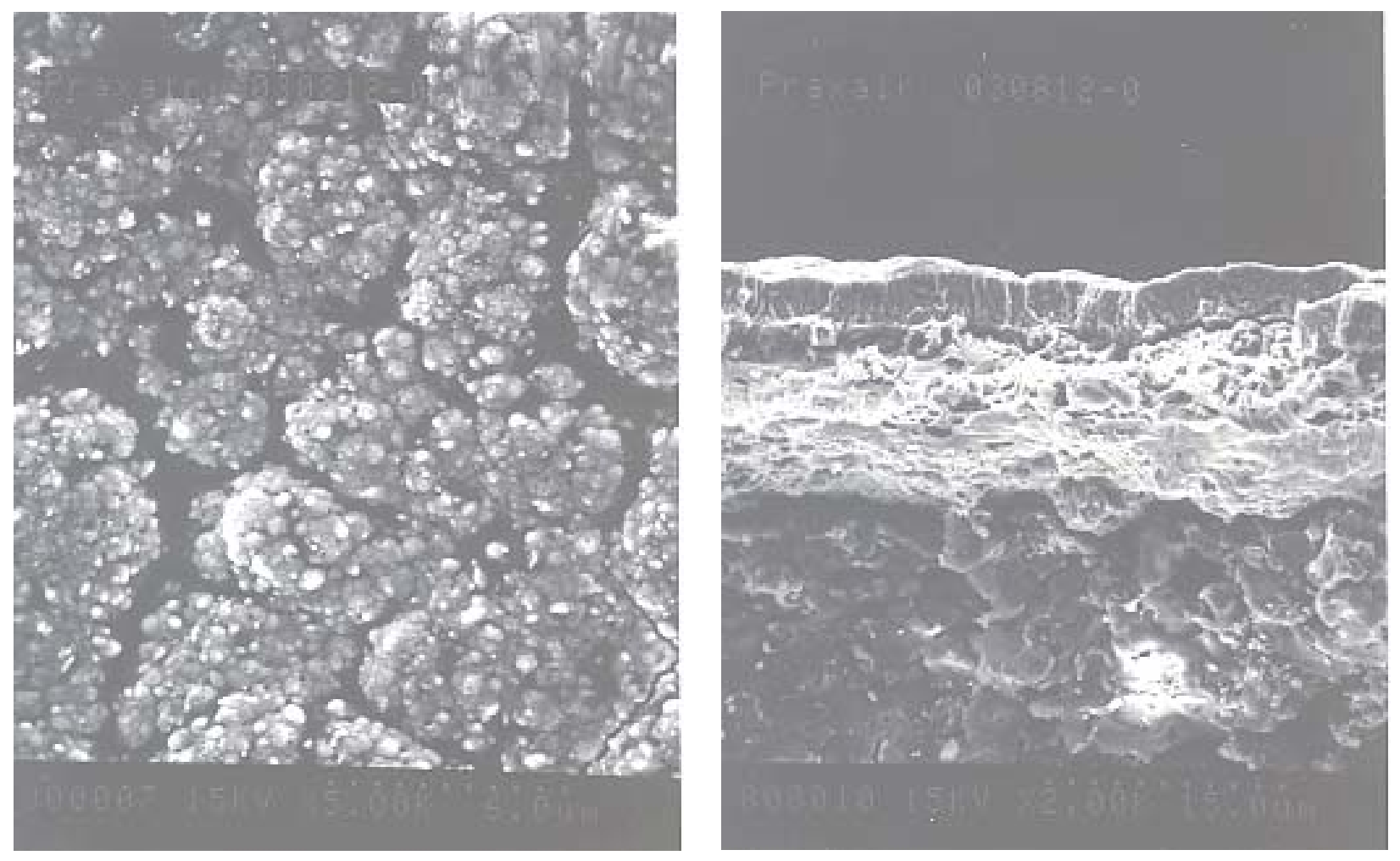

Figure 11. Top Surface and Cross-Section of a Plated Tube (Group 5 Tube \#030812-0)

Because the substrate tube is homogeneous in nature (i.e. similar pore size distribution throughout the tube mass) palladium plating was expected to be similar on the inside or outside of the tube. An additional palladium layer was applied to the inside surface of the same tube. The nitrogen leak rate was dramatically reduced to about $4 \mathrm{cc} / \mathrm{min}$ at $10 \mathrm{psid}$. This observation indicated better closing of pores on the inside surface of the tube by metal plating and/or smaller pore size openings on the inner surface of the tube compared to the outside surface of the tube. The outside metal plating was repeated with another substrate tube in this group and a third composite membrane was prepared with plating on the inside of another substrate tube. For the composite membrane tube prepared with plating on the outside, the nitrogen permeation rate was about $62 \mathrm{cc} / \mathrm{min}$ at $5 \mathrm{psid}$. Surprisingly, the tube prepared with plating on the inside had a nitrogen permeation rate that was substantially lower, about $18 \mathrm{cc} / \mathrm{min}$ at $30 \mathrm{psid}$. The order-of-magnitude lower nitrogen permeation rate with inside plating indicated either better pore closing on the inside surface and/or a much smaller pore size distribution on the inside surface of the substrate tubes. 
Figure 12 shows the outside substrate surface of Tube \#030917-0 before and after plating. This SEM scan indicates much smaller pore size compared to the earlier substrate tubes, however, the pore size was still large causing incomplete filling of the pores by plating of $\sim 5 \mu \mathrm{m}$ film.
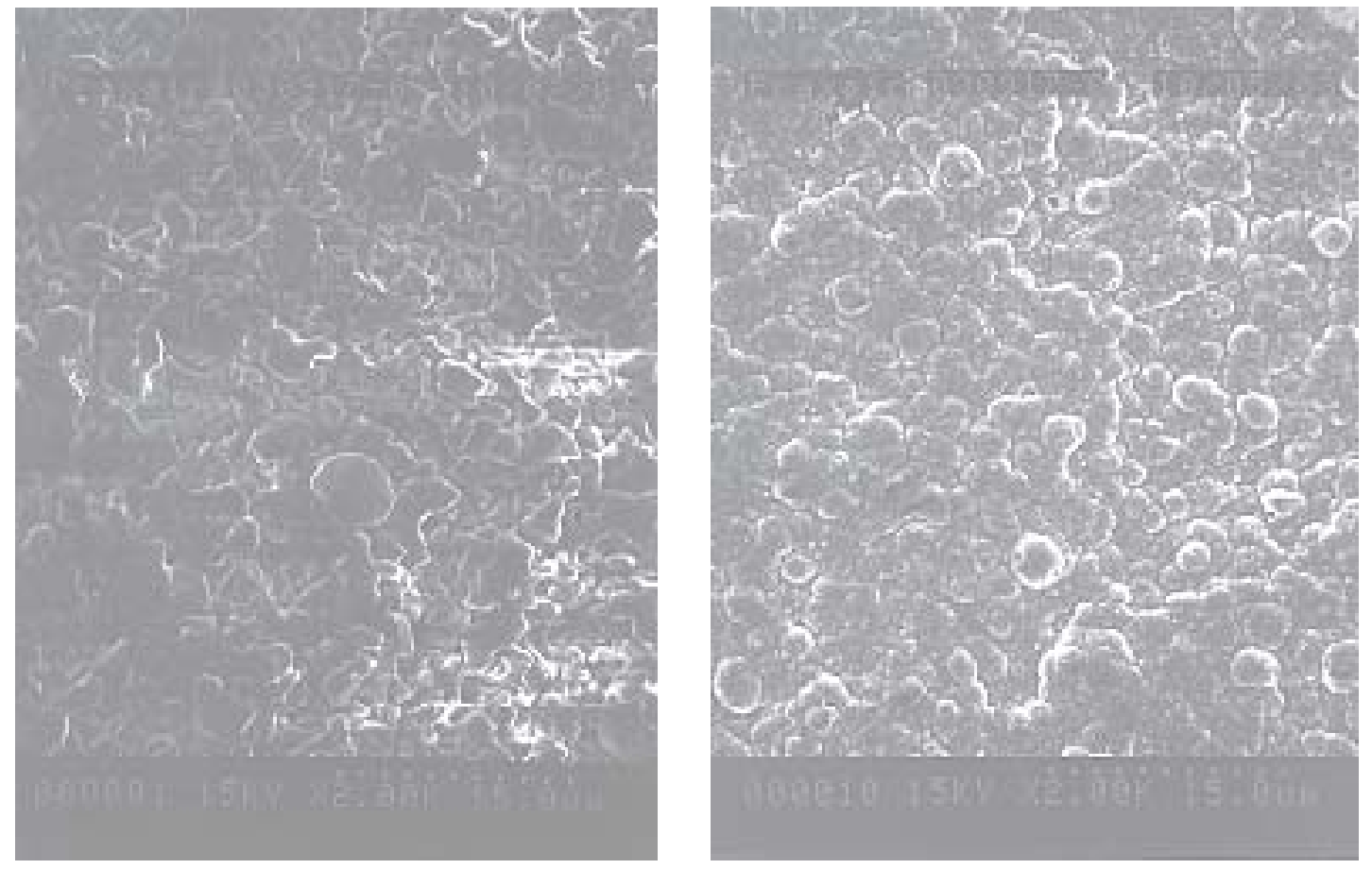

Figure 12. Top Surface of a Tube (Group 5 Tube \#030917-0) Before and After Plating

The ends of the substrate tube 030922-0 are porous because the original intention was to conduct plating on the outside of the tube and provide a seal using a gasket compressed directly against the plated metal surface. In order to conduct testing of the composite membrane tube prepared with inside plating of substrate tube 030922-0, it was necessary to seal the tube ends. For quick testing, a 5-minute epoxy was applied on the ends of the tube on the cross-section as well as on the outside surface. The tube was then loaded in the permeation housing using graphite tape and Swagelok fittings. The membrane was heated in nitrogen to $550^{\circ} \mathrm{C}$ at $1^{\circ} \mathrm{C} / \mathrm{min}$. During heating, the nitrogen permeation rate decreased initially to 6 $\mathrm{cc} / \mathrm{min}$ at $30 \mathrm{psi}$ differential pressure but eventually increased with time presumably due to hardening and eventually cracking of the epoxy end-seal. However, the nitrogen permeation rate was still small enough to allow hydrogen permeation testing. The observed hydrogen permeation rates attributed to hydrogen diffusion through the film (subtracting estimated flow due to leak from the total permeate flow) at $550^{\circ} \mathrm{C}$ are shown in Figure 13 as a function of pressure difference. The observed hydrogen flux rate of 18.8 $\mathrm{sccm} / \mathrm{cm}^{2}$ at $40 \mathrm{psi}$ hydrogen pressure difference was somewhat lower than that observed in earlier studies conducted at RTI. The lower flux rate was attributed to lower surface porosity of the current developmental substrate and a thicker metal film. The hydrogen flux appears to be a linear function of pressure. If the palladium layer were the controlling resistance to flux, the flux would vary with the square root of the pressure. Therefore, it was concluded that the substrate provided the controlling resistance to hydrogen flux for this membrane. Figure 14 shows the annealed membrane cross-section and the membrane surface indicating a film thickness of about $10 \mu \mathrm{m}$ with good surface coverage. 


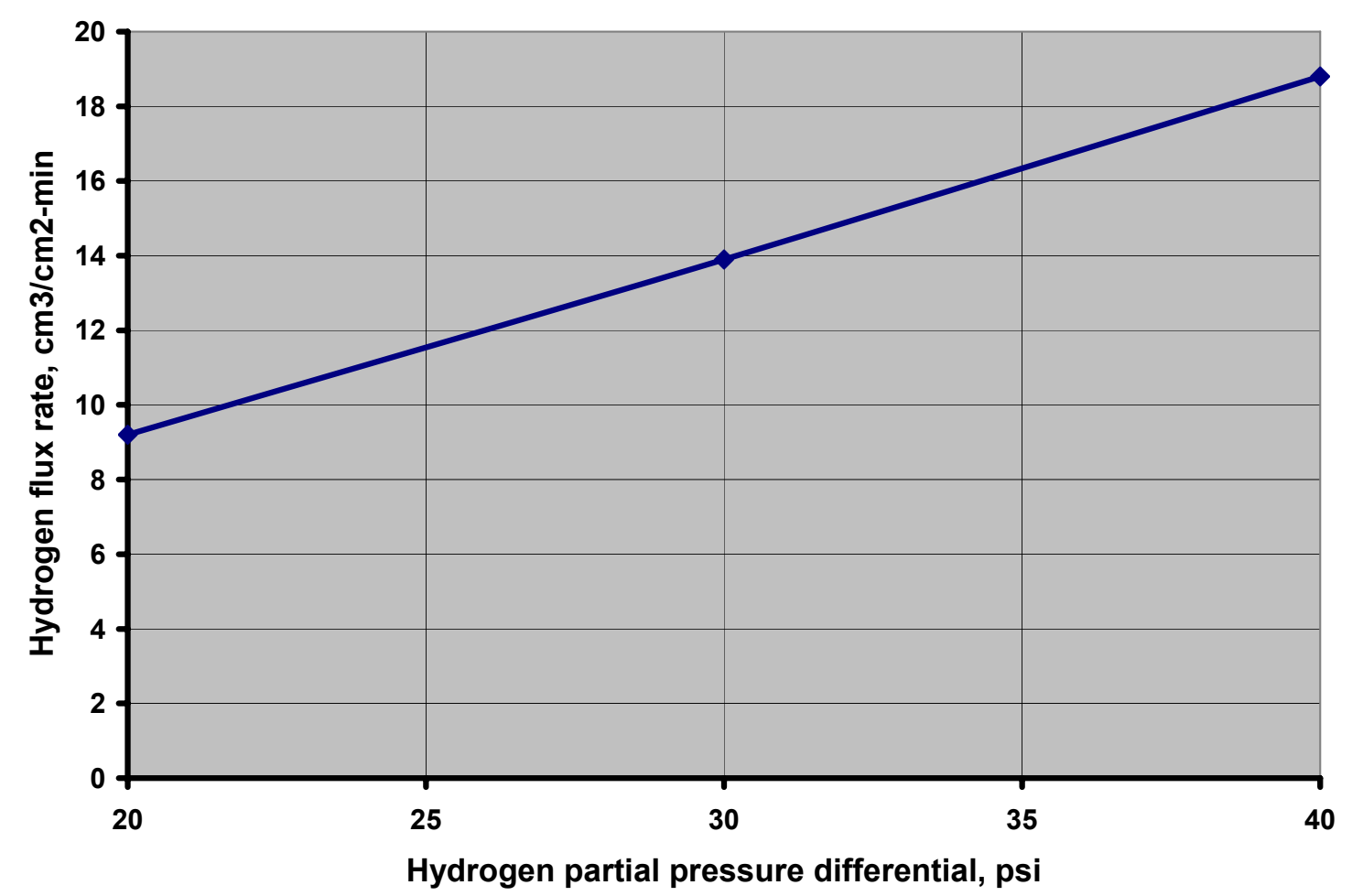

Figure 13. Hydrogen Flux of a Plated Tube (\#030922-0) at $550^{\circ} \mathrm{C}$
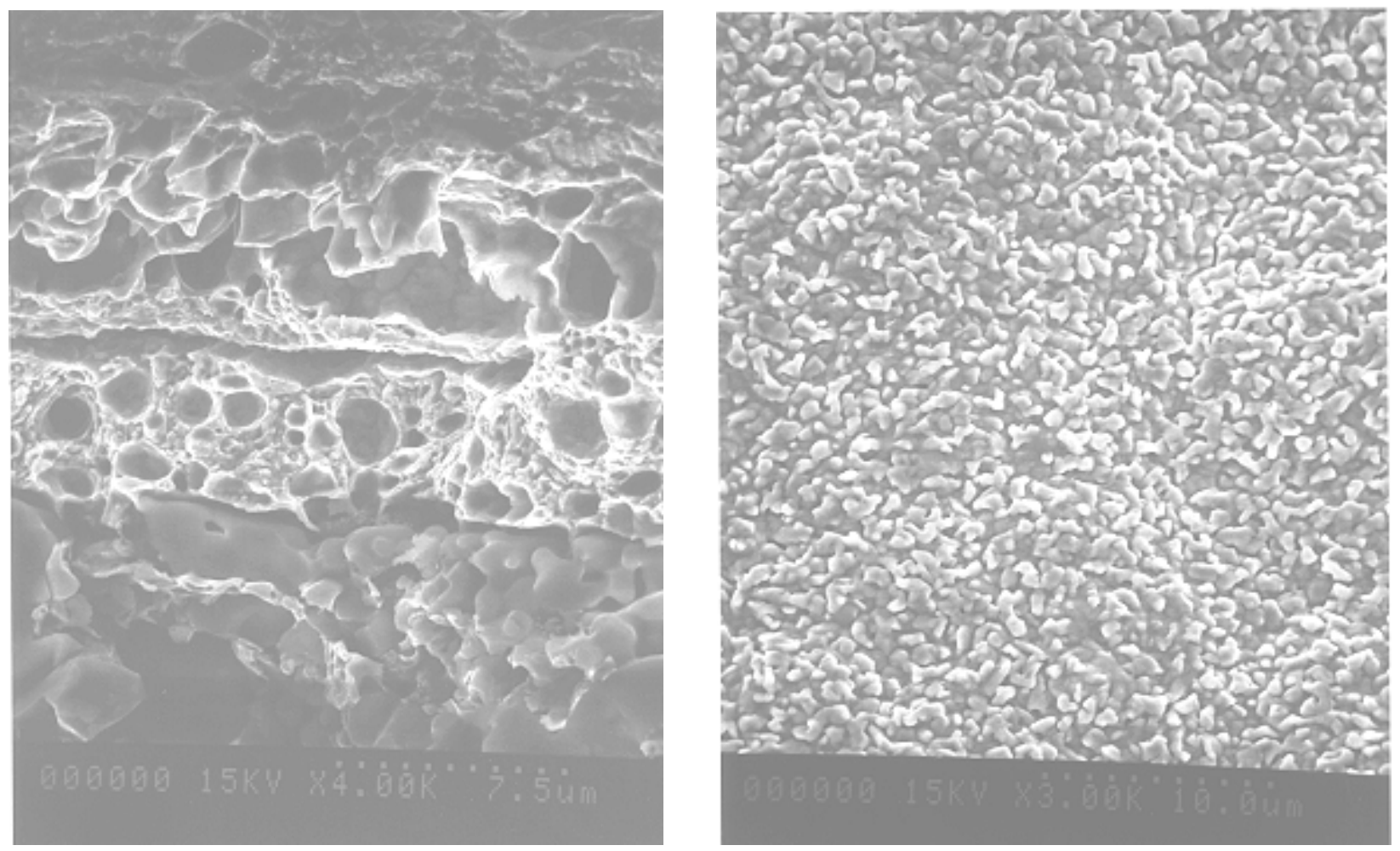

Figure 14. Cross-Section and Top Surface of a Plated Tube (\#030922-0) 


\section{Group 6 Substrates}

Most of the progress in the early stages of Phase IIA came from decreasing the size of the pore formers. The use of small pore formers alone was not sufficient to further reduce the pore size to below $5 \mu \mathrm{m}$, so other techniques were developed. These methods allowed us to further reduce the pore size to below 5 $\mu \mathrm{m}$, which was essential to producing effective substrates

Several Pd-Ag composite membrane tubes were prepared and tested for hydrogen flux. Figure 15 shows the results for a representative tube made near the completion of Phase IIA.

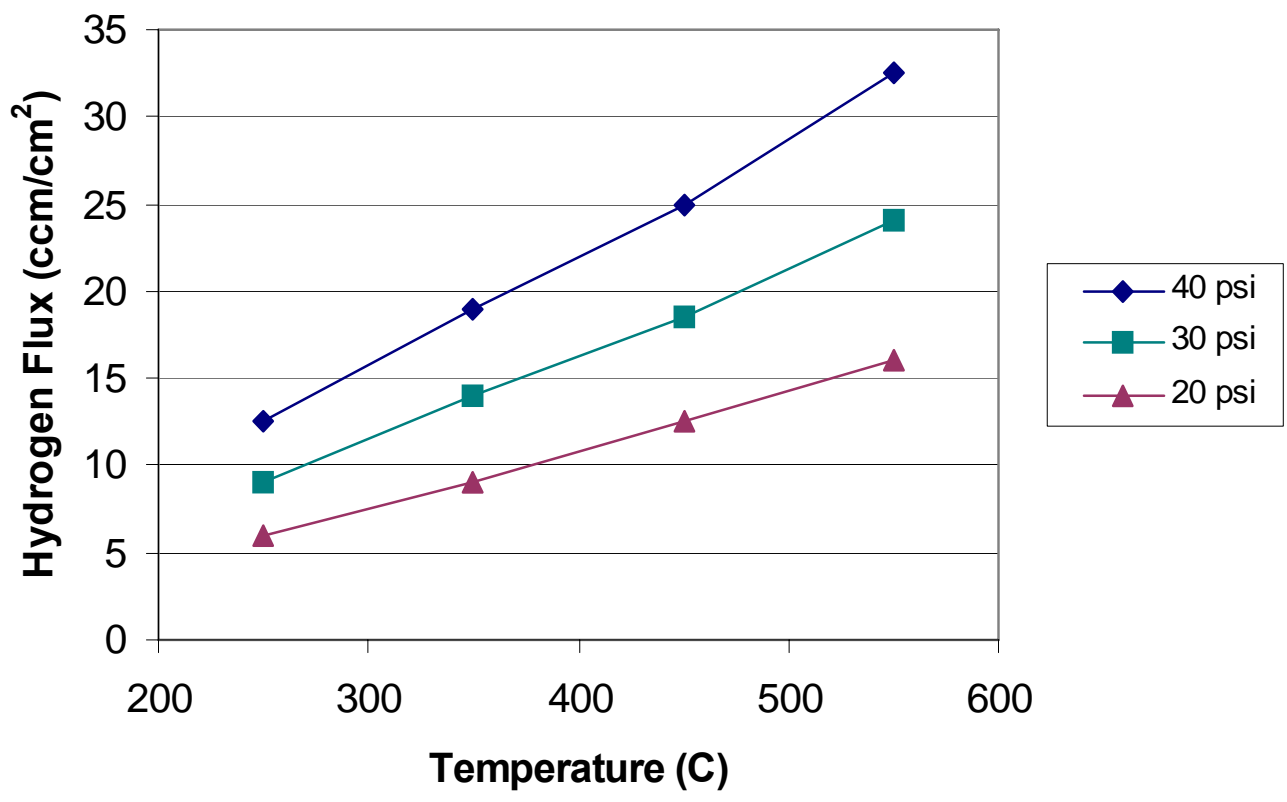

Figure 15. Hydrogen Flux for a Pd-Ag Membrane with a $5 \mu \mathrm{m}$ Film

As can be seen from Figure 15, increasing the hydrogen partial pressure difference or increasing the temperature over the range studied $\left(250-550^{\circ} \mathrm{C}\right)$ increased the hydrogen flux. In order to quantify the effect of temperature, the data from another tube were used in the Arrhenius plot shown in Figure 16. 


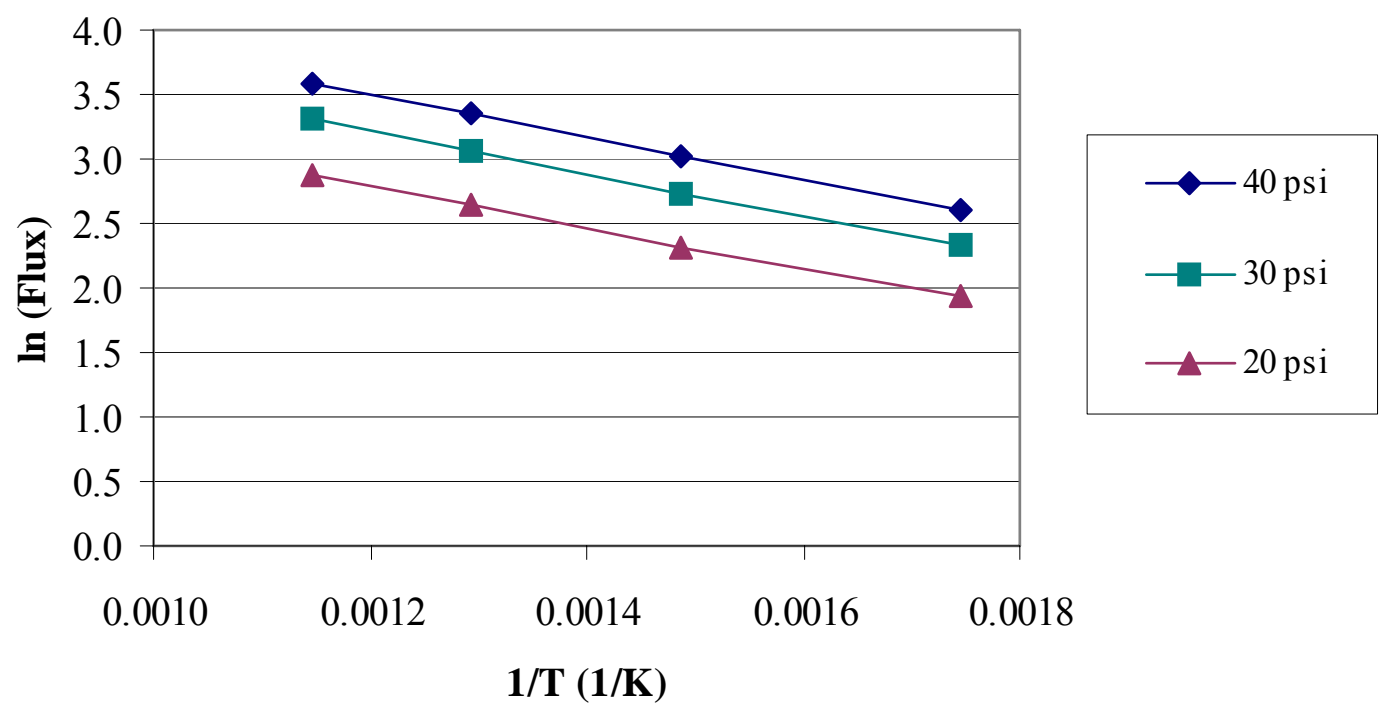

Figure 16. Arrhenius Plot Showing an Apparent Activation Energy

In each case, the correlation was very good with each line showing $\mathrm{r}^{2}>0.999$. The apparent activation energy was $3.2 \mathrm{kcal} / \mathrm{mol}$, showing a consistently strong temperature dependence. The dependence of flux on the square root of the hydrogen partial pressure was also confirmed, indicating that the palladium film controlled flux instead of the substrate, such as the case of the tube shown in Figure 13. Producing substrates with pores small enough to be coated without leaking, yet large enough that they did not limit the hydrogen flux represented a significant improvement in substrate production. 
The effect of Pd-Ag layer thickness was also examined using three different tubes tested under identical conditions. Figure 17 shows the effect of membrane thickness on flux. The flux improvement due to using thinner layers confirmed that the palladium layer was now the dominant resistance to hydrogen flux instead of the substrate.

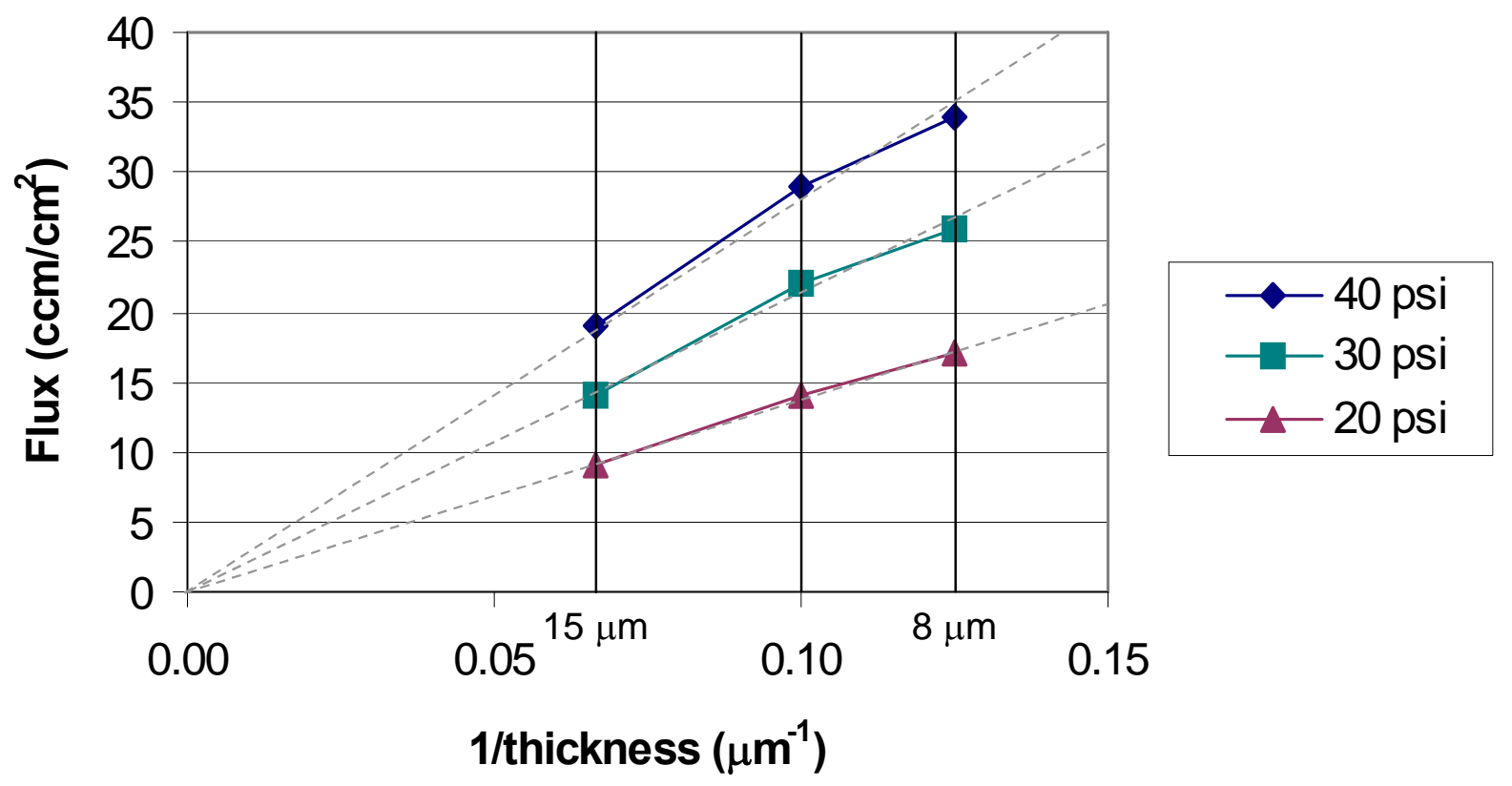

Figure 17. Hydrogen Flux Increased as Membrane Thickness Decreased

As expected, the hydrogen flux increased in inverse proportion to the membrane alloy layer thickness. This is a good indication that the alloy layer is the rate determining step in hydrogen flux for layers of at least $8 \mu \mathrm{m}$ using Group 6 substrates. Eventually, the thickness of the layer will become low enough that other resistances will become more important, so decreasing the layer thickness beyond that level will have less benefit than might be expected. At this time, finding ways to decrease the membrane layer thickness below $8 \mu \mathrm{m}$ became important to improving the hydrogen flux. If this trend is extrapolated, the alloy layer thickness will have to be about $2 \mu \mathrm{m}$ in order to reach the DOE target flux using the current substrates. Because a $2 \mu \mathrm{m}$ film appeared to be difficult to achieve at the time, further work was required to improve the substrate to allow for thinner films and to reduce flow resistance due to the substrate. 
Tube 040304-1 was plated first with $\mathrm{Pd} / \mathrm{Pd} / \mathrm{Cu} / \mathrm{Pd}$ layers. SEM scans of the cross-sections of the annealed $\mathrm{Pd} / \mathrm{Cu}$ alloy film indicated a film thickness of $\sim 13 \mu \mathrm{m}$. The hydrogen flux observed with this composite membrane is shown in Figure 18 as a function of pressure differential and membrane temperature. The observed nitrogen leak rate was about $0.2 \mathrm{cc} / \mathrm{min}$ at $40 \mathrm{psi}$ with a resulting pure component hydrogen to nitrogen selectivity of about 750 . The hydrogen flux observed with this $\mathrm{Pd} / \mathrm{Cu}$ membrane is significantly lower than those expected with a $\mathrm{Pd} / \mathrm{Ag}$ alloy composite membrane of similar thickness. The most likely cause of the low flux is that the composition of the $\mathrm{Pd} / \mathrm{Cu}$ alloy was not exactly 60/40. Earlier work has shown that even small deviations of a few percent in composition can cause the permeability to be significantly lower [6].

\section{Hydrogen Flux - 040304-1 Pd/Cu composite membrane}

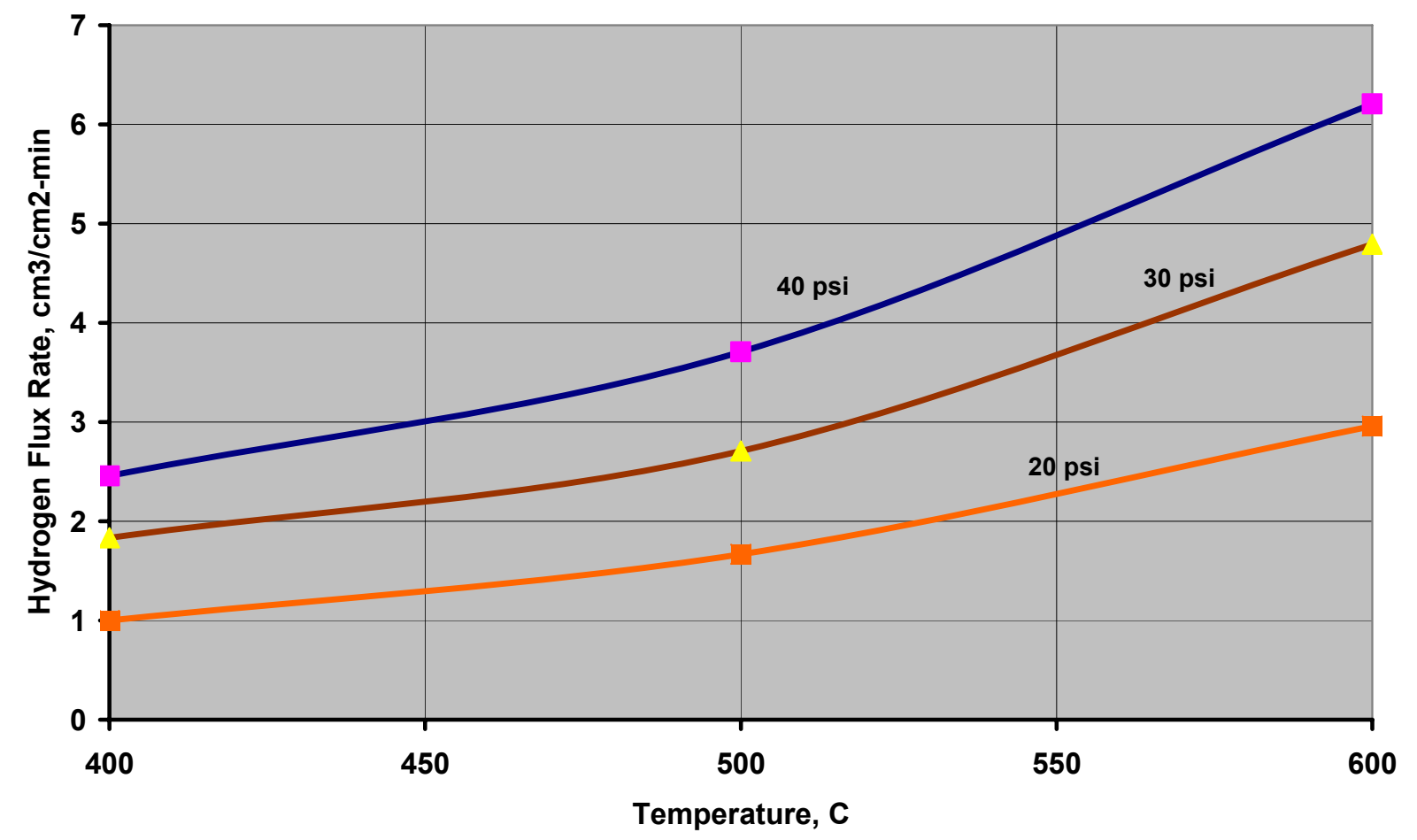

Figure 18. Observed Hydrogen Flux Rates for Pd-Cu Alloy Composite Membrane

A thinner Pd-Cu membrane was therefore prepared using 040301-1 substrate tube. The final Pd layer step was also eliminated for this composite membrane to increase the copper percentage. The SEM scans of the cross-sections of the Pd-Cu alloy film showed a final annealed film thickness of about $7 \mu \mathrm{m}$. The 040301-1 composite membrane was annealed in a nitrogen atmosphere under pressure at $625^{\circ} \mathrm{C}$. The nitrogen leak rate was about $0.74 \mathrm{cc} / \mathrm{min}$ at $40 \mathrm{psi}$ pressure differential across the membrane. The corresponding hydrogen permeation rate at 40 psi pressure differential was about $489 \mathrm{cc} / \mathrm{min}$ resulting in a pure component $\mathrm{H}_{2} / \mathrm{N}_{2}$ selectivity of about 660 . 
The motivation for testing Pd-Cu alloy composite membranes is to provide resistance to $\mathrm{H}_{2} \mathrm{~S}$. This membrane was exposed to 50 and $250 \mathrm{ppm}$ of $\mathrm{H}_{2} \mathrm{~S}$ in a $\mathrm{H}_{2}: \mathrm{N}_{2}$ mixed gas and its effect on hydrogen permeation rate was observed with time as shown in Figure 19. The hydrogen permeation rate decreased by about $7 \%$ with initial exposure to $50 \mathrm{ppm} \mathrm{H}_{2} \mathrm{~S}$. After increasing the $\mathrm{H}_{2} \mathrm{~S}$ concentration, the permeation decreased by about $16 \%$. The reduction in hydrogen permeation rate appeared to occur quickly to a lower stable permeation rate instead of continuous degradation of performance. The hydrogen permeation rate recovered partially upon reverting back to the sulfurless mixed feed gas. The nitrogen leak rate appeared to increase significantly upon exposure to $\mathrm{H}_{2} \mathrm{~S}$ and increased with time.

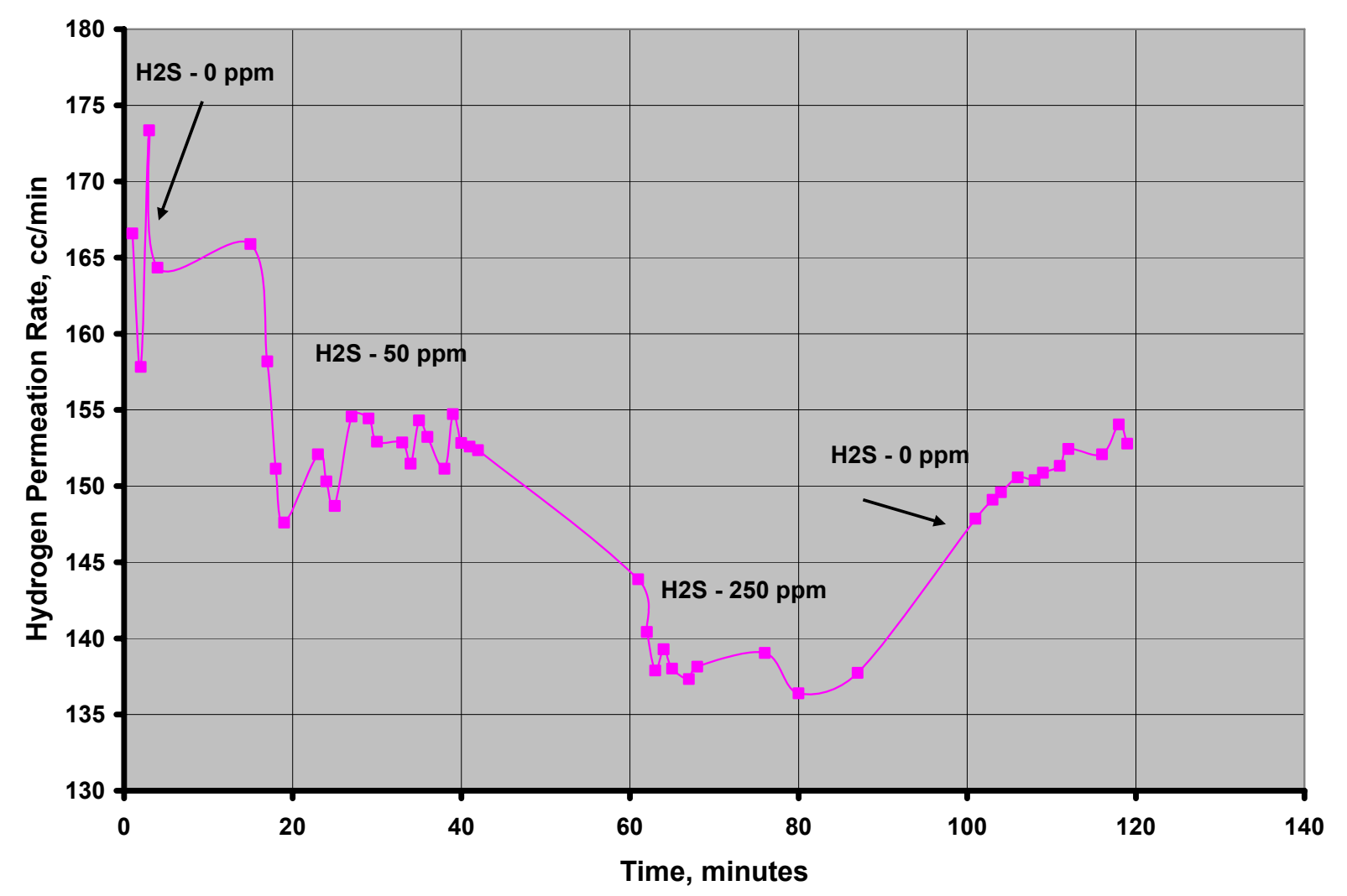

Figure 19. Hydrogen Permeation with $\mathrm{H}_{2} \mathrm{~S}$ Exposure (Pd-Cu Composite Membrane) 
Pure component hydrogen permeation rates were then measured as a function of temperature and pressure differential as shown in Figure 20. Clearly, exposure to $\mathrm{H}_{2} \mathrm{~S}$ decreased the hydrogen permeation, but the membrane was still able to selectively permeate hydrogen after exposure.

\section{Hydrogen Flux - 040301-1 Pd/Cu composite membrane}

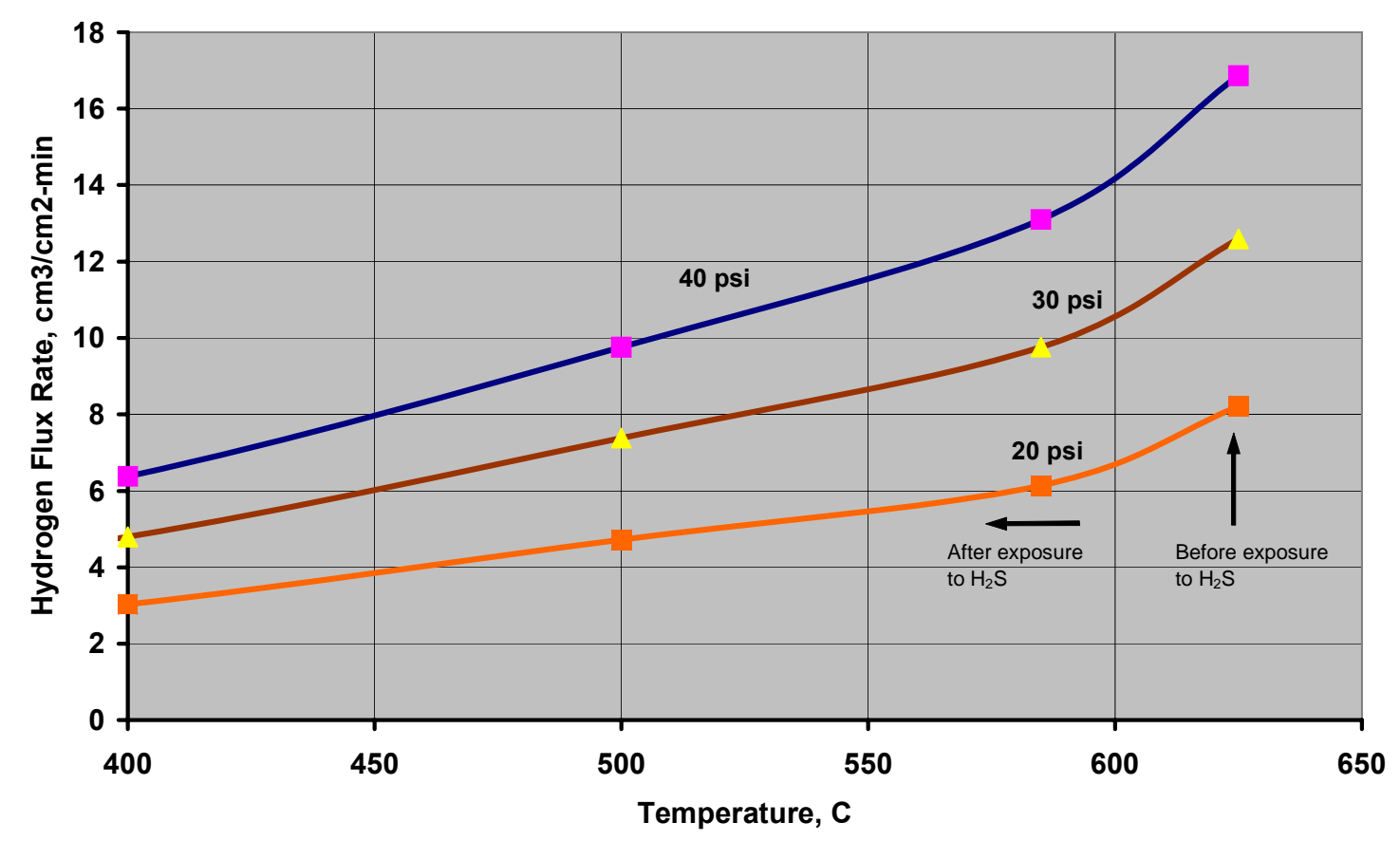

Figure 20. Hydrogen Flux for a Pd-Cu Alloy Composite Membrane

The tube was initially tested at $627^{\circ} \mathrm{C}(900 \mathrm{~K})$ to establish the maximum possible flux. Then, the tube was exposed to $\mathrm{H}_{2} \mathrm{~S}$ and tested at $400^{\circ} \mathrm{C}, 500^{\circ} \mathrm{C}$, and $580^{\circ} \mathrm{C}$. Extrapolating these results to $627^{\circ} \mathrm{C}$ shows that the flux was reduced by $\mathrm{H}_{2} \mathrm{~S}$ exposure, but that the reduction was less than $25 \%$. This reduction was less of an impact than would be expected for other Pd alloys. 


\section{Task 5 - Process Economics}

Cost and performance targets were established for the Pd-Ag and Pd-Cu membranes. Phase IIA featured consistent improvement in substrate and membrane manufacturing and performance and it was believed that improvements in Phase IIB would meet the DOE targets. Additional cost reduction appeared to be possible if larger membranes could be produced in larger quantities. This effort was undertaken in another program.

The cost of the Pd that was required for a unit producing $2000 \mathrm{scfh}$ of hydrogen was less than $\$ 2500$, assuming a Pd price of $\$ 300 / \mathrm{oz}$. Further improvements in membrane microstructure and performance would drive this down further. This shows that the Pd cost of the final hydrogen production system is likely to be less than $1 \%$ of the total unit cost. In other words, even though Pd is very expensive, the total cost of the Pd for a hydrogen production system is small because Pd can be deposited in very thin films and the hydrogen flux through thin films is high. Furthermore, the cost of the high-temperature syngas generating reactor is much higher than the lower temperature HTM unit. For example, for a Pd-Ag film of about $5 \mu \mathrm{m}$, the cost of the metal will be about $\$ 40 / \mathrm{ft}^{2}$, which is within the cost targets established by the process economic analysis.

\section{Task 6 - Program Management and Reporting}

General program management and reporting were done throughout the project period. The progress made in Phase IIA allowed the program to continue to the next phase.

\section{Conclusions}

Phase IIA of the Integrated Ceramic Membrane System for Hydrogen Production program began in 2003 and ended in 2004. Candidate substrate materials and alloys were identified and porous ceramic tubes were produced and coated with Pd. Most of the effort was focused on reducing the pore size in the substrate tubes while restricting ourselves to manufacturing processes that can be economically scaled up. The pore size consistently decreased to the point where effective membrane tubes could be produced. At the end of Phase IIA, the focus was on increasing the porosity of the substrate tube while continuing to decrease surface layer pore size and palladium alloy film thickness to increase hydrogen flux through the membrane and decrease the overall cost of hydrogen.

The results from these tests were used to update the technoeconomic analysis from Phase I to confirm that the sequential membrane reactor system can potentially be a low-cost hydrogen supply option when using an existing membrane on a larger scale.

The objectives of Phase IIA were met to a sufficient degree to proceed with the remainder of the program. Sufficient membrane performance had not been demonstrated in Phase IIA, but there was some progress made, going from nothing to Pd alloy tubes that could be tested. This led to Phase IIB reported below. 


\section{Phase IIB}

The tasks of Phase IIB were designed to build on the progress made in Phase IIA. Furthermore, another DOE program (DE-FC26-07NT43054) was awarded while Phase IIB was underway. Significant progress in membrane development made in that other program was used to benefit this program and greatly improved overall performance.

\section{Approach}

Phase IIB focused on developing a composite Pd membrane that could meet performance targets to enable an economical HTM reactor. The first task was to continue to develop the membrane by improving the substrate properties and coating procedures. Once the membrane was defined, tubes would be prepared and tested to demonstrate a potential process and the test results would be used to develop a model to design and size a reactor. Meanwhile, in a parallel effort, the cost of the HTM system would be compared to competitive processes and systems to ensure that it had the potential to be cost effective if performance targets were met.

\section{Task 1 - HTM Development}

There was significant progress made in HTM development toward the end of Phase IIA and beginning of Phase IIB. As shown in Figure 21, the flux of the membranes improved by a factor of three in less than a year. This was the first period of tremendous improvement and performance breakthroughs in the project. Improvements in the substrate enabled thinner coatings, and consequently, higher flux. Further improvements in substrate production, membrane coating, and composition control led to much higher fluxes at the end of the project.

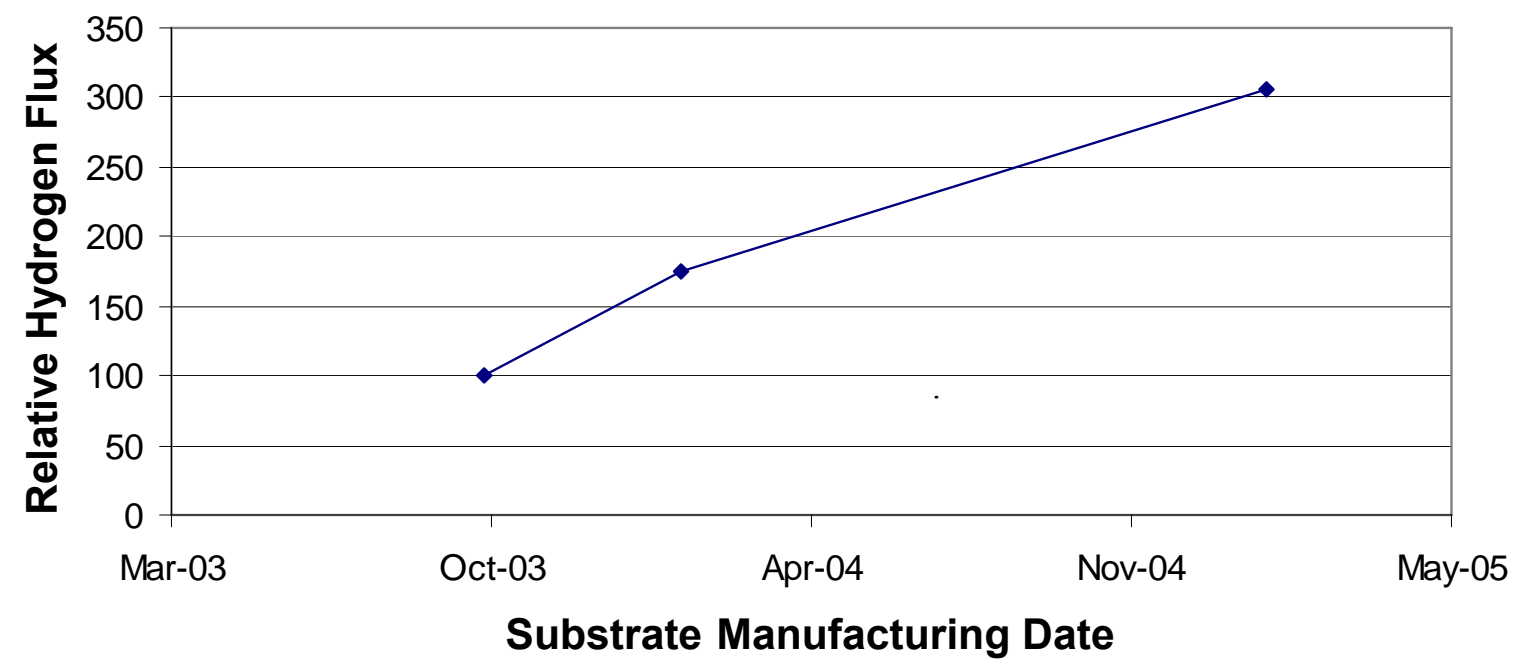

Figure 21. Hydrogen Flux Improvement 
Substrate pore size was decreased using new techniques to modify the surface pore structure. Substrate porosity increased because the smaller pores existed only on the surface. Figure 22 shows the pores of the substrate and a cross-section of the alloy film. The pores were significantly smaller at the interface with the membrane. This allows a thinner film to span the pores without producing any pinholes. Developing graded porosity in the substrate was a significant breakthrough and milestone in the progress from the beginning of the program to where we are today. The adhesion of the metal alloy to the substrate can also be seen in Figure 22 due to the degree of penetration of the metal into the substrate.

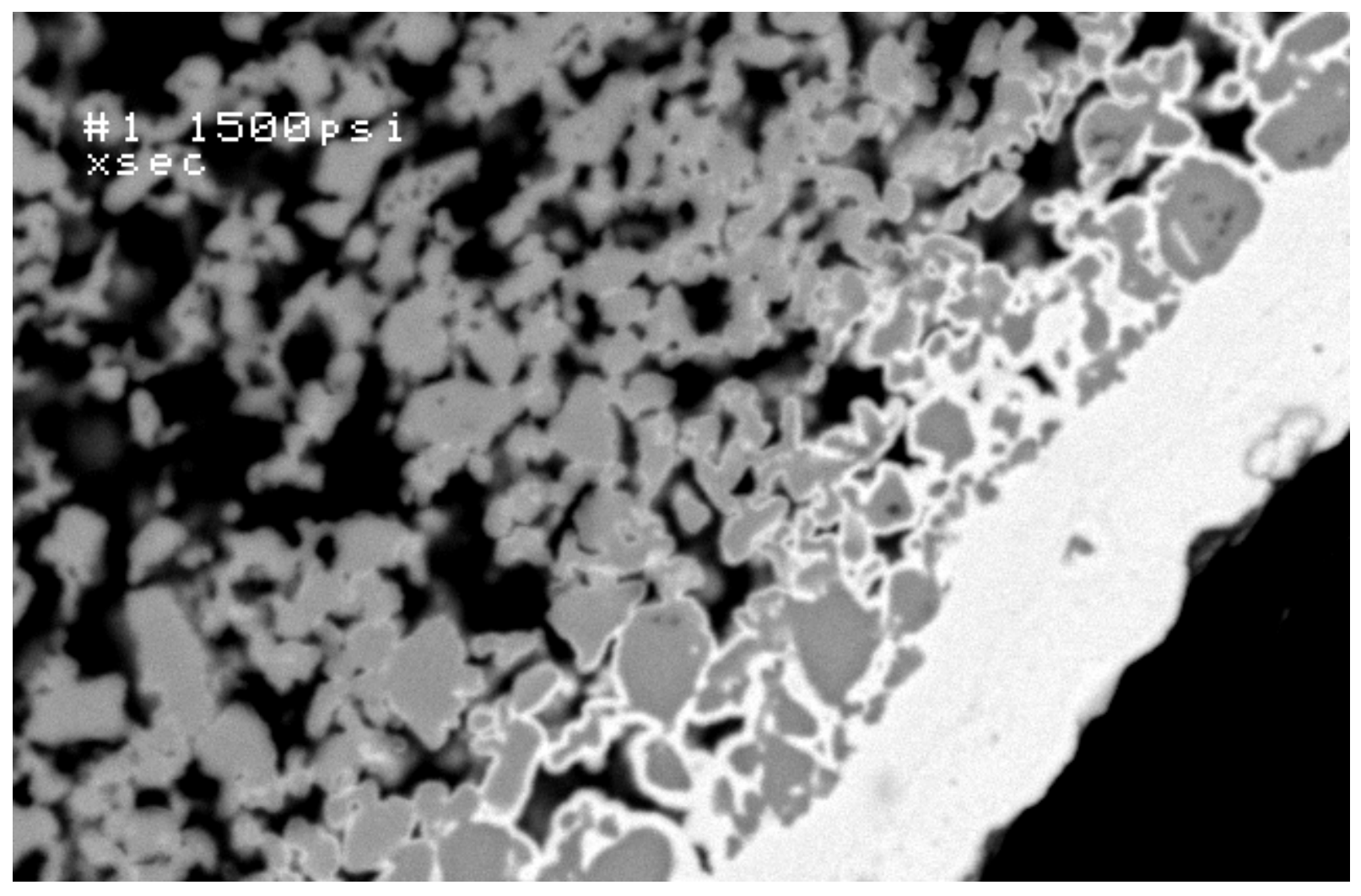

Figure 22. Cross-Section of Pd Alloy Membrane and Substrate 
The mixing of the Pd and Ag in the alloy after annealing was excellent. The electroless plating procedure used to deposit the alloy allows for a uniform composition in the film. Figure 23 shows a normal crosssection view of the membrane and substrate followed by elemental analysis. As can be seen in the figure, the Pd and Ag mix well and penetrate the modified $\mathrm{Zr}$ oxide substrate enough to adhere properly, but do not fill the pores.
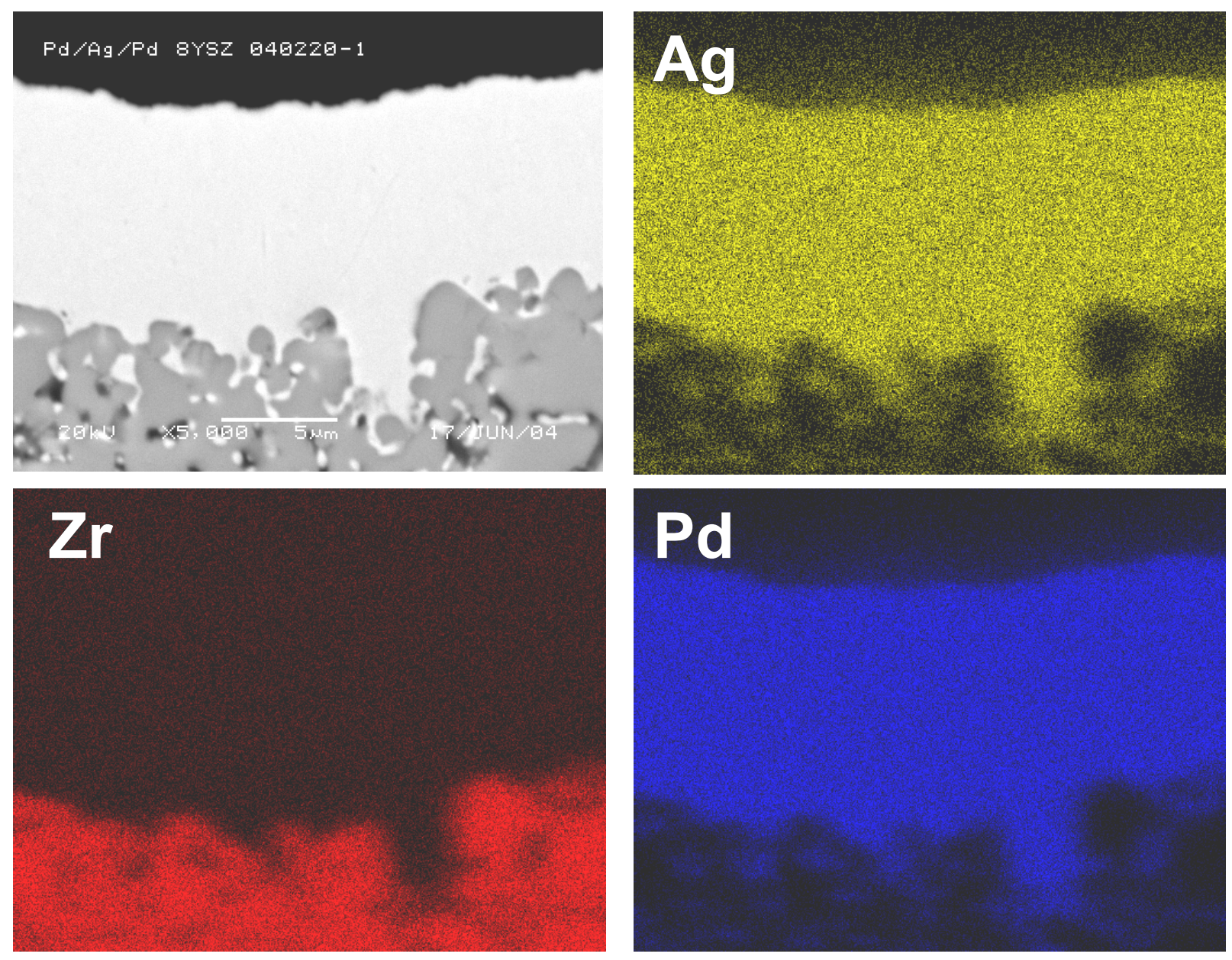

Figure 23. Elemental Analysis of the Membrane 
Another important goal of this task was to determine the effects of potential contaminants, such as $\mathrm{H}_{2} \mathrm{~S}$ and CO. Figure 24 shows the effect of $\mathrm{H}_{2} \mathrm{~S}$ on a Pd-Ag membrane. There is an initial loss of performance with $\mathrm{H}_{2} \mathrm{~S}$ introduction, but performance can be recovered after feeding hydrogen and performing a thermal cycle. Thermal cycling and pure hydrogen were not tried with the Pd-Cu membrane shown in Figure 19, but it recovered more than half of the lost flux simply by removing the $\mathrm{H}_{2} \mathrm{~S}$ from the feed stream. This is a larger flux reduction than the Pd-Cu tube shown in Figure 20. The Pd-Ag sample also passed the 500-hour goal for a life test and demonstrated three complete thermal cycles. Life and cycling were also important goals of Task 1.

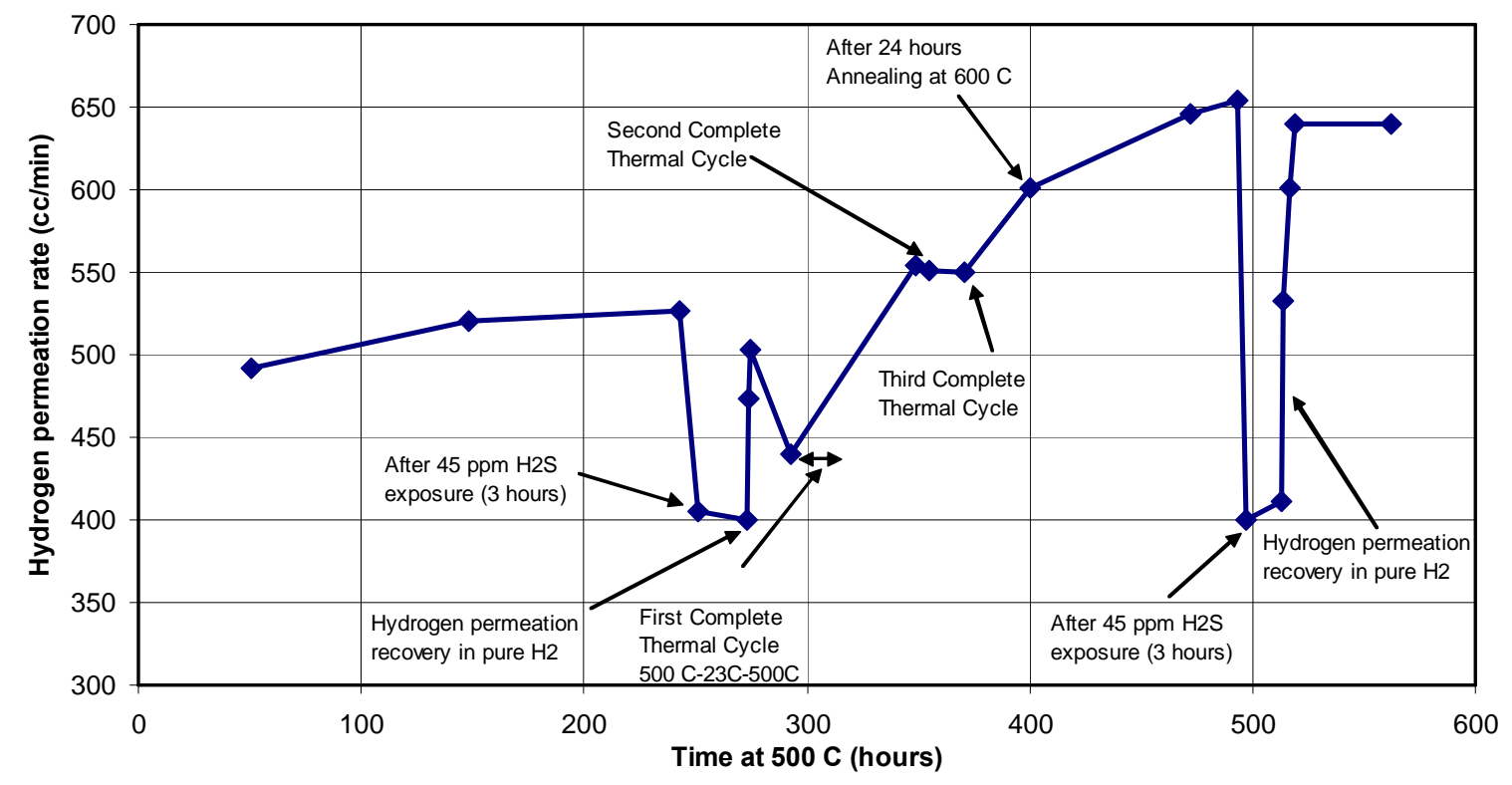

Figure 24. Effect of $\mathrm{H}_{2} \mathrm{~S}$ on Pd-Ag Membrane

\section{Improvements Made Outside the Integrated Ceramic Membrane Program}

At this time, it was apparent that further improvements in membrane production, including substrate and coating improvement, would be required for the membrane to achieve sufficient performance to be effective in a water gas shift environment. Praxair began working with Colorado School of Mines (CSM) on another DOE program, DE-FC26-07NT43054. This program developed membranes with significantly better performance than we were able to make previously. The Integrated Ceramic Membrane program was delayed until improved membranes became available. The rest of this report discusses membranes tested after many substantial improvements in substrate manufacturing and membrane coating. These include improved coating processes to eliminate impurities and make thinner films on substrates with reduced surface pore size and increased porosity in the bulk of the substrate. 


\section{Thermal Cycling Test for a Pd-Au Tube}

One of the major goals of the program was to demonstrate thermal cycling. This was a particular concern because the membrane and substrate are different materials with different thermal expansion characteristics. Early in this program, differential thermal expansion was an important issue and led to membrane stress and failure. Figure 25 shows the temperature profile of the thermal cycling test for a PdAu tube completed in the other program. CSM had previous test experience showing that an air treatment could improve flux, so after ten thermal cycles were completed, the tube was treated with air for a short time to try to increase the flux. As shown in Figure 26, the air treatment increased the hydrogen flux by about $30 \%$. The tube had a pinhole leak. After ten cycles, the tube was pressurized on the inside to find the leak. Ceramic glaze was used to cover the leak and the tube was heated to $600^{\circ} \mathrm{C}$ to solidify the glaze. As shown in Figure 26, this attempt was not entirely successful because the nitrogen flux increased slightly. This was mainly due to a seal leak, but the defect repair does not appear to have been very effective.

All thermal cycles were done in nitrogen. Nitrogen flux was measured at different pressures at $300^{\circ} \mathrm{C}$ to measure the leak. Hydrogen was introduced at $300^{\circ} \mathrm{C}$ and the hydrogen flux was measured at 10, 20, 40, and 70 psi. The hydrogen flux increased over the first 100 hours of testing and then remained stable over the rest of the first ten thermal cycles. The air treatment increased the flux and the flux increase remained over the next ten thermal cycles. The test was stopped after 20 thermal cycles and the tube was removed intact.

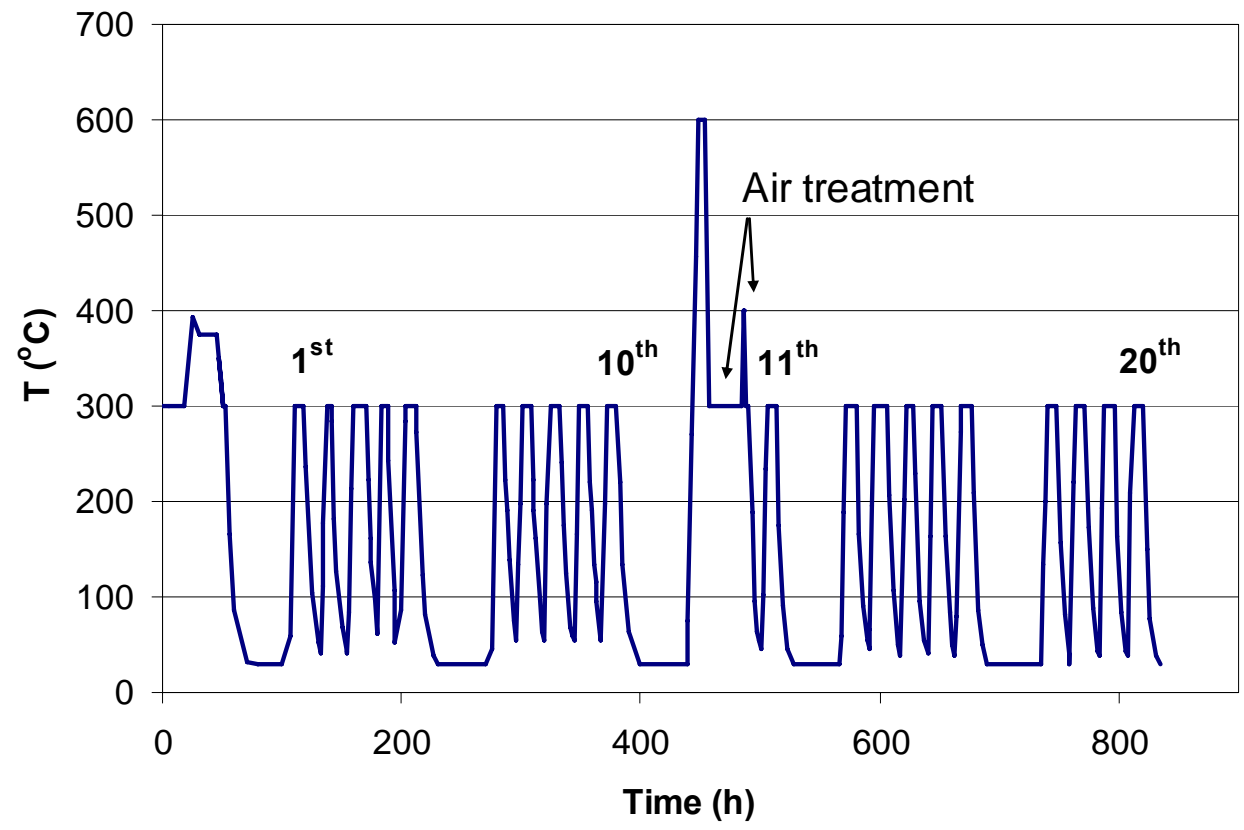

Figure 25. Thermal Cycling Test Temperature Profile 


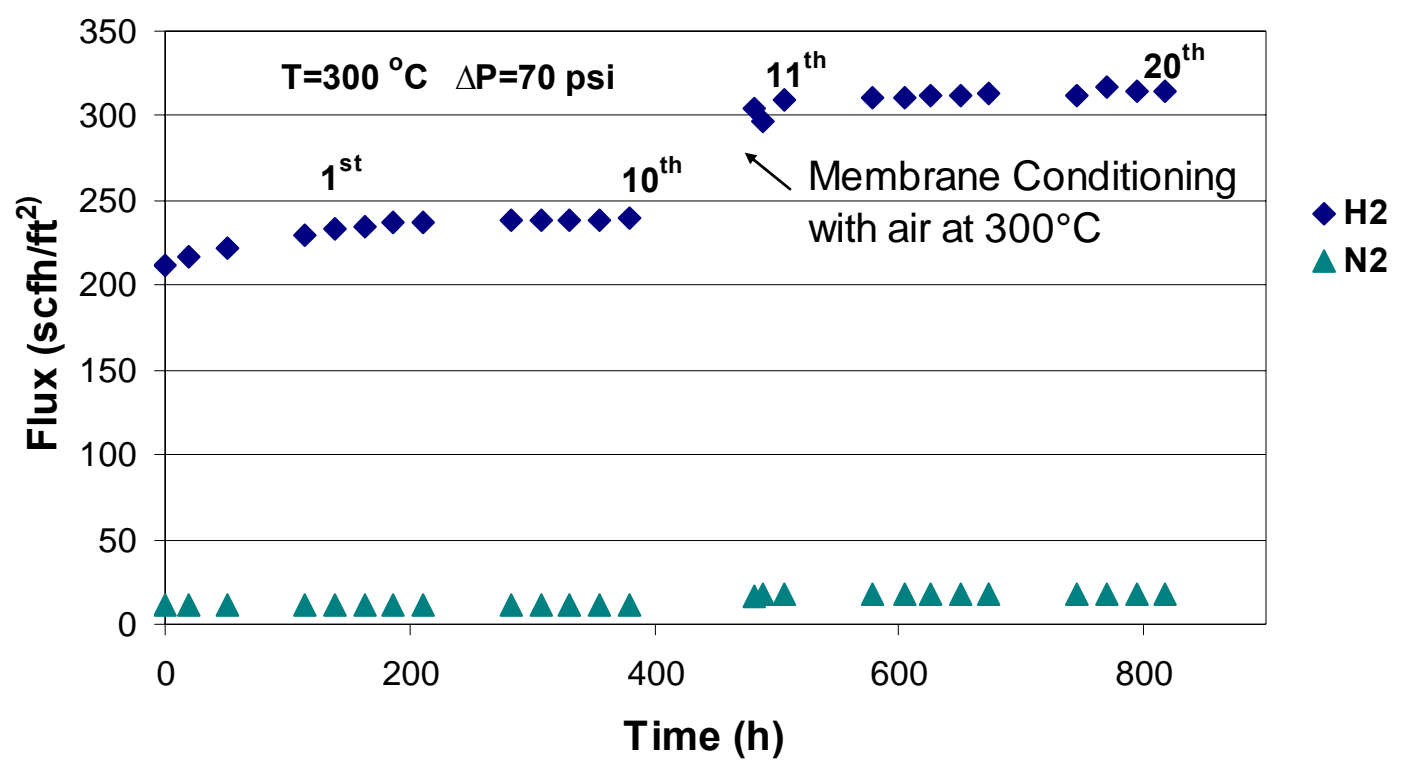

Figure 26. Thermal Cycling Test Flux for a Pd-Au Tube 


\section{$\mathrm{H}_{2}$ Flux Test Results for a Pd-Au Tube}

Another Pd-Au tube was used to measure the hydrogen flux at different temperatures and pressures. Figure 27 shows the test results. The membrane thickness was estimated to be about $6 \mu \mathrm{m}$. The tube was tested from $300-400^{\circ} \mathrm{C}$ initially. After those tests were complete, testing was repeated at $300^{\circ} \mathrm{C}$ with no significant change in performance. The temperature was then decreased to 275,250 , and $225^{\circ} \mathrm{C}$ to get results at lower temperatures. Notice that the flux was at least an order of magnitude higher than was achieved in Phase IIA as shown in Figures 18 and 20 because of the improvements made in the other program working with CSM.

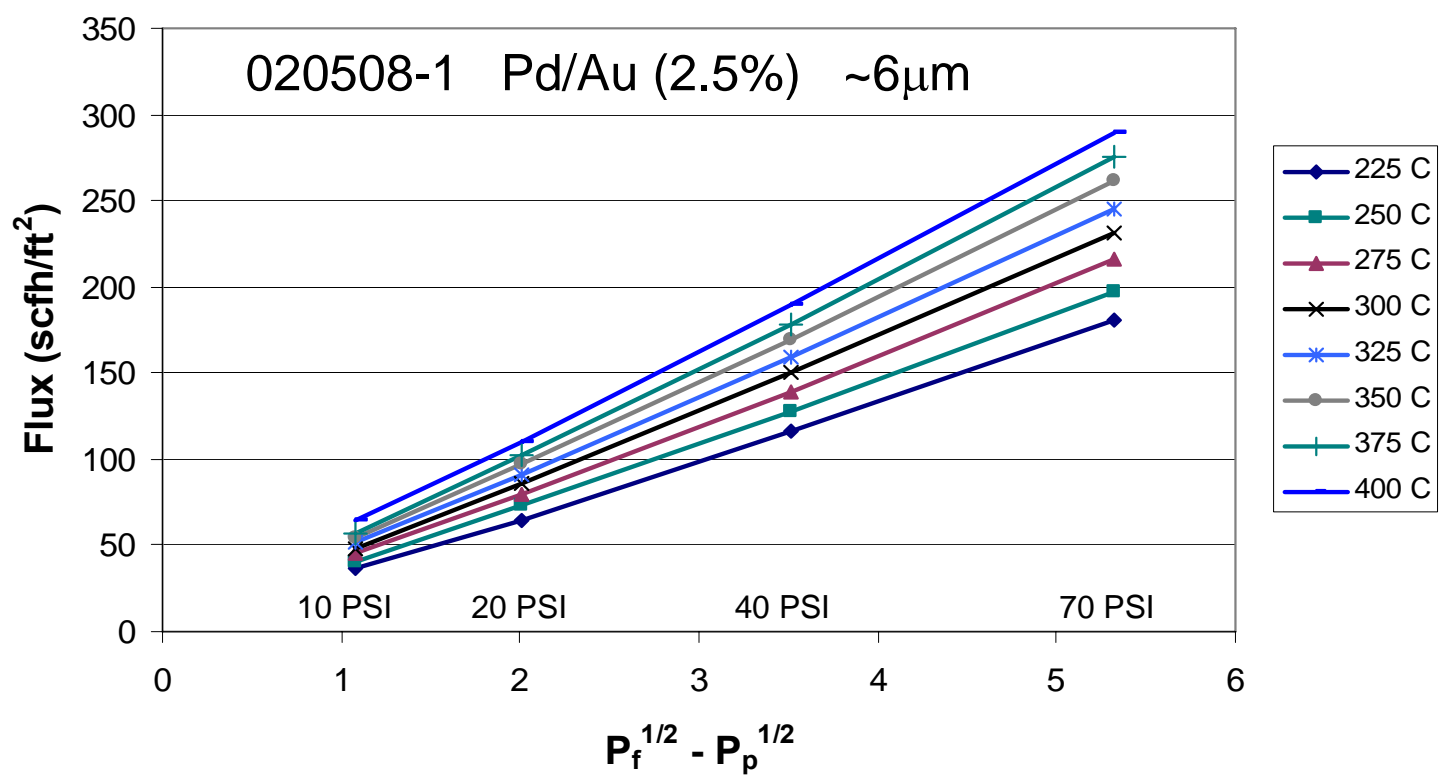

Figure 27. Flux Test Results for a Pd-Au Tube 
The membrane thickness of $6 \mu \mathrm{m}$ was estimated based on the coating process. Post mortem examination of the tube, as shown in Figure 28, showed that the membrane thickness was 5-7 $\mu \mathrm{m}$, in excellent agreement with the estimate.

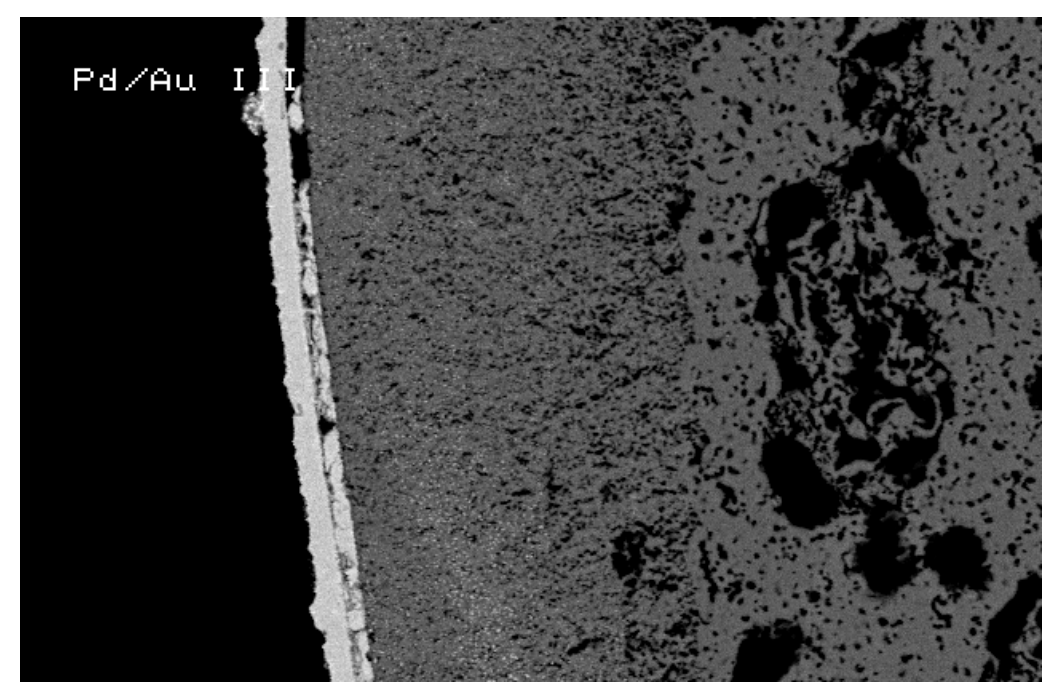

Figure 28. Pd-Au Membrane Structure

Figure 28 shows the large pores in the bulk of the substrate on the right side and the smaller pores in the asymmetric substrate structure closer to the coating. This enables excellent bulk flow through most of the substrate while providing small pores at the interface to enable coating a thin film. Figure 28 can also be compared to Figure 22, which represented a tremendous breakthrough made in Phase IIA. Figure 28 shows that the pores in the bulk of the substrate are larger and that the porosity is higher, reducing flow resistance. Furthermore, the surface pores are smaller, enabling thinner films to be deposited, further increasing flux. 


\section{Progress in Substrate Development}

Producing substrates with the proper pore size is essential to making a state-of-the-art membrane. Many of the substrates produced early in the program had a few pores that were too large, such as 061012-4, as shown in Figure 29. These pores made the substrate difficult or impossible to coat with a continuous alloy layer, so pinhole leaks formed in the membrane. The substrate manufacturing process was modified to reduce surface pore size as part of the program working with CSM. These process improvements led to 063008-4, as shown in Figure 29, which had the smallest average surface pore size and the smallest number of large pores of any of the substrates made to that point. These small pores enabled a very thin palladium alloy layer to produce a leak-free membrane. It was this progress in substrate development that enabled membranes that have a chance to be effective in a water-gas-shift membrane reactor to be produced.

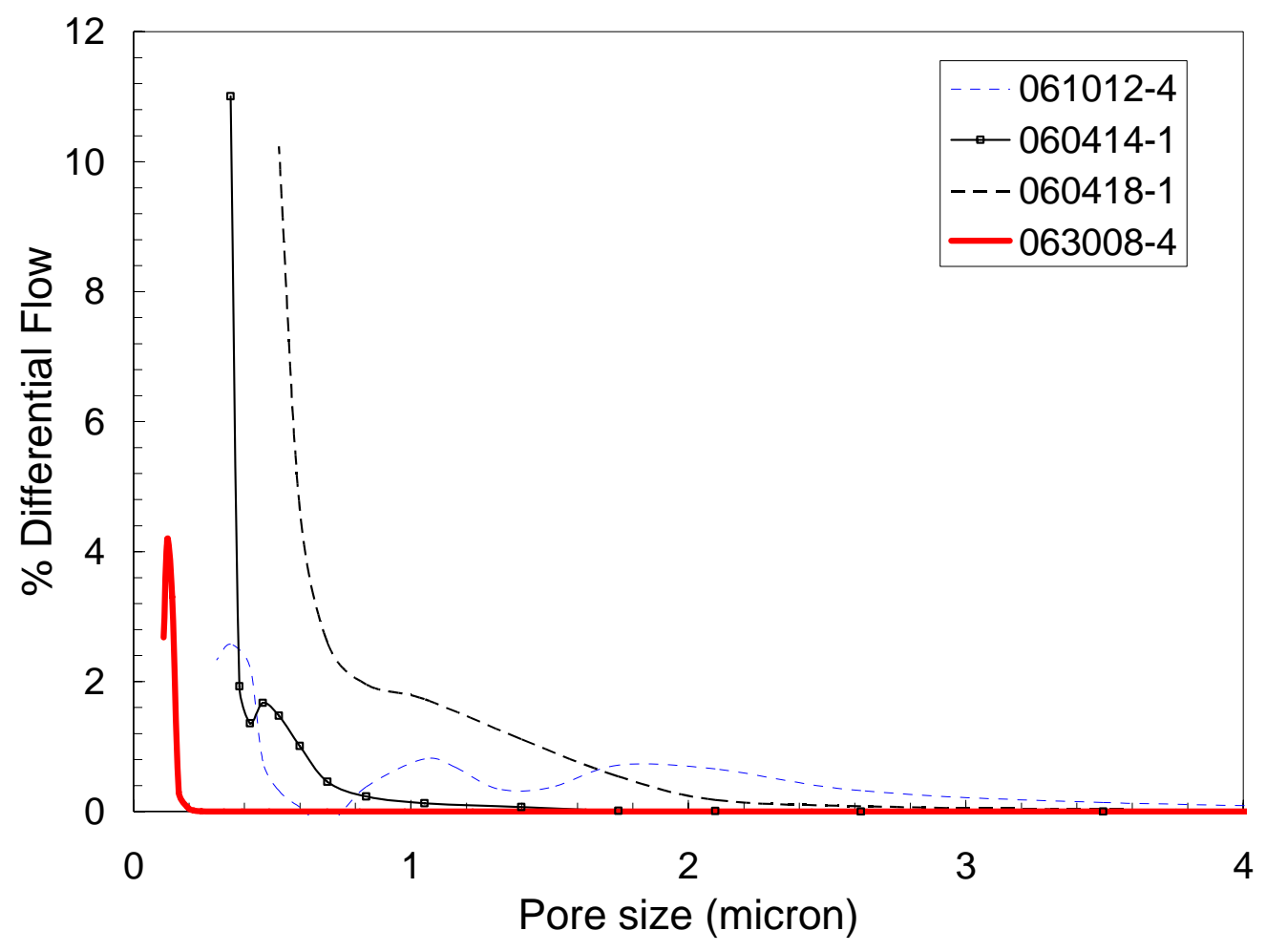

Figure 29. Surface Pore Size Data for Different Substrates 


\section{Task 2 - Process Development Integration of HTM with WGS}

For a membrane to work in an integrated WGS reactor, it must have the following capabilities:

- High flux to remove sufficient hydrogen to affect WGS equilibrium

- Resistance to contamination by other gas stream components, including CO

- Compatibility with WGS catalyst

Pd-Au membranes maintain high flux in gas mixtures and Pd-Ru membranes can be made with high flux. Pd-Ru has significantly higher tensile strength than most Pd alloys, which could lead to a more robust thin membrane. A Pd-Ru-Au tube, which might be able to provide the benefits of both alloying metals, was synthesized and tested. The flux in pure hydrogen was lower than the fluxes for either Pd-Au or $\mathrm{Pd}-\mathrm{Ru}$ binary alloys under the same conditions. However, the ternary composition has not been optimized, so it is likely that finding a better composition will increase the flux.

A Pd-Ru-Au tube was tested in hydrogen in another program. This same membrane was tested in mixed gas. Figure 30 shows the results of the pure gas and mixed gas tests at $400^{\circ} \mathrm{C}$. The gas mixture contained $3 \% \mathrm{CO}, 14 \% \mathrm{CO}_{2}, 56 \% \mathrm{H}_{2}$, and $27 \% \mathrm{H}_{2} \mathrm{O}$. As shown in Figure 30, the $\mathrm{H}_{2}$ flux in a mixed gas test was similar to the flux in the pure gas test at the same hydrogen partial pressure.

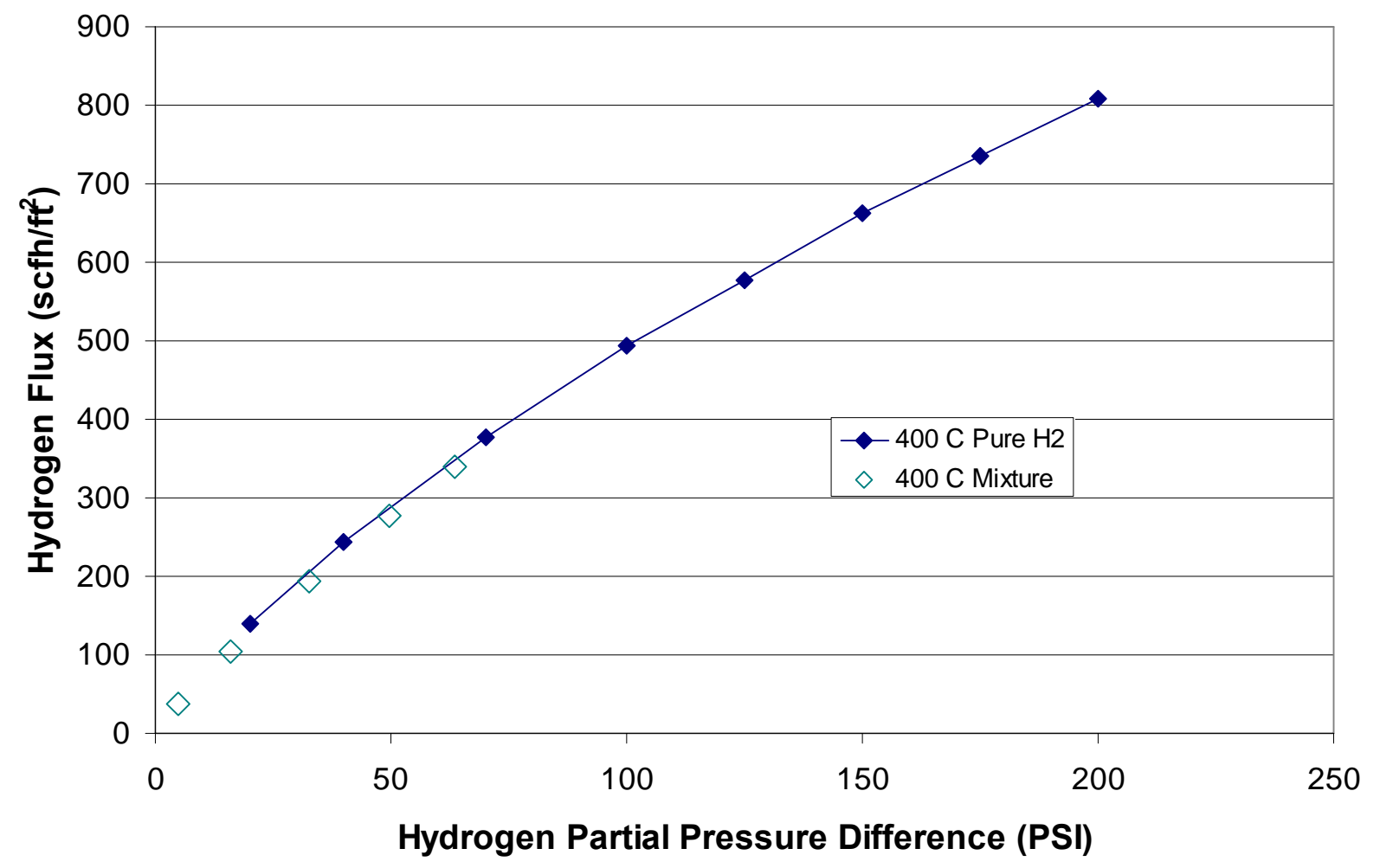

Figure 30. Mixed Gas Flux Results for Ternary Pd-Ru-Au Tube

This is an important result because it shows that the other components of the gas mixture do not have an impact on the membrane performance. Other tests using different membrane compositions have shown a 
decrease in flux when using a mixed gas, most likely because these other tests were done with higher hydrogen recovery, and consequently lower feed side hydrogen partial pressure at the outlet. Another possible reason is that membranes containing gold are less susceptible to flux reduction due to $\mathrm{CO}$, probably because gold makes it more difficult for $\mathrm{CO}$ to adsorb on and block the surface. This is a particularly important result when considering processes such as hydrogen production from syngas, where the feed is likely to contain $\mathrm{CO}, \mathrm{CO}_{2}$, and $\mathrm{H}_{2} \mathrm{O}$ in significant quantities. Obviously, as hydrogen recovery increases, the partial pressure of hydrogen on the retentate side of the membrane decreases and flux decreases due to dilution. This factor can be calculated and membrane reactors must be sized properly to account for this effect. Furthermore, this result could also lead one to select a membrane composition that is less susceptible to flux reduction, such as compositions containing gold.

The same ternary $\mathrm{Pd}-\mathrm{Ru}-\mathrm{Au}$ membrane prepared using electroless plating was tested in hydrogen at $300-400^{\circ} \mathrm{C}$ and $20-200 \mathrm{psid}$, as shown in Figure 31. The maximum flux was $809 \mathrm{scfh} / \mathrm{ft}^{2}$ at $400^{\circ} \mathrm{C}$ and $200 \mathrm{psid}$. The flux was fitted using a modified Sievert's law and showed a pressure dependence of 0.62 and an activation energy of $14.4 \mathrm{~kJ} / \mathrm{mol}$.

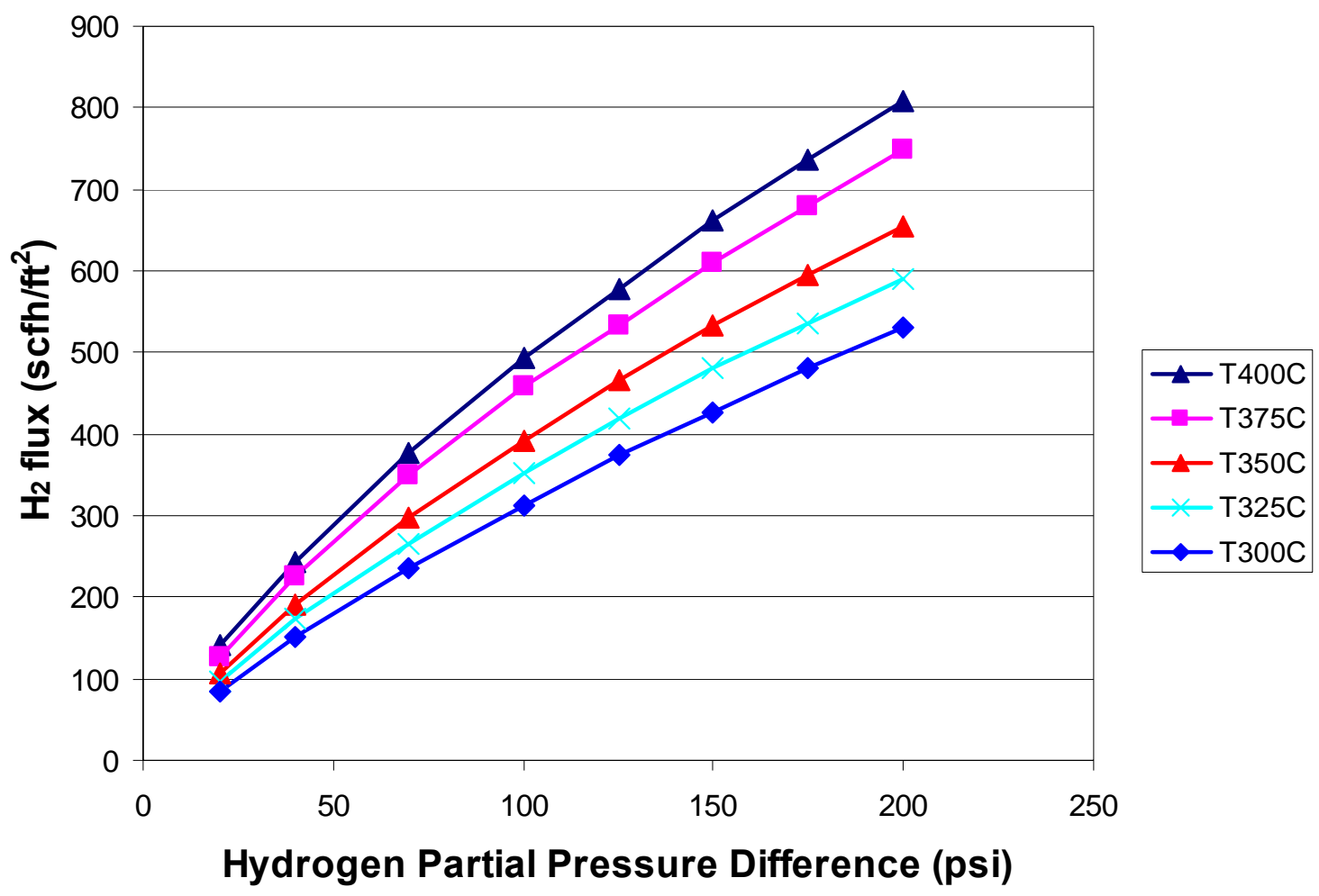

Figure 31. Hydrogen Flux for Ternary Pd-Ru-Au Tube 
The same membrane was then used for the water gas shift reaction with a commercial catalyst. The reaction was carried out at different pressures (20-125 psi) and flow rates (1-4 lpm) at $400^{\circ} \mathrm{C}$. The feed stream composition was $10 \% \mathrm{CO}, 36 \% \mathrm{H}_{2} \mathrm{O}, 49 \% \mathrm{H}_{2}$, and $5 \% \mathrm{CO}_{2} \cdot \mathrm{H}_{2}$ was not introduced into the reactor until the reactor temperature reached $300^{\circ} \mathrm{C}$ to avoid possibly damaging the membrane. Results are shown in Figures 32 and 33.

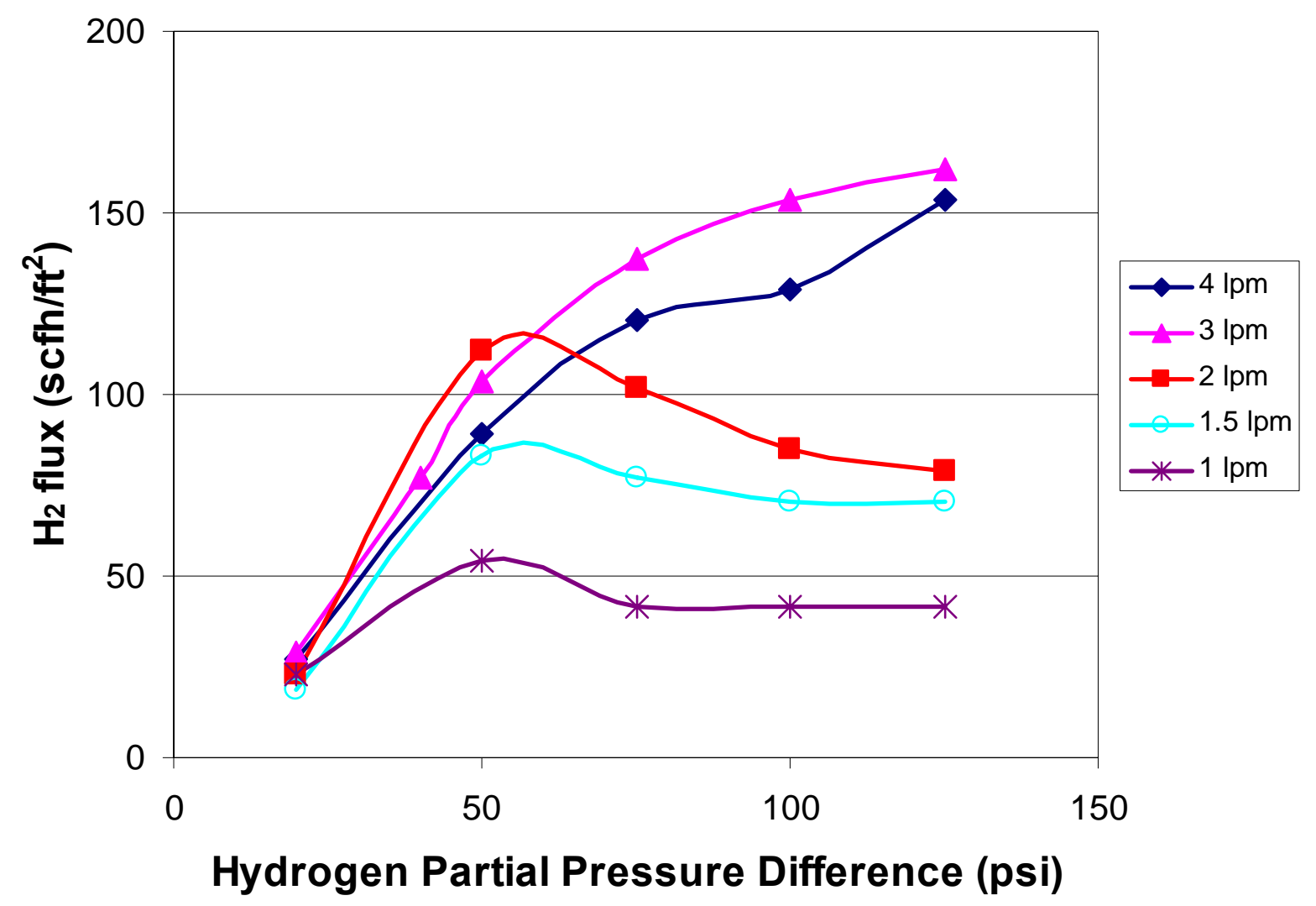

Figure 32. The Effect of Pressure on Hydrogen Flux

The large amount of methane produced at high pressure and low gas hourly space velocity (longer residence time and lower flow rate) indicates that the catalyst was damaged before or during testing. Methane can be produced through two possible methanation reactions,

$$
\begin{aligned}
& \mathrm{CO}+3 \mathrm{H}_{2} \leftrightarrow \mathrm{CH}_{4}+\mathrm{H}_{2} \mathrm{O}, \text { and } \\
& \mathrm{CO}_{2}+4 \mathrm{H}_{2} \leftrightarrow \mathrm{CH}_{4}+2 \mathrm{H}_{2} \mathrm{O} .
\end{aligned}
$$

Commercial water gas shift catalysts are made to avoid methanation, but are not expected to operate in the hydrogen-deficient environments that can result from hydrogen removal due to the membrane. At higher pressures, hydrogen flux decreased with increasing pressure and increasing residence time because hydrogen was consumed to produce methane via methanation reactions. Eliminating these methanation reactions is essential to developing an effective hydrogen production process. When methanation is eliminated, it is expected that flux will monotonically increase with increasing pressure at sufficiently high flow rates to maintain a reasonable hydrogen concentration on the retentate side of the membrane. The local maxima in Figure 32 are because initially, flux increased with increasing pressure and residence 
time, as expected, but hydrogen was consumed by methanation at higher pressures and longer residence times, corresponding to higher flow rates.

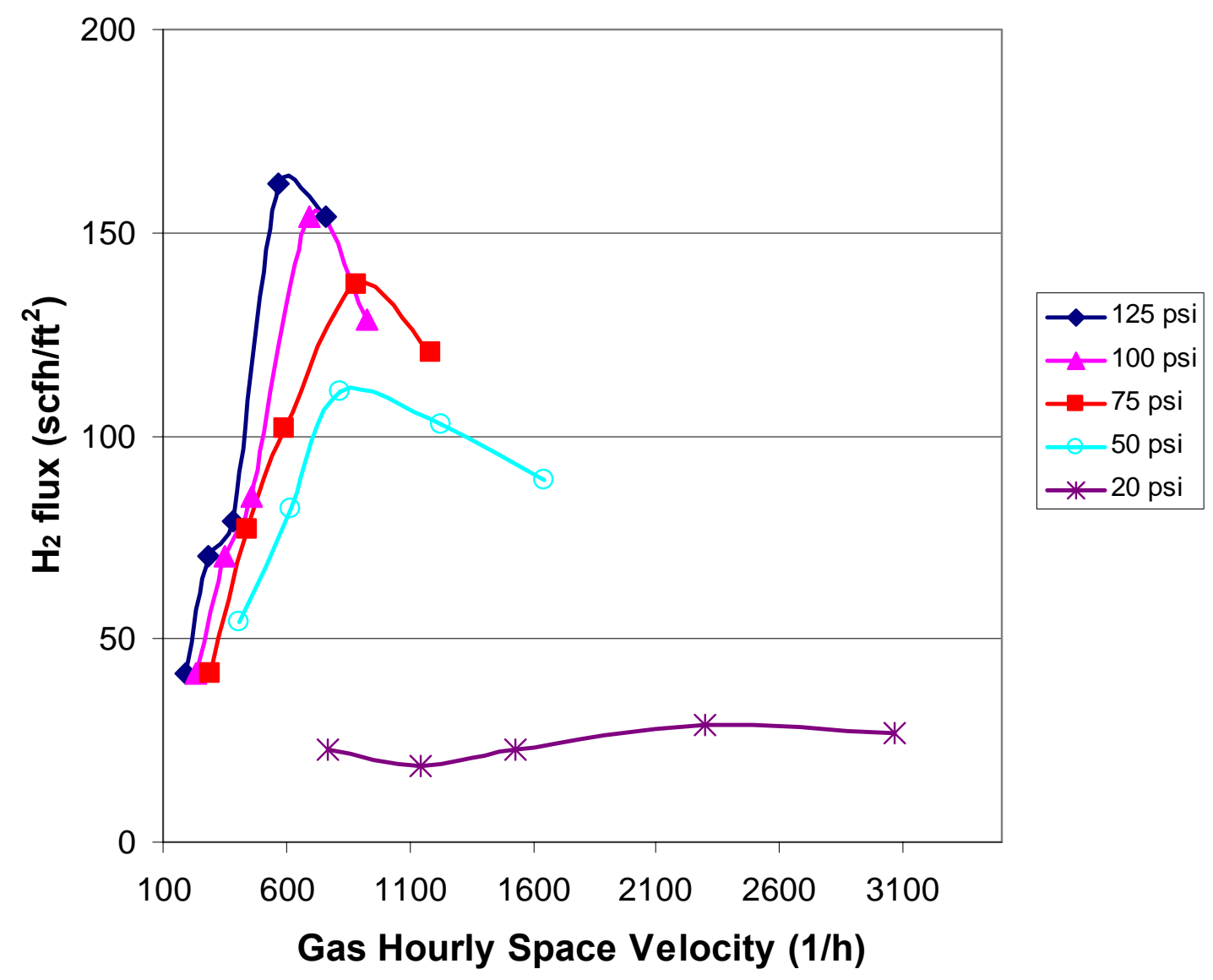

Figure 33. The Effect of Gas Hourly Space Velocity on Hydrogen Flux

Figure 33 presents the same data as Figure 32, but shows the effect of flow rate at different pressures. Lower flow rates would be expected to produce higher hydrogen flux because of longer residence time in proximity to the membrane. This was not the case for this test because longer residence times led to more methanation, which consumed hydrogen. 


\section{Pd-Au Tube}

A Pd-Au membrane was prepared and tested for $\mathrm{H}_{2}$ flux at $400^{\circ} \mathrm{C}$ and a pressure range of $20-200$ psi as shown in Figure 34, to establish its baseline performance. Pd-Au was selected for this test as a comparison to the tri-component alloy of the other tests because Pd-Au has shown excellent performance in gas mixtures containing $\mathrm{CO}$. The temperature of $400^{\circ} \mathrm{C}$ was selected because that is a reasonable temperature for a high-temperature water gas shift reactor. The $\mathrm{H}_{2}$ flux was $384 \mathrm{scfh} / \mathrm{ft}^{2}$ and the $\mathrm{H}_{2} / \mathrm{N}_{2}$ selectivity was 495 at 200 psi. An air treatment at $400^{\circ} \mathrm{C}$ increased $\mathrm{H}_{2}$ flux slightly.

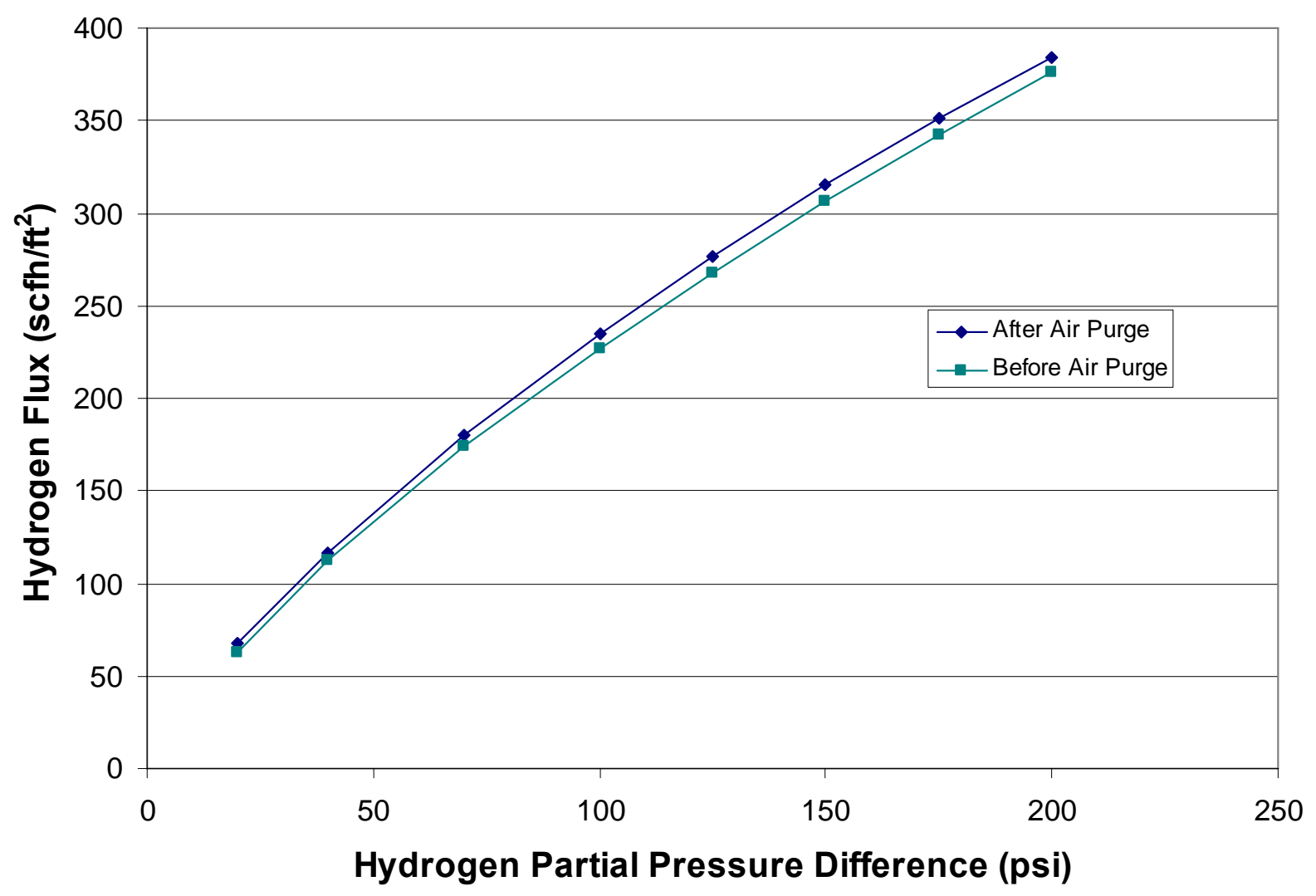

Figure 34. Flux Test Results for Binary Pd-Au Tube at $400^{\circ} \mathrm{C}$ 
This membrane was then used for the water gas shift reaction with a commercial catalyst. The reaction was carried out at different pressures $(20-125 \mathrm{psi})$ and flow rates $(4-5 \mathrm{lpm})$ at $400^{\circ} \mathrm{C}$. The feed stream composition was $10 \% \mathrm{CO}, 36 \% \mathrm{H}_{2} \mathrm{O}, 49 \% \mathrm{H}_{2}$, and $5 \% \mathrm{CO}_{2}$.

The amount of net hydrogen generated in the permeate and retentate streams was measured at different pressures. The size of our laboratory test unit is limited, but a reactor could be designed at any size, so much of the hydrogen remaining on the retentate size could be recovered if the membrane being tested were larger. Results of the test are shown in Figure 35.

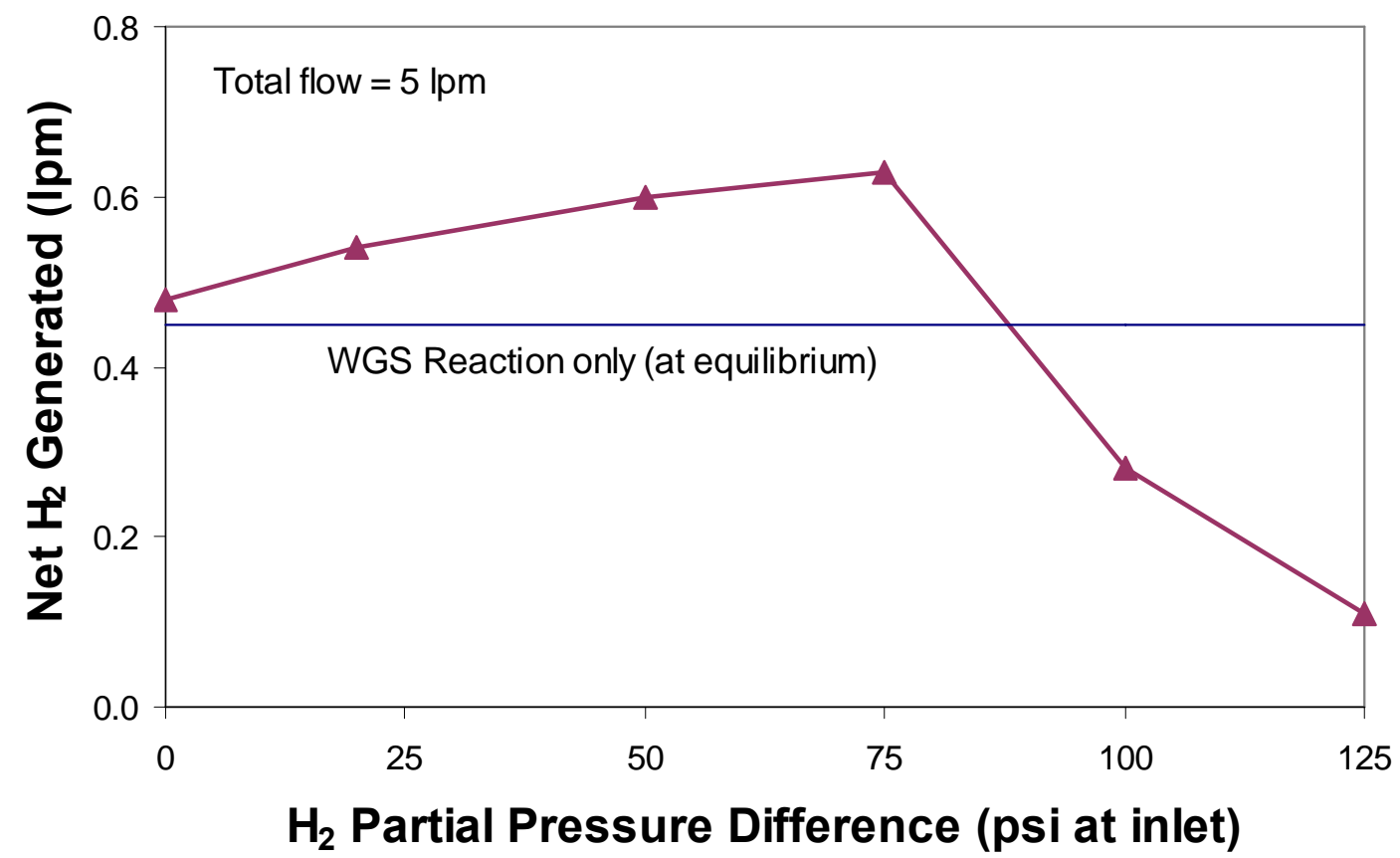

Figure 35. Hydrogen Generation with a Low $\mathrm{CO}_{2} / \mathrm{CO}$ Ratio of 0.5

As expected, the amount of hydrogen on the permeate side increased with pressure. This is because flux increases with pressure. The hydrogen on the retentate side decreased with pressure because of the amount of hydrogen lost to the permeate side. The increase in total hydrogen generated is because of the water gas shift reaction and the shift in equilibrium due to hydrogen removal, as expected, up to 75 psi. At pressures up to $75 \mathrm{psi}$, no methane was detected on the retentate side. However, at higher pressures, methane was detected in sufficient quantities to not only reverse the expected trend of increasing hydrogen with increasing pressure, but actually led to less hydrogen in the system than would be expected by equilibrium conversion without methanation and without a membrane.

Up to $75 \mathrm{psi}$, the area between the results shown and the equilibrium line represents the enhanced hydrogen production observed because of the membrane. However, at higher pressures, methanation became significant and consumed a substantial amount of hydrogen. The product from a steam methane reformer contains some methane that does not convert in the reactor. This methane in the product stream would be expected to reduce the equilibrium driving force for methanation and could reduce the impact of the observed methanation in these tests.

An additional test was done with more $\mathrm{CO}_{2}$ to reduce the effect of methanation. 


\section{HTM/WGS with a High $\mathrm{CO}_{2} / \mathrm{CO}$ Ratio of 1}

To see if a more oxidizing condition can avoid methanation, a feed gas with a high $\mathrm{CO}_{2} / \mathrm{CO}$ ratio of 1 $\left(45 \% \mathrm{H}_{2}, 39 \% \mathrm{H}_{2} \mathrm{O}, 8 \% \mathrm{CO}\right.$, and $\left.8 \% \mathrm{CO}_{2}\right)$ was tested at the same conditions. For all pressures tested, no methane was observed indicating the more oxidizing condition reduced methanation.

Test results of net $\mathrm{H}_{2}$ generated, defined as the difference between hydrogen produced and fed, are shown in Figure 36. For all pressures tested, the net $\mathrm{H}_{2}$ generated was higher than one obtainable with a water gas shift reaction at equilibrium because of the shift of equilibrium by continuous removal of hydrogen in the permeate side. By combining the membrane with a water gas shift reaction in a single unit, a significant enhancement in hydrogen production was observed (40-60\%). The enhancement increased with pressure up to $75 \mathrm{psi}$ and declined slightly at high pressures.

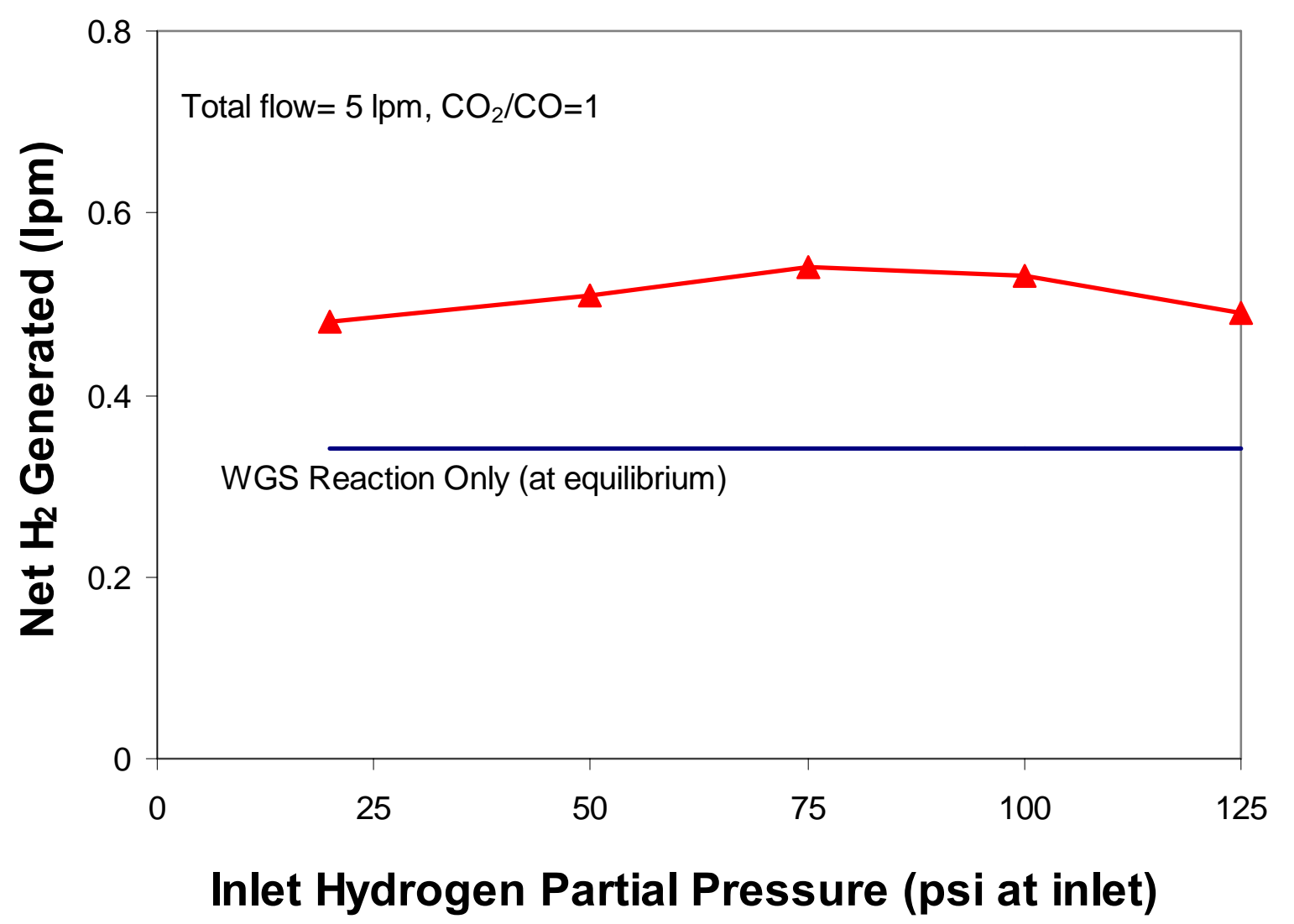

Figure 36. Hydrogen Generation with a High $\mathrm{CO}_{2} / \mathrm{CO}$ Ratio of 1 
The $\mathrm{H}_{2}$ flux test results of the Pd-Au membrane in a pure gas and a water gas shift environment are shown in Figure 37. At lower pressures, the $\mathrm{H}_{2}$ flux in the reaction condition was similar to the flux in the pure gas condition at the same hydrogen partial pressure. At higher pressures, the flux was lower, especially for the case where the $\mathrm{CO}_{2} / \mathrm{CO}$ ratio was 0.5 , which can be due to a significant consumption of hydrogen for methanation at high pressures. The deviation at the higher $\mathrm{CO}_{2} / \mathrm{CO}$ ratio of 1.0 , and part of the deviation at the lower ratio, is due to dilution. At a higher hydrogen flux, enough hydrogen is removed that the hydrogen partial pressure in the reaction mixture is sufficiently reduced that it affects the retentate hydrogen partial pressure, reducing driving force and flux.

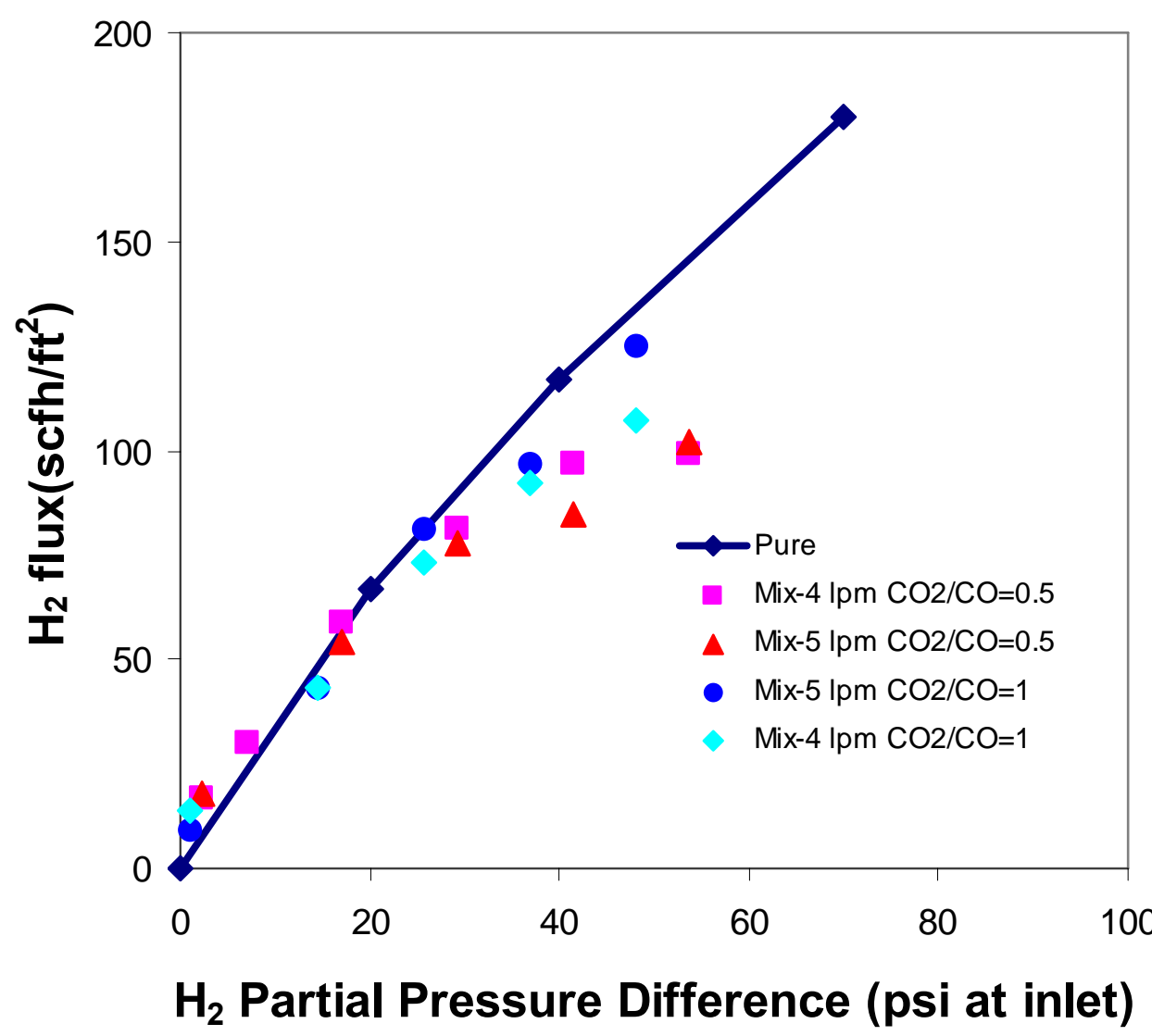

Figure 37. Flux Results for Pd-Au membrane 


\section{Task 3 - Develop Conceptual Design for the ICMS Membrane Modeling Results Without Methanation}

A model was developed to predict reactor performance. The base case was a conventional steam methane reformer, water gas shift reactor, and pressure swing adsorption unit producing $2000 \mathrm{scfh}$ of hydrogen. The membrane case used the same syngas inlet flow and composition as the conventional shift reactor. Figure 38 shows the modeling results assuming that a catalyst that does not promote methanation can be identified or developed.

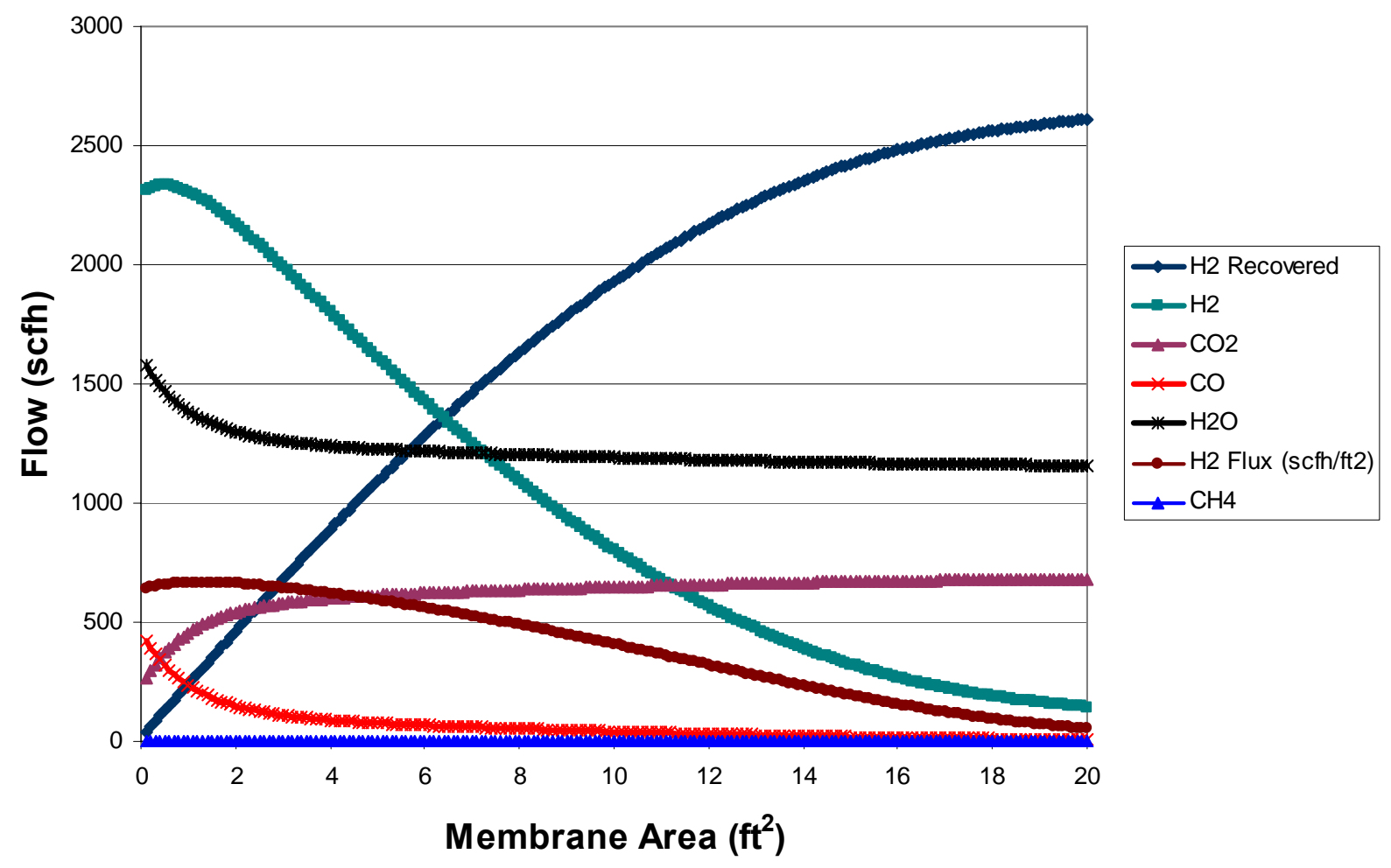

Figure 38. Modeling Results for a Case Without Methanation

When there is no methanation, a membrane reactor with a membrane area of $10.5 \mathrm{ft}^{2}$ will produce as much hydrogen as the conventional system. Doubling the membrane area under the same conditions results in a $30 \%$ increase in hydrogen production. As expected, each incremental square foot of membrane produces less hydrogen. This means that the final membrane area selected will result from a trade off of more hydrogen produced, but at steadily decreasing marginal productivity.

The membrane simulation can also examine the effects of co-current and countercurrent sweep streams. Purge streams allow the hydrogen partial pressure on the permeate side to be very low, but introduce the additional cost and complication of further separation because the hydrogen must be separated from the purge stream, particularly in the case where the hydrogen product is expected to be used for fuel cells, which have very stringent hydrogen purity requirements. This is another important consideration when doing economic analysis. The cases reported here do not include the effects of a sweep stream. 


\section{Membrane Modeling Results With Methanation}

When methanation does occur, the hydrogen yield decreases. Figure 39 shows the effect of producing $5 \%$ methane in the retentate outlet stream. Under the same conditions, $11.3 \mathrm{ft}^{2}$ of membrane area is required to produce $2000 \mathrm{scfh}$ of hydrogen. This represents a $7.6 \%$ increase in membrane area over the case where no methane was formed shown in Figure 38. Furthermore, the maximum amount of hydrogen that can be produced also decreased significantly from about $2600 \mathrm{scfh}$ to about $2400 \mathrm{scfh}$.

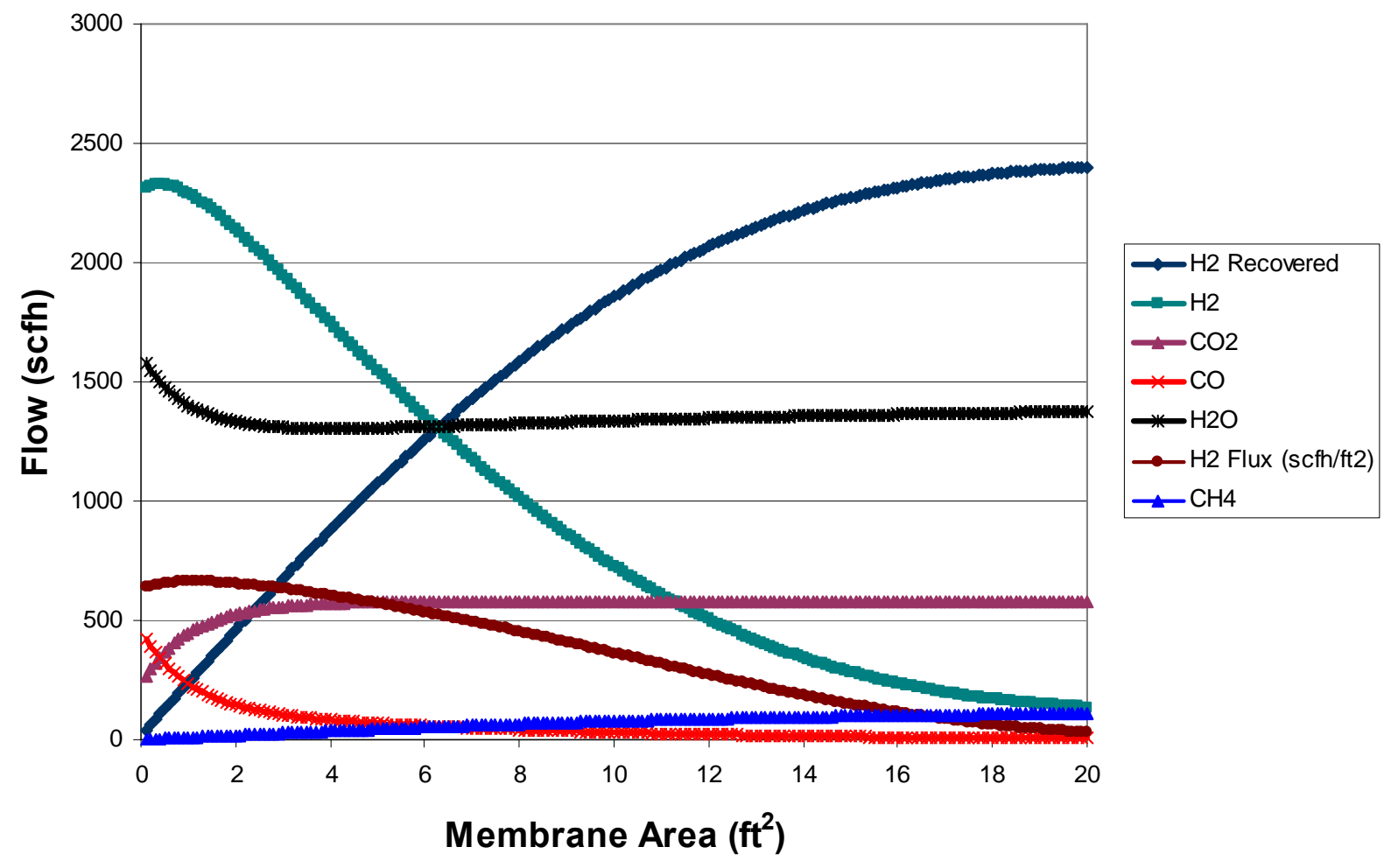

Figure 39. Modeling Results for a Case With 5\% Methane in the Retentate

Clearly, eliminating methanation is important to the performance of the reactor for both conventional and membrane reactors. It is also apparent that there are conditions under which the membrane reactor can produce more hydrogen than the conventional system. Identifying these conditions and ensuring that the membrane and shift reactor can operate under them will be very important. Using the current catalyst, lower pressure reduces the impact of methanation, but creates many other problems, such as the possible need for increased hydrogen product compression or increased membrane area due to reduced driving force. It is likely that a better catalyst will need to be identified or developed that can operate at higher pressure without consuming hydrogen to form methane for the process to realize its full potential. 
One important aspect of using a hydrogen transport membrane in a water gas shift reactor is that the operating temperature can be increased without sacrificing hydrogen production. This allows for a smaller membrane, less catalyst, and a smaller, more compact and presumably less expensive reactor. This is particularly important at the small scale of an onsite hydrogen production unit, such as might be implemented at a fueling station in the future. Figure 40 shows the results of modeling comparing a standard case with a shift reactor and PSA, assuming 75\% recovery in the PSA, with membrane reactors having 5 and $10 \mathrm{ft}^{2}$ of membrane area respectively. Each case shown in Figure 40 is at a pressure of 300 psig on the feed side.

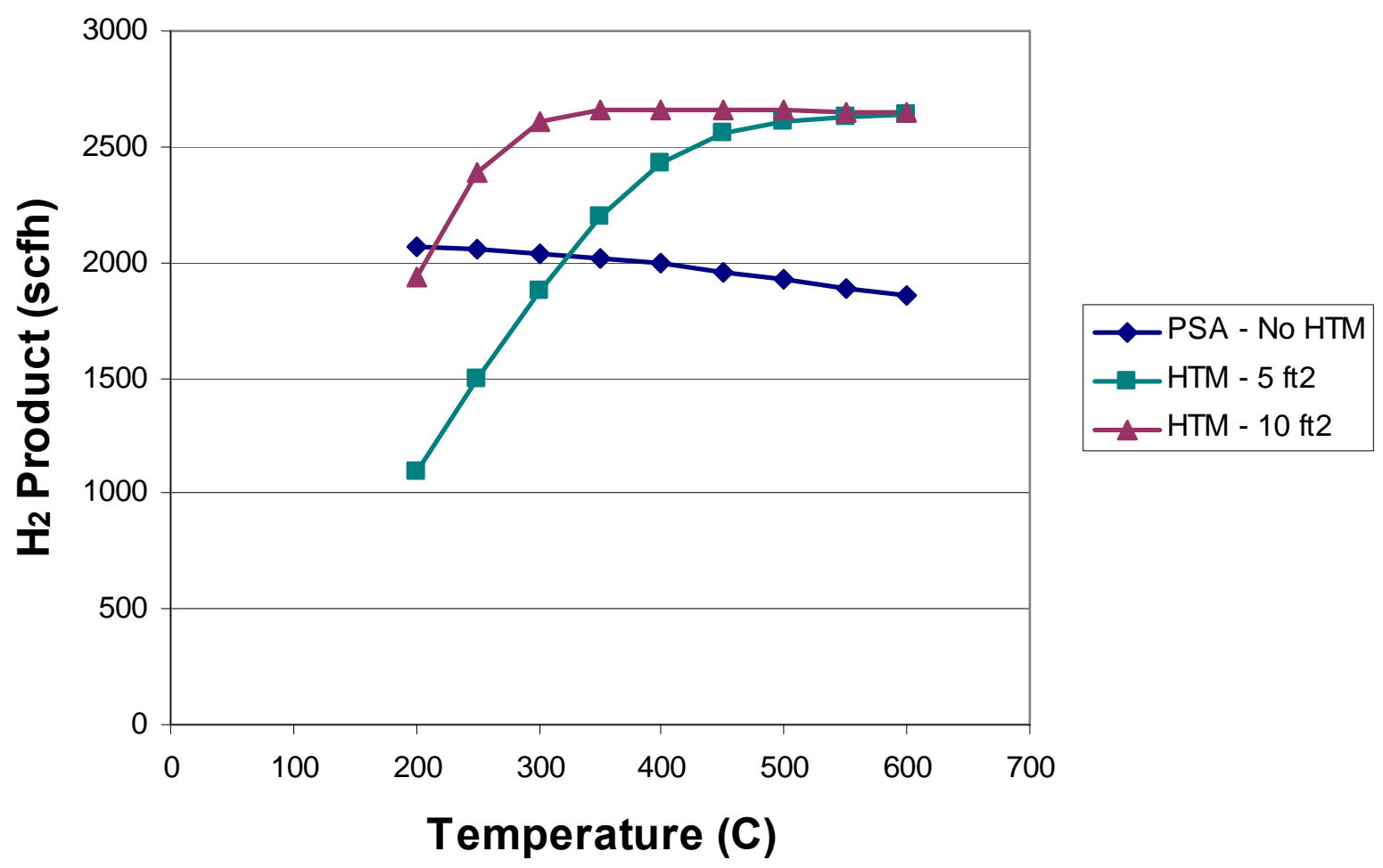

Figure 40. Modeling Results Showing the Effect of Temperature

At low temperatures the PSA system outperforms the membrane. This is because the membrane flux is low at lower temperatures. The yield from the PSA process decreases as temperature increases due to an equilibrium shift away from hydrogen production as temperature increases. This does not limit the membrane case because hydrogen removal shifts the equilibrium back towards hydrogen production instead of consumption. At higher temperatures, the flux is so high that the additional $5 \mathrm{ft}^{2}$ of membrane area does very little for increasing hydrogen production. The model shows that the area can be optimized based on flux for a given temperature so that additional area is not wasted. Ultimately, the reactor will be sized based on a tradeoff of increased hydrogen production for a marginal increase in membrane area being justified based on the cost and benefit of the additional area. Operating the membrane reactor at higher temperature than a conventional water gas shift reactor provides an opportunity to make the reactor smaller and potentially provides a significant capital cost savings compared to a shift reactor/PSA combination. 
The effect of feed pressure was also studied using the model. Figure 41 shows the results of modeling comparing membrane reactors having 5 and $10 \mathrm{ft}^{2}$ of membrane area respectively. Each case shown in Figure 41 is at a temperature of $400^{\circ} \mathrm{C}$ and assumes that there is no methanation.

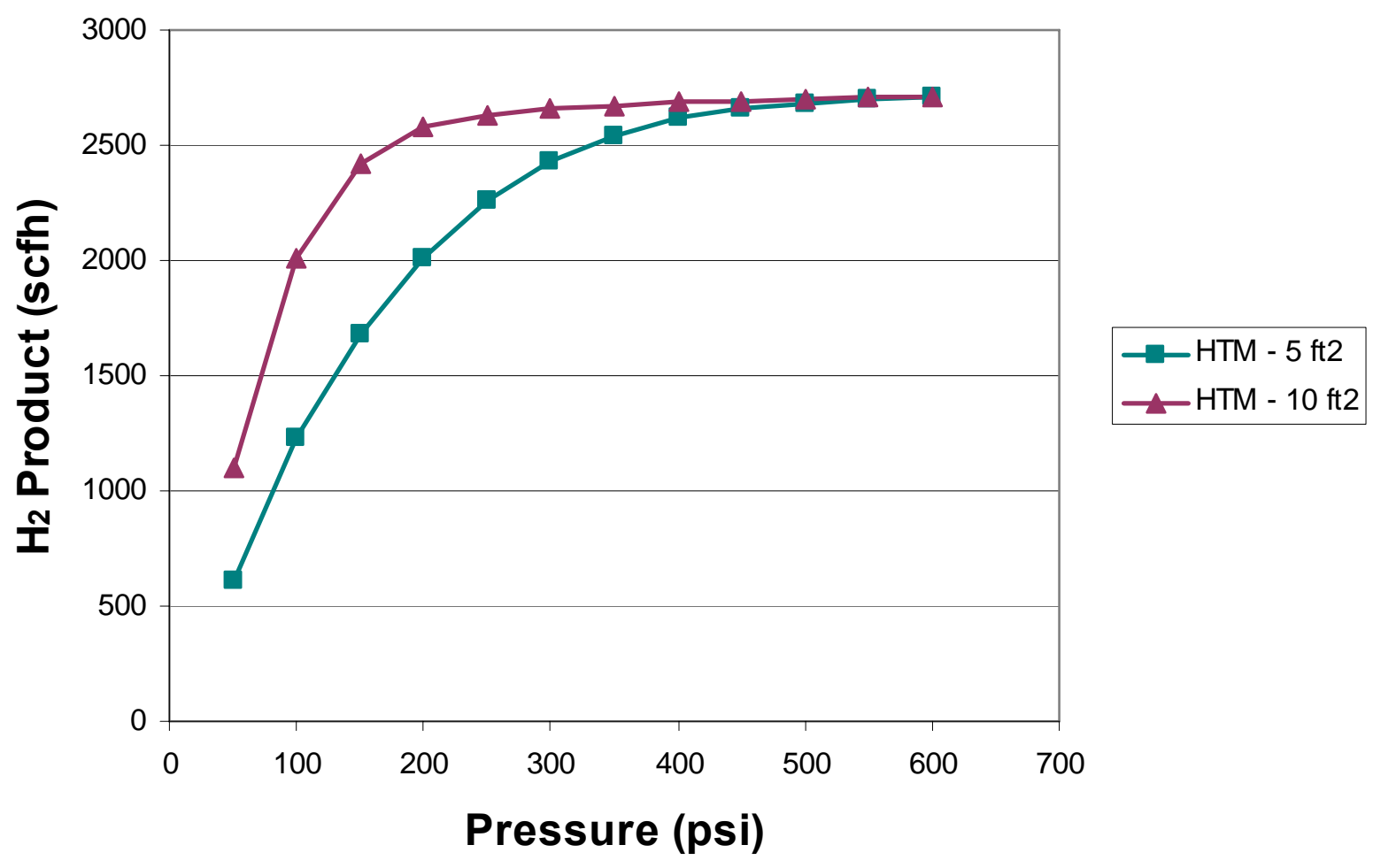

Figure 41. Modeling Results Showing the Effect of Feed Pressure

As expected, the hydrogen flux and yield increase with increasing pressure. At lower pressures, the larger membrane area provides significant additional hydrogen because the flux is low enough that $5 \mathrm{ft}^{2}$ is not sufficient area. At higher pressures, above about 450 psi, the additional area of the larger membrane reactor provides very little value. Unlike temperature, pressure does not affect the reaction equilibrium. The model shows that the area can be optimized based on flux for a given pressure so that additional area is not wasted. Operating the membrane reactor at higher pressure provides an opportunity to make the reactor smaller, but increases gas compression costs and reactor material costs, so the benefit of reduced membrane area must overcome these potential costs. 
The effect of permeate pressure was also studied using the model. Figure 42 shows the results of modeling comparing membrane reactors with different membrane areas. Each case shown in Figure 42 is at a temperature of $400^{\circ} \mathrm{C}$, a feed pressure of $300 \mathrm{psig}$, a hydrogen recovery of $2000 \mathrm{scfh}$, and assumes that there is no methanation.

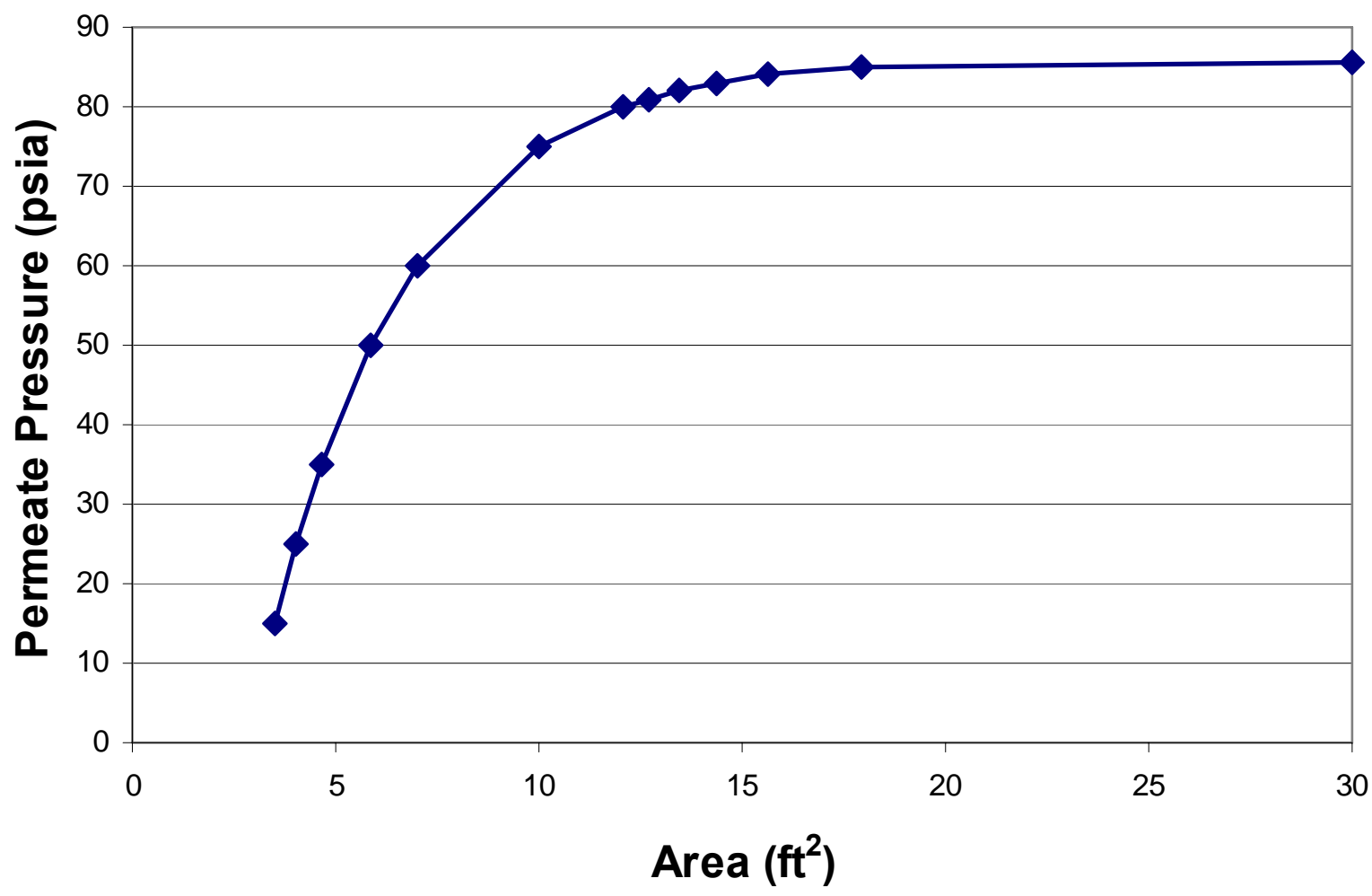

Figure 42. Modeling Results Showing the Effect of Permeate Pressure

As expected, the hydrogen flux decreases with increasing permeate pressure, requiring more membrane area to achieve the same hydrogen recovery. Once the permeate pressure gets to about $85 \mathrm{psia}$, the hydrogen partial on the feed side is about the same as the permeate side, so there is very little driving force and almost no additional hydrogen recovery when more area is added. This effect is most clearly seen above about $15 \mathrm{ft}^{2}$ of membrane area for this case. Clearly, trying to drive the permeate pressure over about 80 psia is not cost effective in this case. A permeate pressure of 50 psig (64.7 psia) was selected to keep the area reasonable. 
Figure 43 shows the marginal gain in hydrogen permeate for each extra square foot of membrane area at $400^{\circ} \mathrm{C}, 300$ psig inlet pressure, 50 psig outlet pressure, and $4600 \mathrm{scfh}$ syngas inlet flow. Above about 10 $\mathrm{ft}^{2}$, the additional hydrogen produced by adding membrane area is very small compared to the product gained from each square foot of membrane area below $10 \mathrm{ft}^{2}$. For this reason, $10 \mathrm{ft}^{2}$ of membrane area was selected for the base case design.

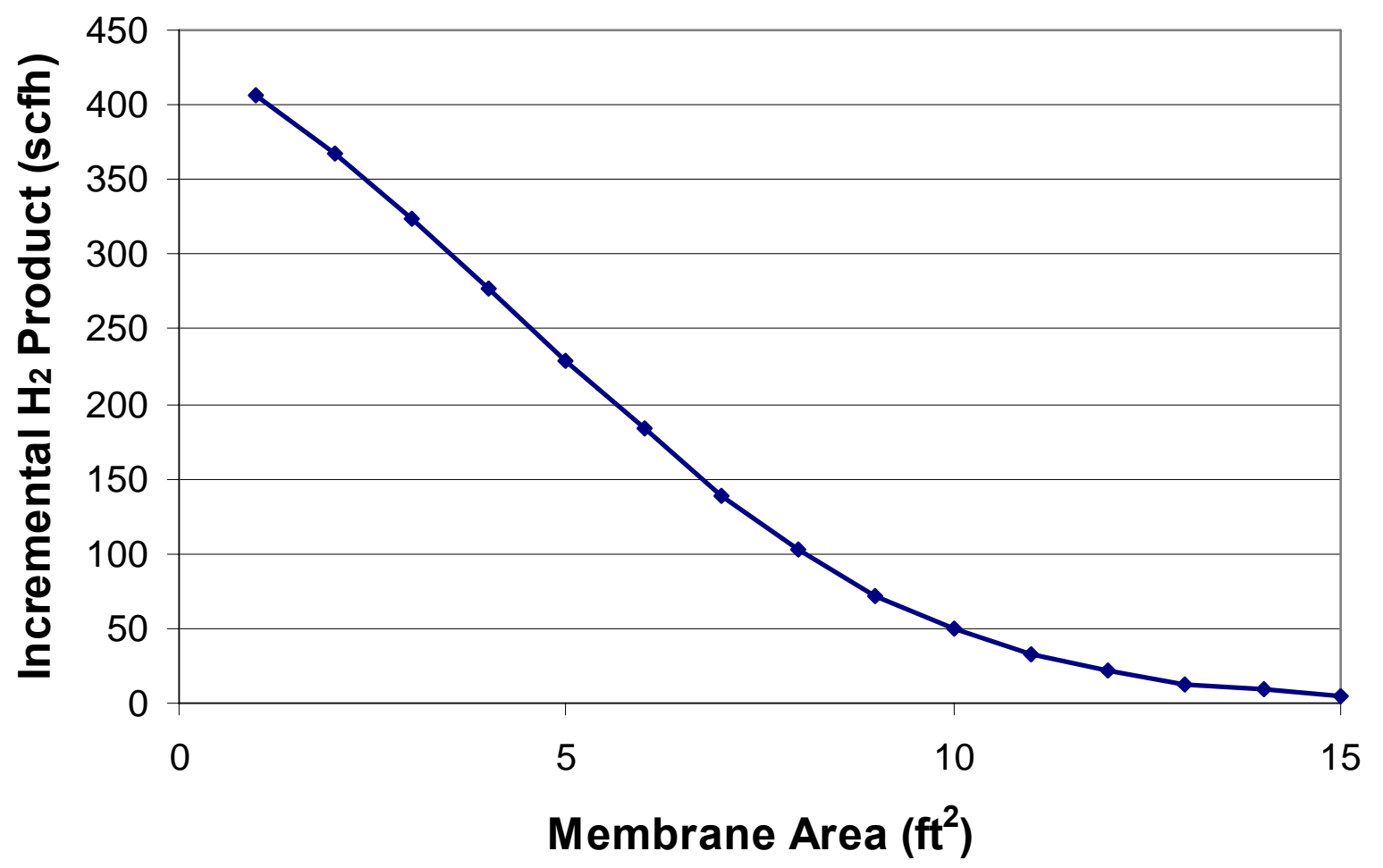

Figure 43. Modeling Results Showing the Effect of Incremental Increase in Membrane Area

\section{Conceptual Design}

The conceptual design was based on the following:

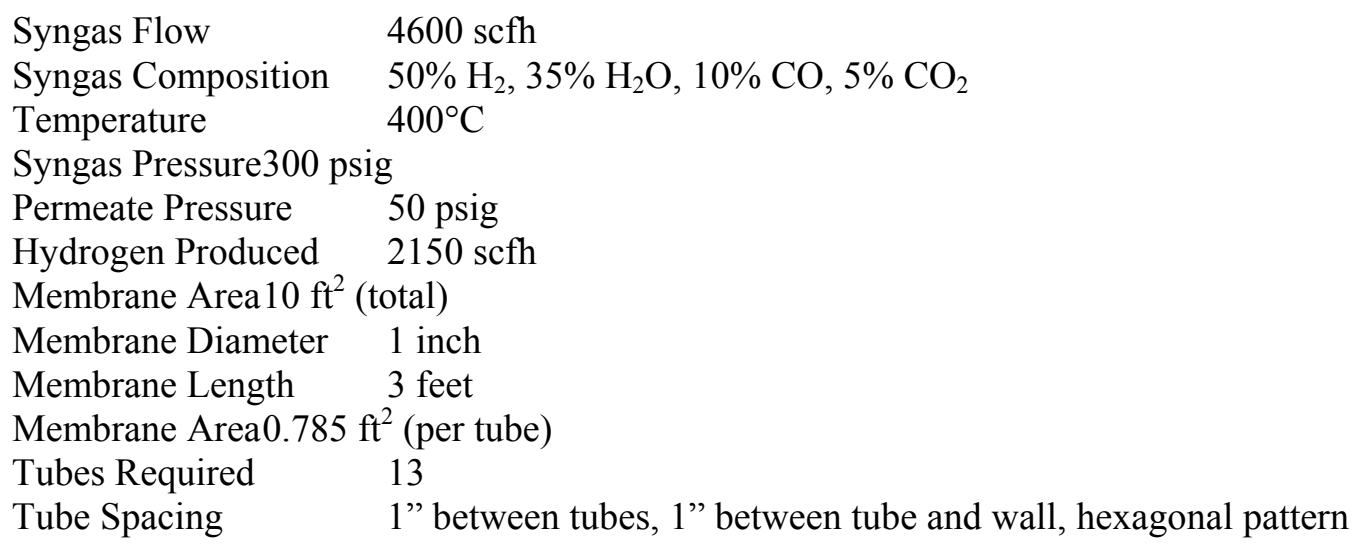


Figure 44 shows the tube layout. The entire system fits within a 10" circle when allowing for 1" of space between the outside edge of the tube and the inside edge of the vessel. This system allows for $1.4 \mathrm{ft}^{3}$ of catalyst volume assuming that the vessel is packed with catalyst outside the tubes.

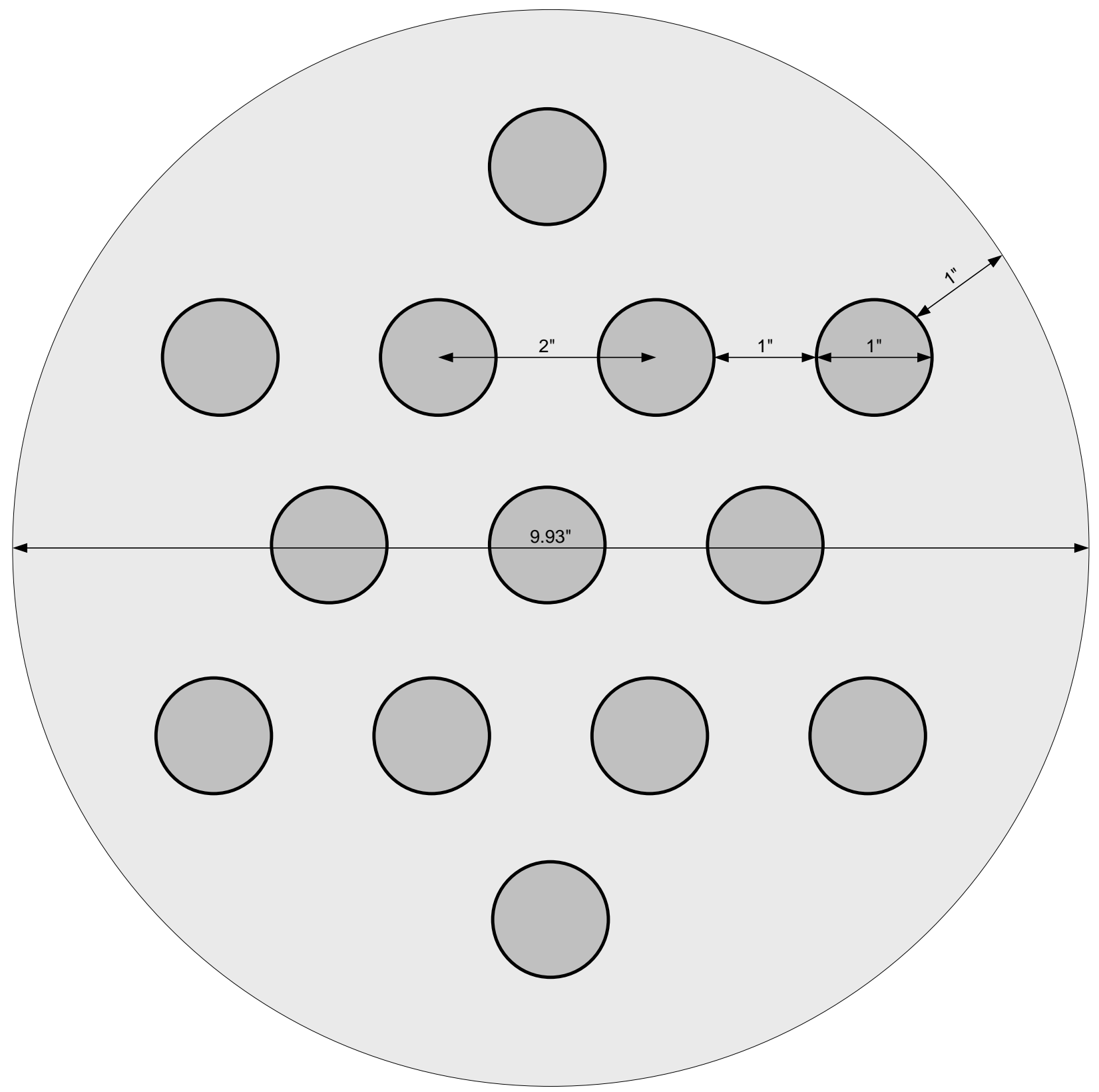

Figure 44. Tube Layout 
Figure 45 shows the conceptual design. This is a significantly simpler design than the original design proposed in Figure 2 because the OTM tubes, burner, and steam sweep have been eliminated.

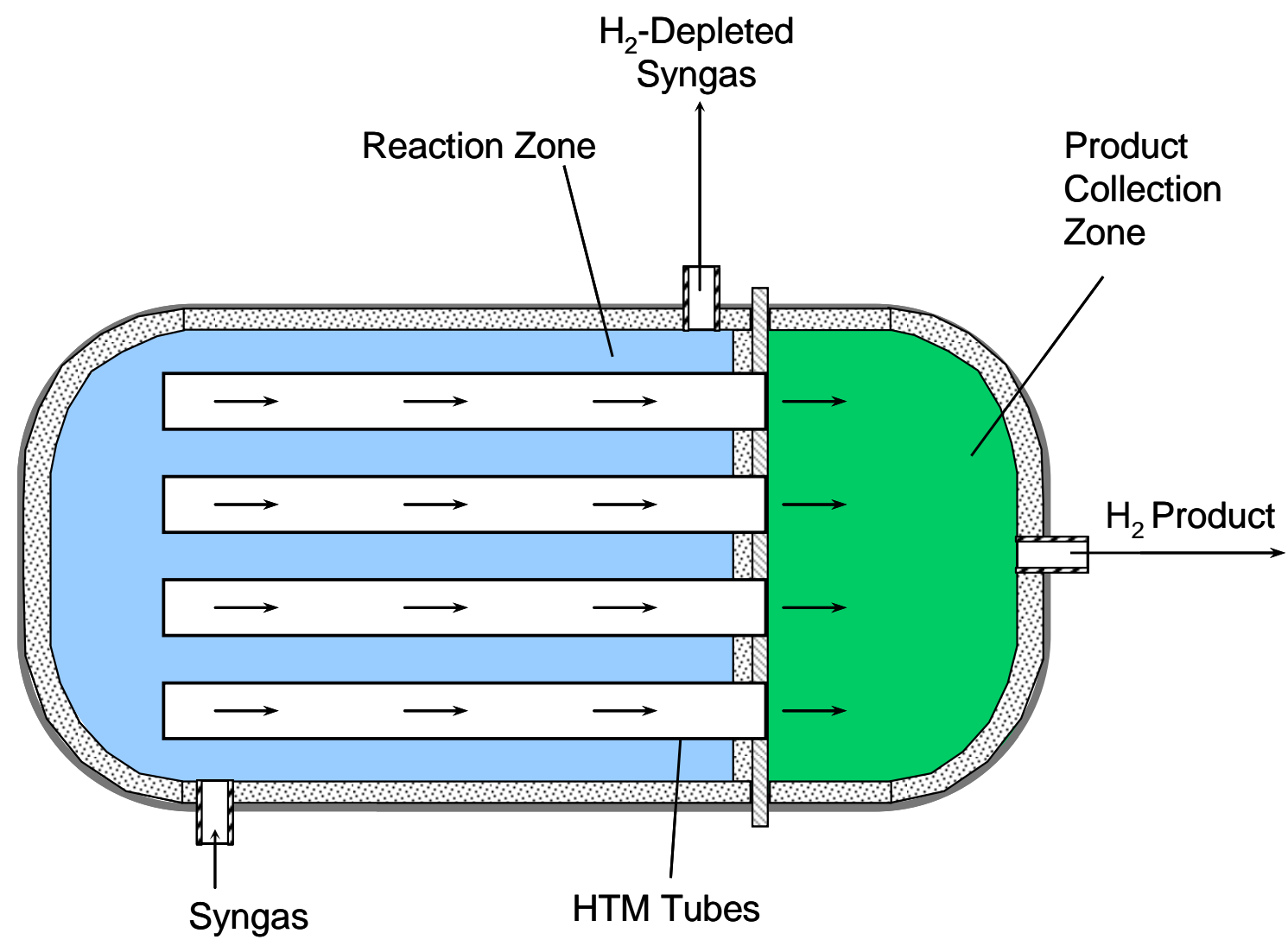

Figure 45. Reactor Conceptual Design

This reactor takes hot syngas coming from a high-temperature syngas generation reactor that has been cooled in a heat exchanger, most likely a boiler. The hot syngas passes over water gas shift catalyst in the reaction zone to increase its hydrogen content and HTM tubes, which remove high-purity hydrogen product. The hydrogen product is collected in the product collection zone and exits the reactor based on the permeate pressure. The $\mathrm{H}_{2}$ depleted syngas exits the catalyst zone and can be used as fuel for the syngas generator. 


\section{Task 4 - Process Economics Economic Analysis Results}

One important target to establish is the required thickness of the membrane to be able to meet the DOE goals. The 2010 DOE flux target is $250 \mathrm{scfh} / \mathrm{ft}^{2}$. The DOE cost target is $\$ 1000 / \mathrm{ft}^{2}$ [11]. The goal of our program is to minimize the cost of producing hydrogen. Therefore, these two targets are combined into one. The cost target is $\$ 4 / \mathrm{scfh}$ capital cost. This combines two components of the cost that are interrelated. For example, a membrane that met both targets would lead to a capital cost of $\$ 4 / \mathrm{scfh}$ while a membrane that had a flux of $200 \mathrm{scfh} / \mathrm{ft}^{2}$, short of the DOE target, and a capital cost of $\$ 500 / \mathrm{ft}^{2}$ would have a hydrogen cost of $\$ 2.50 / \mathrm{scfh}$. Even though the second membrane does not meet the flux target, it would be a better fit for the goals of this program because it has a lower cost of hydrogen.

This analysis assumes that the cost of the substrate, seals, membrane fittings, and reactor housing is $\$ 250 / \mathrm{ft}^{2}$ of membrane area, the cost of palladium is $\$ 455 / \mathrm{oz}$ and the cost of silver is $\$ 18.11 / \mathrm{oz}$. Both prices are based on market prices as of July 9, 2010. This means that the cost of Pd-Ag for a $75 \% \mathrm{Pd}$ membrane is about $\$ 12$ per square foot per micron of membrane thickness. The analysis also assumes a membrane flux of $200 \mathrm{scfh} / \mathrm{ft}^{2}$ for a $10 \mu \mathrm{m}$ membrane and that the flux is inversely proportional to membrane thickness, as has been verified in membrane testing.

Figure 46 shows the results of this analysis including the revised target of $\$ 4 / \mathrm{scfh}$, or $\$ 8000$ for a 2000 scfh system. This analysis indicates that the program cost target can be met using a membrane that is less than about $15 \mu \mathrm{m}$. We have produced several membranes that are less than $15 \mu \mathrm{m}$, so this is an achievable target.

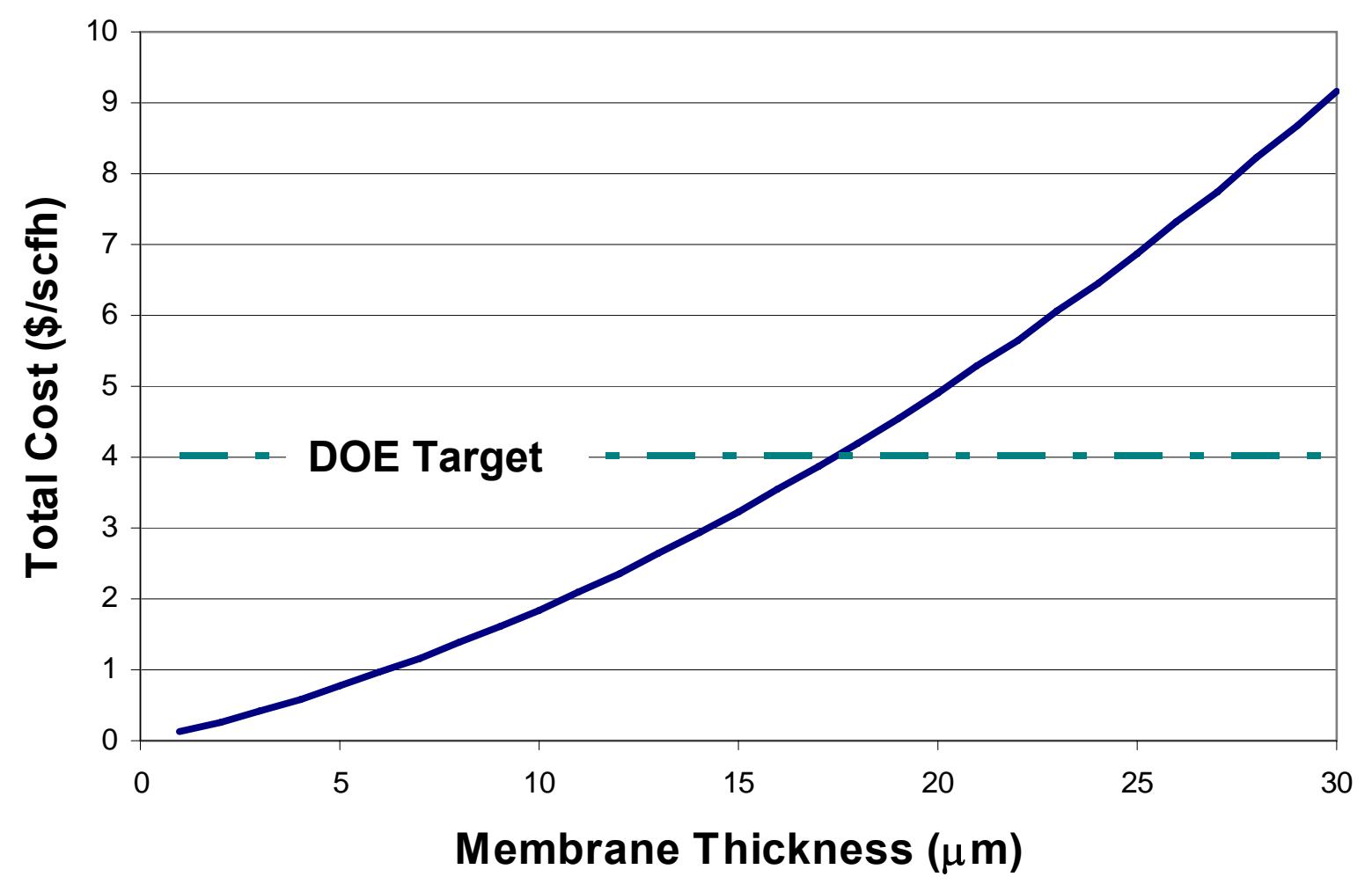

Figure 46. Capital Cost as a Function of Membrane Thickness 
In addition to comparing the performance of the system with current DOE targets, it is also important to consider alternative processes. The conventional process for hydrogen production using SMR is shown in Figure 47.

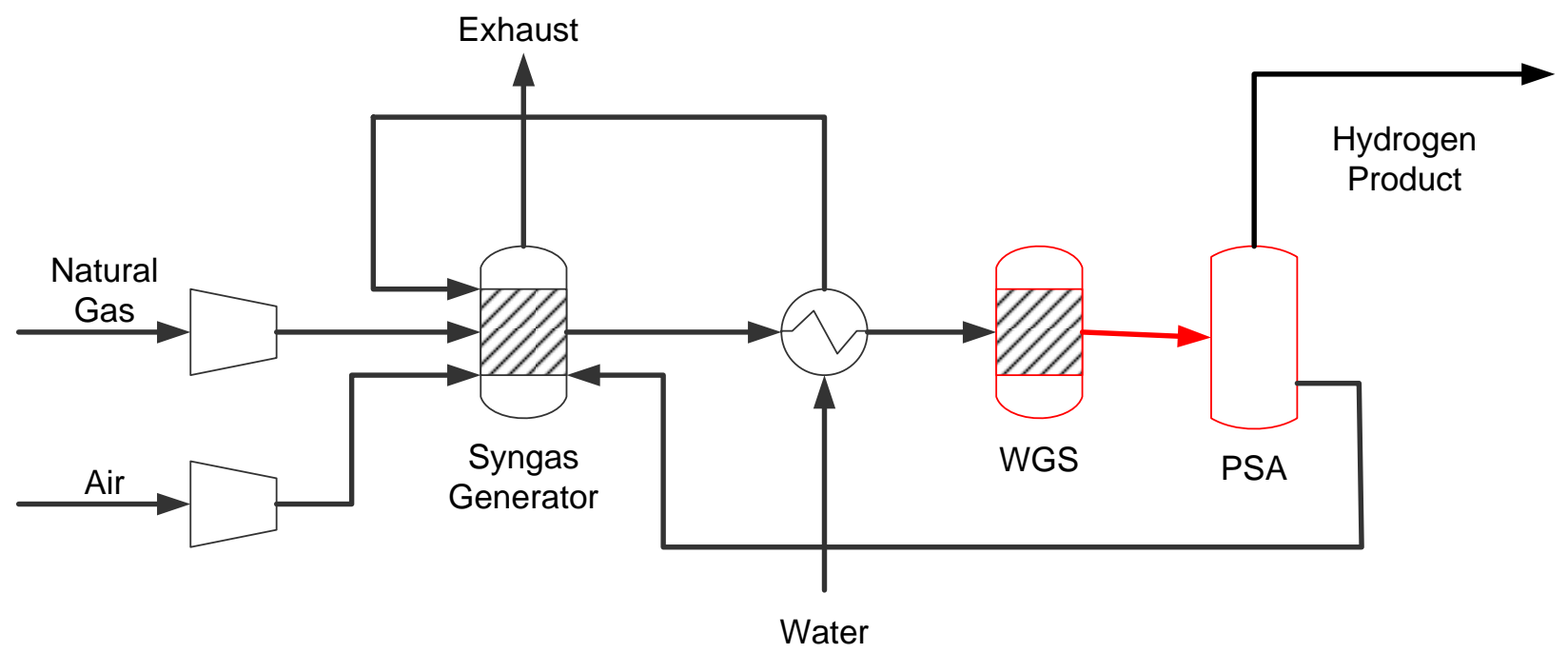

Figure 47. Conventional SMR Process

As shown in Figure 47, natural gas is compressed and fed to a steam reformer (syngas generator) along with steam. PSA tail gas and air are fed to a burner to provide heat for the endothermic reforming reaction. Syngas exits the reactor, is cooled, producing steam, and fed to a water gas shift reactor to produce additional hydrogen. The WGS product stream is fed to a PSA to separate hydrogen at pressure from tail gas, which leaves the PSA at low pressure and is burned. 
The process using the integrated membrane reactor system is shown in Figure 48. The differences between the two processes are that the shift reactor is integrated with a hydrogen membrane, so no PSA is required. However, because the membrane produces hydrogen at lower pressure than the PSA, product hydrogen compression may be required. In the case of a hydrogen fueling station, compression will be required for either system because the hydrogen storage pressure is several thousand psi, but the membrane process will require more compression because the product pressure is lower.

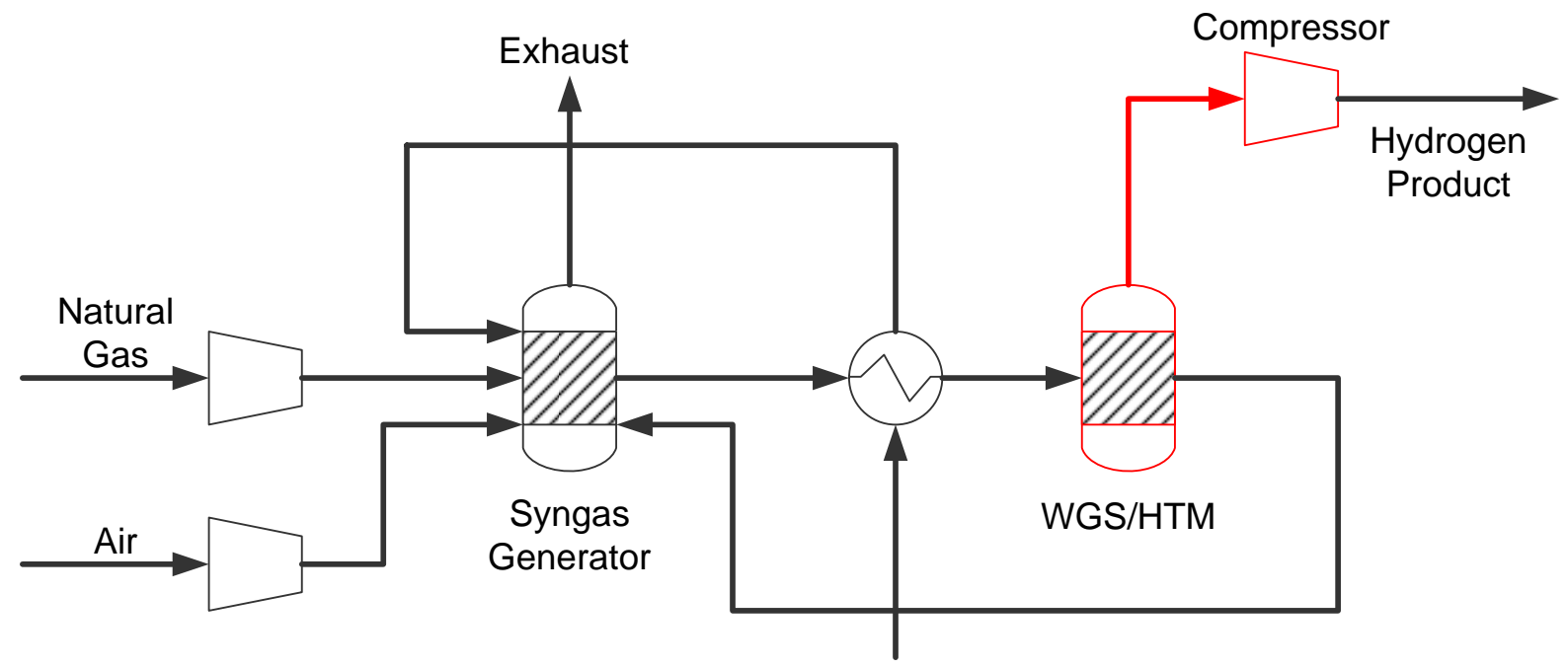

Figure 48. Integrated Membrane Reactor System Process

A comparison between the two processes must consider the cost of the membrane and compressor compared to the cost of the PSA. Furthermore, improved yield from the membrane process must also be considered.

The cost analysis shown in Table 3 assumes that the system shown in Figure 47 meets the DOE cost target of $\$ 2.00 / \mathrm{kg}$ and assumes that the cost of compression, storage, and dispensing is $\$ 0.50 / \mathrm{kg}$. This means that the cost target for production is $\$ 1.50 / \mathrm{kg}$. This analysis considers the cost of the additional hydrogen produced $(0.48 \mathrm{~kg} / \mathrm{hr})$ and compares it to the cost target of $\$ 1.50 / \mathrm{kg}$ for hydrogen production from natural gas. Table 3 shows the comparison between the two processes: 
Table 3. Parameters for Economic Cost Comparison of Incremental Hydrogen

\begin{tabular}{|c|c|c|}
\hline Item & PSA Process & HTM Process \\
\hline \multicolumn{3}{|l|}{ Reactor Parameters } \\
\hline Hydrogen production (scfh) & 2000 & 2200 \\
\hline Hydrogen production $(\mathrm{kg} / \mathrm{h})$ & 4.82 & 5.30 \\
\hline Hydrogen production difference $(\mathrm{kg} / \mathrm{h})$ & 0 & 0.48 \\
\hline PSA recovery & $75 \%$ & $\mathrm{n} / \mathrm{a}$ \\
\hline Membrane thickness $(\mu \mathrm{m})$ & $\mathrm{n} / \mathrm{a}$ & 10 \\
\hline Membrane area $\left(\mathrm{ft}^{2}\right)$ & $\mathrm{n} / \mathrm{a}$ & 10 \\
\hline Hydrogen product pressure (psig) & 300 & 100 \\
\hline Hydrogen storage pressure (psig) & 6250 & 6250 \\
\hline \multicolumn{3}{|l|}{ Capital Cost Difference (\$) } \\
\hline Membranes and seals & 0 & 3,700 \\
\hline WGS reactor modifications & 0 & 10,000 \\
\hline PSA & Variable & 0 \\
\hline *Compressor (due to additional stages) & $\begin{array}{ll}--- \\
--\end{array}$ & 20,000 \\
\hline TOTAL & Variable & 33,700 \\
\hline \multicolumn{3}{|l|}{ Operating Cost Difference } \\
\hline Compressor power $(\mathrm{kW})$ & $\begin{array}{c}--- \\
--1\end{array}$ & 2.55 \\
\hline Power cost $(\$ / \mathrm{kWh})$ & 0.10 & 0.10 \\
\hline Compressor power cost $(\$ / \mathrm{h})$ & 0 & 0.255 \\
\hline **Natural gas $(\mathrm{Btu} / \mathrm{h})$ & 0 & 55,000 \\
\hline Natural gas cost (\$/MMBtu) & 5.00 & 5.00 \\
\hline Natural gas cost $(\$ / \mathrm{h})$ & 0 & 0.275 \\
\hline TOTAL $(\$ / h)$ & 0 & 0.53 \\
\hline \multicolumn{3}{|l|}{ Economic Parameters } \\
\hline Capital cost recovery factor $(\% /$ month $)$ & 2.5 & 2.5 \\
\hline Reactor utilization & $70 \%$ & $70 \%$ \\
\hline
\end{tabular}

* Based on H2A model assumptions

** Additional natural gas is required for the HTM case because more hydrogen is recovered. In the PSA case, this hydrogen is provided to the burner in the tail gas to drive the reforming reaction. In the HTM case, this energy must be replaced using natural gas.

Assuming that the conventional system produces hydrogen at a total cost of $\$ 1.50 / \mathrm{kg}$, meeting the DOE target, the cost of the additional hydrogen produced by the HTM system will need to be at or below $\$ 1.50 / \mathrm{kg}$ for the HTM process to be economical based on the target. Figure 49 shows the cost comparison between the two cases. The variable used is the capital cost of the PSA, which is beyond the scope of this program. As seen in Figure 49, if the capital cost of the PSA is more than about $\$ 30,000$, the HTM process has an advantage. If the capital cost of the PSA is less than about $\$ 30,000$, the conventional process has an advantage. Another way to look at this is that Figure 49 represents the available cost that can be added to replace the PSA. If the PSA is very inexpensive, and therefore, a minor part of a process that meets the target, then the replacement cost must be low. If the PSA is very expensive, and therefore, a major part of a process that meets the target, then a higher replacement cost can be tolerated. 


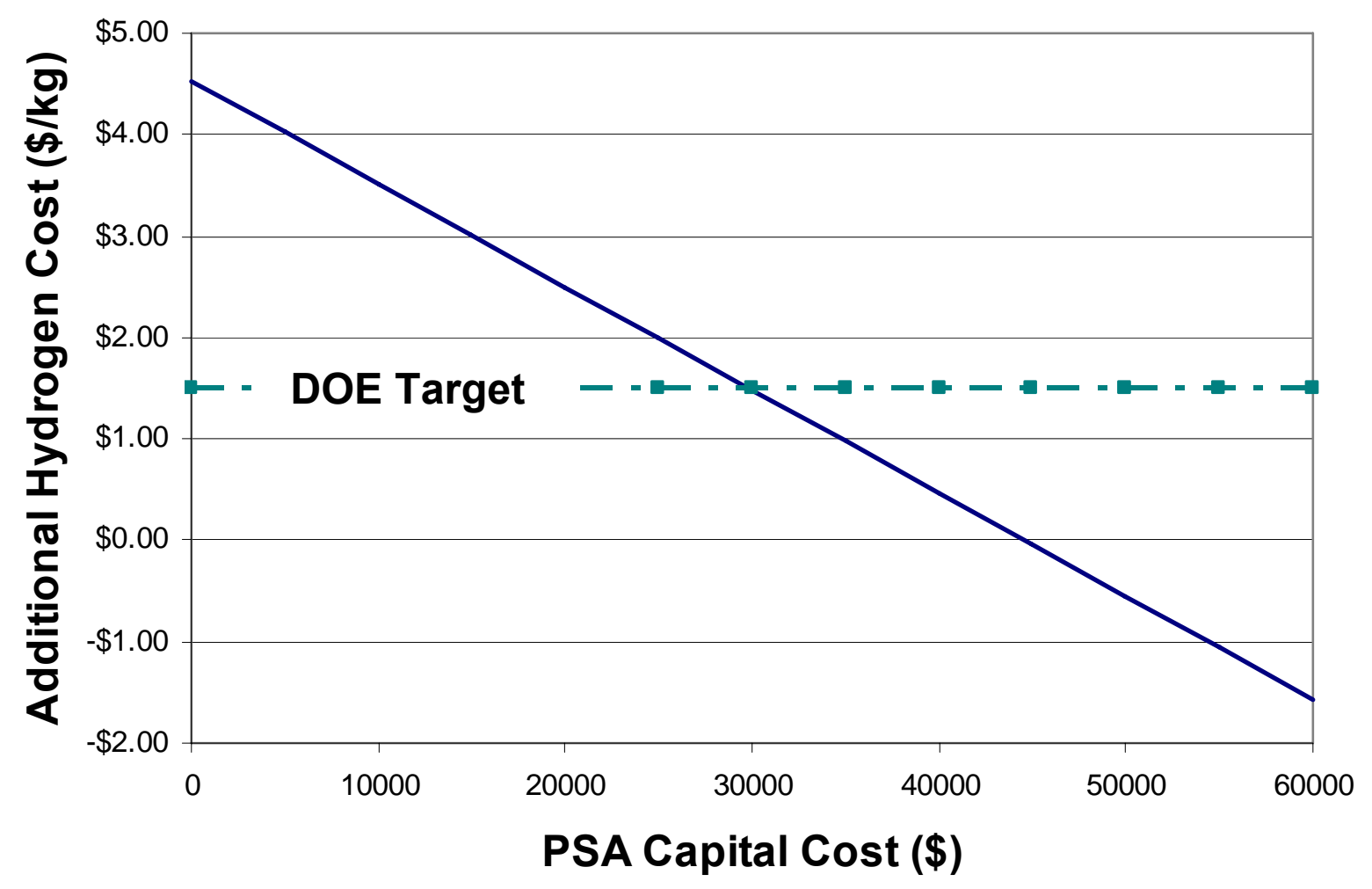

Figure 49. Cost Comparison Between HTM and PSA Processes

Figure 49 assumes that the capital cost of the HTM process components required to replace the PSA is $\$ 33,700$ and that the HTM process produces an additional $0.48 \mathrm{~kg} / \mathrm{hr}$ of hydrogen with an additional $\$ 0.53 / \mathrm{hr}$ of operating cost. As the PSA cost increases, the capital cost difference decreases until the assumed PSA cost reaches $\$ 33,700$, at which point further increase in the PSA capital cost makes the PSA process more expensive on a capital cost basis. At equal capital cost, the cost of additional hydrogen is $\$ 0.53$ for $0.48 \mathrm{~kg}$, or $\$ 1.10 / \mathrm{kg}$.

\section{Task 5 - Program Management and Reporting}

General program management and reporting were done throughout the project period.

\section{Conclusions}

Phase IIB of the Integrated Ceramic Membrane System for Hydrogen Production program ended in June 2010. The primary objectives of Phase IIB were met. Membranes were produced that demonstrated sufficient performance to enable the integrated water gas shift membrane reactor to have superior performance compared to conventional WGS and PSA technology. Tests showed excellent membrane performance and the results were used to develop a model to predict membrane performance and design a reactor.

The results from this program, combined with the results of other research done by Praxair, will be used to implement improved membranes in hydrogen production and purification. 


\section{Acknowledgments}

The authors wish to thank Prasad Apte, Shawn Callahan, Joey Corpus, Ashok Damle, David Makuch, and Minish Shah, for their work on this program.

\section{References}

[1] Shah, M., Drnevich, R., Gottzmann, C., Van Hassel, B. "Hydrogen Production Method." U.S. Patent $6,783,750,2004$.

[2] Kingery, W. D., Bowen, H. K., and Uhlmann, D. R. Introduction to Ceramics, Second Edition. New York: John Wiley and Sons, 1976.

[3] Metals Handbook, Ninth Edition, Vol. 2., Properties and Selection of Nonferrous Alloys and Pure Metals.

[4] Lane, J. D., Praxair, Inc. Private Communication.

[5] McKinley, D. L. "Metal Alloy for Hydrogen Separation and Purification." U.S. Patent 3,350,845, 1967.

[6] Edlund, D. “A Membrane Reactor for $\mathrm{H}_{2} \mathrm{~S}$ Decomposition." Proceedings of the U.S. DOE Advanced Coal-Fired Power Systems Review Meeting, 1996.

[7] McKinley, D.L. "Method for Hydrogen Separation and Purification.” U.S. Patent 3,439,474, 1969.

[8] Kajiwara, M., Uemiya, S., and Kojima, T. "Stability and Hydrogen Permeation Behavior of Supported Platinum Membranes in Presence of Hydrogen Sulfide." International Journal of Hydrogen Energy; 24 (839) 1999.

[9] Damle, A.S., Krishnan, G. N., Sanjurjo, A., Wood, B. J., and Lau, K. H. "Thermal and Chemical Degradation of Inorganic Membrane Materials.” Final Report Submitted to U.S. DOE, 1995.

[10] Ma, D. and Lund, C. R. F. "Assessing High-Temperature Water-Gas Shift Membrane Reactors.” Ind. Eng. Chem. Res.; 42 (711) 2003.

[11] http://www1.eere.energy.gov/hydrogenandfuelcells/mypp/pdfs/production.pdf 